\title{
Análise e implementação de suporte a SMP (multiprocessamento simétrico) para o sistema operacional eCos com aplicação em robótica móvel
}

Maikon Adiles Fernandez Bueno 



\title{
Análise e implementação de suporte a SMP (multiprocessamento simétrico) para o sistema operacional eCos com aplicação em robótica móvel
}

\author{
Maikon Adiles Fernandez Bueno
}

Prof. Dr. Eduardo Marques

(Orientador)

Dissertação apresentada ao Instituto de Ciências Matemáticas e de Computação, como parte dos requisitos para a obtenção do título de Mestre em Ciências de Computação e Matemática Computacional.

USP - São Carlos

Fevereiro de 2007 

Dedico este trabalho aos meus amados pais Onival e Oronciana, e ao meu querido irmão Moacir. 



\section{Agradecimentos}

Primeiramente, agradeço a Deus por ter me presenteado com minha linda família, por ter me dado a graça de viver, por todos os amigos que compartilham essa vida comigo e por todas as oportunidades que me deu até hoje. "Quem a Deus tem, nada lhe falta. Só Deus basta." Santa Teresa de Ávila.

Aos meus amados pais Onival e Oronciana, e meu irmão Moacir, por todo amor, por terem me ensinado a viver, por terem me criado com tanto carinho e estarem presentes em cada momento da minha vida. "Não se assinala o caminho apontando-o com o dedo, mas sim caminhando à frente." Provérbio Macua - Moçambique. Obrigado por tudo.

Ao meu orientador Prof. Dr. Eduardo Marques, pela orientação deste trabalho, pela sua dedicação aos alunos, sempre visando o melhor pra eles, pela sua fé, pela sua amizade e sua descontração. "Se deres um peixe a um homem, ele alimentar-se-á uma vez; se o ensinares a pescar, alimentar-se-á durante toda a vida." Kuan-Tsu.

$\grave{A}$ minha querida Christiane, por todos esses anos de companherismo, incentivando, orientando e dando forças em todos os momentos; lembre sempre: "El oceano (por más grande que sea) no separa lo inseparable..." Christiane Brasil.

Aos meus grandes amigos Jean, Luis, Augusto e Guilherme pelo apoio e convivência. A todos os colegas do LCR que me auxiliaram na concretização deste trabalho. Aos meus amigos do GOU, Aderson, Evelise, Eduardo, José Eduardo (Du) e Luciene (Lu), entre tantos outros que compartilharam grandes momentos durante esse período em São Carlos. "Nenhum caminho é longo demais quando um amigo nos acompanha." Desconhecido.

À secretaria da pós-graduação - ICMC, Ana Paula, Elizabeth e Laura, por todo o apoio.

Finalmente, ao CNPq e Finep pelo apoio financeiro. 



\section{Resumo}

O desenvolvimento tecnológico tem diminuído significativamente a distância entre o desempenho de sistemas projetados utilizando computação reconfigurável e sistemas em hardware dedicado. As principais fontes de desempenho são o alto nível de densidade das FPGAs e o aperfeiçoamento de recursos oferecidos por seus fabricantes, que tornam mais atrativa sua utilização em aplicações de âmbitos variados, enfaticamente em sistemas que exigem um grau superior de flexibilidade. Neste contexto, o propósito deste trabalho consiste no aproveitamento dos recursos oferecidos pela FPGA para o desenvolvimento de uma plataforma multiprocessada com a finalidade de execução paralela de tarefas. Deste modo, o sistema operacional eCos foi modificado, com a agregação de novas funcionalidades, para permitir o suporte do modelo Multiprocessamento Simétrico, utilizando três processadores soft-core Nios II da Altera. Neste sistema operacional todo o paralelismo está relacionado diretamente à execução de threads. Esta plataforma foi analisada e validada por meio da execução de algoritmos paralelos, enfatizando aspectos de desempenho e flexibilidade em relação a outras arquiteturas. Este trabalho contribui para o alcance de melhores resultados envolvendo, especificamente, a execução de tarefas inerentes à robótica, a qual pertence a um domínio que demanda grande concorrência de tarefas, principalmente em módulos que envolvem a interação com o ambiente. 


\section{Abstract}

Technological development has significantly reduced the distance between the performance of systems designed using reconfigurable computing and dedicated hardware. The main sources of performance are the high density level of the FPGAs and the resources' improvement offered by manufacturers, who make more its use more attractive in a variety of applications, emphatically in systems that demand a high degree of flexibility. In this context, the objective of this work consists on the exploration of the resources offered by FPGAs for the development of a multiprocessed platform with the purpose of parallel execution of tasks. In this way, the eCos operating system was modified, with the addition of new characteristics to support of the Symmetric Multiprocessing model, using three soft-Core Altera Nios II processors. On this operating system, all parallelism is directly related to execution of the threads. This platform was analyzed and validated through the execution of parallel algorithms, emphasizing aspects of performance and flexibility compared to other architectures. This work contributes for reaching better results in the execution of tasks in robotics area, which belongs to a domain that demand great competition of tasks, mainly in modules that involve interaction with the external environment. 



\section{Sumário}

Lista de Figuras $\quad$ xv

Lista de Tabelas $\quad$ xvii

Lista de Abreviaturas e Siglas $\quad$ xix

1 Introdução 1

2 Sistemas Operacionais 5

2.1 Considerações iniciais . . . . . . . . . . . . . . . . . . . . . 5

2.2 Conceitos de sistemas operacionais . . . . . . . . . . . . . . . 5

2.3 Sistemas operacionais para multiprocessadores . . . . . . . . . . . . . . 7

2.3.1 Um SO para cada CPU . . . . . . . . . . . . . . . 7

2.3.2 Multiprocessadores 'mestre-escravo' . . . . . . . . . . . . . . 8

2.3.3 Multiprocessadores simétricos . . . . . . . . . . . . . . 8

2.4 Sistemas operacionais de tempo real . . . . . . . . . . . . . . . . . . . . . . 9

2.5 Sistemas embarcados . . . . . . . . . . . . . . . . . . . 11

2.6 Considerações finais . . . . . . . . . . . . . . . . . . . . . . . . 14

3 Computação Reconfigurável $\quad 15$

3.1 Considerações iniciais . . . . . . . . . . . . . . . . . . . . 15

3.2 A tecnologia FPGA . . . . . . . . . . . . . . . . 15

3.3 Sistemas Operacionais Reconfiguráveis . . . . . . . . . . . . . . . 18

3.3.1 Tarefas de Hardware . . . . . . . . . . . . . . . . . . . . . . . . 20 
3.3.2 Módulos do sistema operacional . . . . . . . . . . . . . . . . . . 22

3.4 Processadores em FPGA . . . . . . . . . . . . . . . . . . . . 23

3.4.1 PicoBlaze .......................... 24

3.4 .2 MicroBlaze . . . . . . . . . . . . . . . . . . . . 24

3.4.3 Nios II . . . . . . . . . . . . . . . . . . . . . 25

3.5 Considerações finais . . . . . . . . . . . . . . . . . . 26

4 O sistema operacional eCos 29

4.1 Considerações iniciais . . . . . . . . . . . . . . . . . . . . . . . . . 29

4.2 Escalonamento . . . . . . . . . . . . . . . . . . . . 30

4.3 Primitivas de sincronização . . . . . . . . . . . . . . . . . . . . . 30

4.4 Gerenciamento de memória . . . . . . . . . . . . . . . . . . 31

4.5 Processos e controle de interrupção . . . . . . . . . . . . . . . . . . 31

4.6 Contexto de chamadas . . . . . . . . . . . . . . . . . . . . 32

4.7 Sistema de arquivos . . . . . . . . . . . . . . . . . . . 33

4.8 Entrada e saída . . . . . . . . . . . . . . . . . . . . 33

4.9 Licença . . . . . . . . . . . . . . . . . . . . . . . 34

4.10 Considerações finais . . . . . . . . . . . . . . . . . . . . 34

5 Ambiente de desenvolvimento $\quad 35$

5.1 Considerações iniciais . . . . . . . . . . . . . . . . . . . . 35

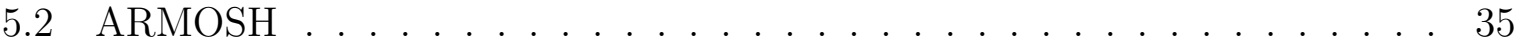

5.3 Plataforma de desenvolvimento . . . . . . . . . . . . . . . 37

5.3 .1 Processador Nios II - Altera . . . . . . . . . . . . . . . . 37

5.3 .2 DE2 - Altera . . . . . . . . . . . . . . 37

5.3 .3 Quartus II - Altera . . . . . . . . . . . . . . . . 39

5.3 .4 Nios II - IDE . . . . . . . . . . . . . . . . . . . . . . 40 
$5.3 .5 \mathrm{eCos} \ldots \ldots \ldots \ldots \ldots \ldots$

5.4 Considerações finais . . . . . . . . . . . . . . . . . . . . . . . . . . 43

6 O processador Nios II $\quad 45$

6.1 Considerações iniciais . . . . . . . . . . . . . . . . . . . 45

6.2 Projeto de hardware com Nios II . . . . . . . . . . . . . . . . 45

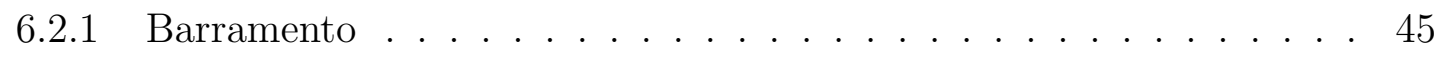

6.2.2 Dispositivos de armazenamento . . . . . . . . . . . . . 46

6.2.3 JTAG Universal Asynchronous Receiver/Transmitter . . . . . . . . 47

6.2.4 Parallel Input/Output . . . . . . . . . . . . . . . . 47

6.3 Endereçamento . . . . . . . . . . . . . . . . . 48

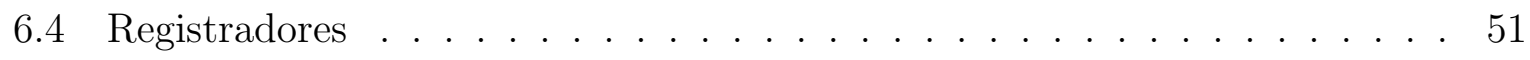

6.5 Processamento de exceção . . . . . . . . . . . . . . . . . . 53

6.6 Inicialização do processador e processo de boot . . . . . . . . . . . . . 54

6.7 Considerações finais . . . . . . . . . . . . . . . . . 55

$\begin{array}{lll}7 & \text { Multiprocessadores } & 57\end{array}$

7.1 Considerações iniciais . . . . . . . . . . . . . . . . . 57

7.2 Arquiteturas paralelas . . . . . . . . . . . . . . . 58

7.3 Symmetric Multiprocessor $-S M P \ldots \ldots \ldots 1$

7.4 Considerações finais . . . . . . . . . . . . . . . . . . 61

8 Arquitetura e implementação do sistema 63

8.1 Considerações iniciais . . . . . . . . . . . . . . . . . 63

8.2 Considerações do projeto de hardware e do sistema operacional . . . . . . . 63

8.2.1 Processadores com áreas de memória separadas - Um sistema operacional para cada $\mathrm{CPU}$. . . . . . . . . . . . . . 64

8.2.2 Multiprocessadores 'mestre-escravo' . . . . . . . . . . . . 65 
8.2.3 Multiprocessamento Simétrico . . . . . . . . . . . . . . . 66

8.3 Implementação do sistema . . . . . . . . . . . . . . . . . . . . . . . . . 69

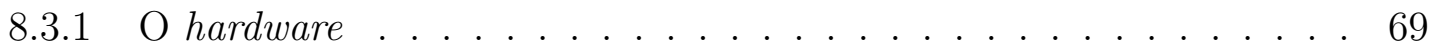

8.3 .2 Processadores . . . . . . . . . . . . . . . . . . 69

8.3.3 Interrupções . . . . . . . . . . . . . . . . . . . . . . . . . . 72

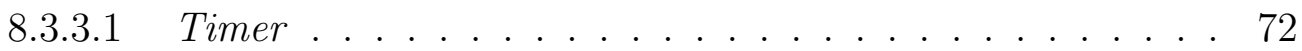

8.3.3.2 JTAG UART . . . . . . . . . . . . . . . . . 73

8.3.3.3 Interrupção inter-CPUs . . . . . . . . . . . . . 73

8.3 .4 Memória . . . . . . . . . . . . . . . . . . . . . . 74

8.3.5 Sincronização . . . . . . . . . . . . . . . . . 76

8.3.6 Sistema operacional . . . . . . . . . . . . . . . 77

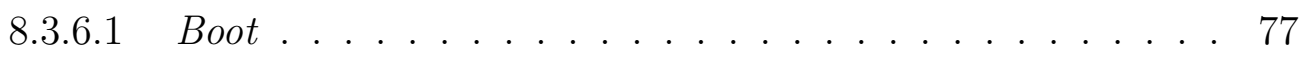

8.3.6.2 Escalonamento . . . . . . . . . . . . . . . 78

8.3.6.3 Interrupções de hardware . . . . . . . . . . . . . . . . 79

8.3.6.4 Coerência de dados em cache . . . . . . . . . . . . 80

8.4 Uma outra implementação: Erika RTOS . . . . . . . . . . . . . . . . . . 81

8.5 Resultados . . . . . . . . . . . . . . . . . . . . . 81

8.5.1 O algoritmo PSRS . . . . . . . . . . . . . 82

8.5.2 O algoritmo de multiplicação de matrizes . . . . . . . . . . . . 86

8.6 Considerações finais . . . . . . . . . . . . . . . . . . . 87

9 Conclusões $\quad 89$

9.1 Considerações finais . . . . . . . . . . . . . . . . . . . . . . 89

9.2 Sugestões para trabalhos futuros . . . . . . . . . . . . . . . . 90 


\section{Lista de Figuras}

2.1 Um sistema operacional para cada CPU (TANENBAUM, 2001). . . . . . . . 8

2.2 Modelo mestre-escravo (TAnenBAUM, 2001) . . . . . . . . . . . . . . 9

2.3 Multiprocessador Simétrico (TAnenbaum, 2001) . . . . . . . . . . . . . 9

2.4 Retorno financeiro e janelas de tempo (CARRO; WAGNER, 2003). . . . . . . 12

2.5 Particionamento Software-Hardware (CARRO; WAGNER, 2003). . . . . . . . 13

3.1 FPGA: Reduzindo a diferença entre ASIC e microprocessador (HARTENS-

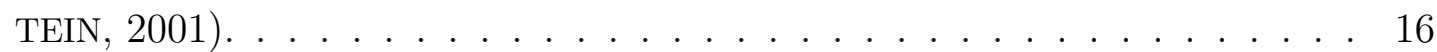

3.2 Estrutura de uma FPGA (BROWn; ROSE, 1996a) . . . . . . . . . . . 17

3.3 Tipos de FPGA. . . . . . . . . . . . . . . . . . . . . . . . . . . 18

3.4 Várias tarefas em execução simultaneamente. . . . . . . . . . . . . . . . 18

3.5 FPGA e áreas destinadas às tarefas e ao SO (RUPPEN, 2003). . . . . . . . 19

3.6 Arquitetura do sistema operacional reconfigurável (STEIGER et al., 2004). 19

3.7 Interface padrão para tarefas (RUPPEN, 2003) . . . . . . . . . . . . . . 20

3.8 Modelos de área: a) Modelo 1D; e b) Modelo 2D. . . . . . . . . . . . . . . 21

3.9 Módulos do sistema operacional reconfigurável (STEIGER et al., 2004) (WALDER; PLATZNER, 2003a). . . . . . . . . . . . . . . . . 22

5.1 Projeto ARMOSH: Diagrama de componentes. . . . . . . . . . . . 36

5.2 Placa de desenvolvimento DE2 - Altera. (ALTERA, 2007) . . . . . . . 38

5.3 Fluxo de projeto no Quartus II (ALTERA, 2004b) . . . . . . . . . . . . 40

5.4 Tela do SOPC Builder. . . . . . . . . . . . . . . . . . . . . 41

5.5 Tela do Quartus II. . . . . . . . . . . . . . . . . . . . 41

5.6 Tela do Nios II IDE. . . . . . . . . . . . . . . . . . . . . . . . . 42 
5.7 Tela da ferramenta de configuração do eCos. . . . . . . . . . . . . . . . . . 42

6.1 Barramento Avalon. (ALTERA CORPORATion, 2006a) . . . . . . . . . 46

6.2 JTAG UART. (ALTERA CORPORATION, 2006f) . . . . . . . . . . . . . 48

6.3 SOPC Builder: Endereçamento dos dispositivos. . . . . . . . . . . . . . . . 49

6.4 Configuração de endereços do Nios II. . . . . . . . . . . . . . . . . . . 50

7.1 Arquitetura SISD. (BARR; REWINI, 2005) . . . . . . . . . . 59

7.2 Arquitetura SIMD. (BARR; REWINI, 2005) $\ldots \ldots \ldots \ldots \ldots$

7.3 Arquitetura MISD. (BARR; REWINI, 2005) . . . . . . . . . . . 59

7.4 Arquitetura MIMD. (BARR; REWINI, 2005) . . . . . . . . . . . 60

7.5 Exemplos de arquiteturas com memória distribuida: (a) UMA, (b) COMA, (c) NUMA. (BARR; REWINI, 2005) . . . . . . . . . . . . 60

8.1 Um sistema operacional para cada CPU. . . . . . . . . . . . . . . . 64

8.2 Modelo mestre-escravo. . . . . . . . . . . . . . . . . . . . . . 65

8.3 Multiprocessador Simétrico (TAnEnBAum, 2001) . . . . . . . . . . 68

8.4 Arquitetura do sistema. . . . . . . . . . . . . . . 70

8.5 Projeto do hardware no SOPC-Builder. . . . . . . . . . . . . . 71

8.6 Interrupção inter-CPUs. . . . . . . . . . . . . . . . . 73

8.7 Disposição da memória. . . . . . . . . . . . . . . . . . . . 74

8.8 Boot do sistema operacional. . . . . . . . . . . . . . . 77

8.9 Exemplo do algoritmo Parallel Sorting by Regular Sampling (LI et al., 1993). 83

8.10 Tempos de execução dos algoritmos. . . . . . . . . . . . . . . 86 


\section{Lista de Tabelas}

3.1 Características dos processadores Nios II. . . . . . . . . . . . . . . . 26

5.1 Principais características da FPGA 2C35. . . . . . . . . . . . . . 38

6.1 Registradores do processador Nios II. (ALTERA CORPORATION, 2006e) . 52

6.2 Registradores do processador Nios II. . . . . . . . . . . . . . . . . . . 53

8.1 Principais IRQs da arquitetura de validação. . . . . . . . . . . . . . . . . 72

8.2 Tempos de execução dos algoritmos de ordenação. . . . . . . . . . . . . . . 85

8.3 Tempos de execução dos algoritmos de multiplicação de matrizes. . . . . . 87 


\title{
Lista de Abreviaturas e Siglas
}

\author{
ALUT Adaptive Look-up Table \\ ARMOSH Aprendizado em Robôs Móveis via Software e Hardware \\ ASIC Application Specific Integrated Circuit \\ $\mathbf{C} / \mathbf{R} \quad$ Configuration and Readback Port \\ COMA Cache Only Memory Access \\ COMM Communication port \\ CPLD Complex Programmable Logic Device \\ CPU Central Processing Unit \\ CPU-ID $\quad C P U$ Identifier \\ DMIPS Dhrystone Millions of Instruction per Second \\ DDR Double Data Rate \\ DDR2 Double Data Rate 2 \\ DSP Digital Signal Processing \\ DSR Deferred Service Routine \\ E/S Entrada e Saída \\ eCos embedded Configurable operating system \\ EP Elementos de Processamento \\ EEPROM Electrical Erasable PROM \\ EPROM Erasable PROM \\ FPGA Field Programmable Gate Array \\ GPL General Public License \\ HAL Hardware Abstraction Layer \\ IDE Integrated Development Environment \\ IP Intellectual Property \\ ISI Information Sciences Institute \\ IRQ Interrupt Request \\ ISR Interrupt Service Rotine \\ LABIC Laboratório de Inteligência Computacional \\ LCR Laboratório de Computação Reconfigurável
}


LE Logic Elements

LUTs Look-up Tables

MIMD Multiple Instruction, Multiple Data

MISD $\quad$ Multiple Instruction, Single Data

MLQ Multi-Level Queue

MMU Memory Management Unit

NASA National Aeronautics and Space Administration

NUMA Non-Uniform Memory Access

ONU Organização das Nações Unidas

PROM Programable Read Only Memory

PSRS Parallel Sorting by Regular Sampling

QDRII Quad Data Rate 2

RAM Random Access Memory

RCU Reconfigurable Unit

RISC Reduced Instruction Set Computer

RLDRAM Reduced Latency DRAM

RTOS Real-Time Operating System

SDRAM Synchronous Dynamic Random Access Memory

SIMD Single Instruction, Multiple Data

SISD Single Instruction, Single Data

SMP Symmetric Multiprocessor

SO Sistemas Operacional

SoC System-on-a-Chip

SRAM Static RAM

STI standard Task Interface

TPU Task Preparation Unit

UART Universal Asynchronous Receiver/Transmitter

ULA Unidade Lógica Aritmética

UMA Uniform Memory Access

VHDL Very High Speed Integrated Circuit Hardware Description Language

VOIP Voice Over Internet Protocol 


\section{Introdução}

A computação reconfigurável está marcando o desenvolvimento de hardware nos últimos anos, e tornou-se um novo paradigma para a execução de tarefas em aplicações diferenciadas. A tecnologia FPGA (Field Programmable Gate Array) tem evoluido significativamente, alcançando elevados níveis de densidade, maior desempenho, e menor custo. Atualmente, as FPGAs podem possuir um conjunto com mais de 300.000 elementos lógicos e uma freqüência de $500 \mathrm{MHz}$ (ALTERA, 2004a) (ALTERA, 2006). Esse avanço torna a FPGA cada vez mais equiparável à tecnologia ASIC (Application Specific Integrated Circuit), a qual por muitos anos tem liderado a fabricação de dispositivos.

A ênfase em requisitos, que envolvam flexibilidade no projeto de hardware, tem passado de uma característica a uma real exigência em muitos tipos de aplicações. A possibilidade de reconfiguração do sistema para adequar o hardware às novas características do ambiente ou acrescentar atributos de desempenho, revela uma economia em custo e tempo quando comparada com a tecnologia de hardware customizado.

Entre as aplicações, atualmente, a robótica constitui um grande nicho para o emprego da computação reconfigurável. Muitos estudos têm sido realizados para a construção de robôs confiáveis capazes de executar suas funções para o ambiente no qual foram projetados. Enfaticamente, essa interação é normalmente crítica, devendo considerar um espaço dinâmico, e tomar decisões em tempo real de acordo com a ocorrência dos eventos. Para isso, os robôs devem apresentar sensores e atuadores, conduzidos por técnicas que permitam alcançar uma interação efetiva com o mundo real.

Alguns robôs têm sido desenvolvidos utilizando computação reconfigurável, justamente pela flexibilidade que essa tecnologia apresenta. A interação com o mundo real normalmente não tem comportamento previsível, sendo que todo o hardware deve possuir a capacidade de adequar-se ao seu ambiente. O sistema de navegação é o componente principal do robô responsável por essa interação, e a computação reconfigurável consiste em uma peça fundamental para a automatização das tarefas nesse sistema. 
Com o avanço tecnológico, as FPGAs apresentam níveis de desempenho cada vez maiores, e muitos recursos são disponibilizados pelos fabricantes. O aumento de sua capacidade lógica motiva a utilização de vários tipos de soluções para explorar as características físicas oferecidas. Uma dessas soluções baseia-se na utilização de processadores específicos ou mesmo de propósito geral implementados em FPGAs. Esses processadores são conhecidos como soft processors, e eventualmente são elaborados por meio de diagramas esquemáticos ou linguagens de descrição de hardware.

Uma placa de FPGA pode suportar diversos soft processors simultaneamente. Essa arquitetura é conhecida como multiprocessador e permite a ampliação no número de processos em execução paralela, aumentando o desempenho do sistema.

O sistema operacional possui a tarefa de controlar a execução dos processos nessa plataforma, fornecendo métodos de sincronização para a exclusão mútua e ordenação de eventos entre processos. Com isso, diversos algoritmos podem ser paralelizados, de modo a utilizar a capacidade oferecida pela FPGA.

Deste modo, a expansão de ambientes propícios para execução de algoritmos, especificamente algoritmos utilizados em robótica móvel, podem oferecer grandes benefícios na relação de flexibilidade alcançada com software e desempenho em tarefas implementadas em hardware.

Com esse intuito, o principal objetivo deste trabalho consiste no projeto de um sistema operacional capaz de suportar uma arquitetura multiprocessada em FPGA, sendo capaz de gerenciar seus recursos de modo transparente. Para tanto, foi utilizando o sistema operacional eCos, no qual algumas funcionalidades inerentes ao modelo SMP foram implementadas. A arquitetura base para execução de processos utilizando o eCos foi composta por três processadores Nios II, interligados por meio do barramento Avalon, com compartilhamento de memória, entre outros periféricos.

Este trabalho, desenvolvido no Laboratório de Computação Reconfigurável ICMC/USP, contribui para aferir a possibilidade de utilização de algoritmos da robótica na arquitetura descrita, assim como, também para atingir maior desempenho em tarefas executadas em FPGA, aumentando a aplicabilidade da computação reconfigurável.

\section{Organização do trabalho}

Este trabalho encontra-se organizado do seguinte modo: 
- Capítulo 2: São apresentados os conceitos relacionados a sistemas operacionais, tipos de sistema operacionais para arquitetura multiprocessada, sistemas operacionais em tempo real e uma introdução sobre sistemas embarcados;

- Capítulo 3: Nesse capítulo é apresentada uma introdução sobre FPGA, são definidos os sistemas operacionais reconfiguráveis e são introduzidos os soft processors;

- Capítulo 4: São apresentadas as características do sistema operacional eCos;

- Capítulo 5: São apresentados o ambiente de desenvolvimento, envolvendo o ARMOSH (Aprendizado em Robôs Móveis via Software e Hardware) e os materiais como softwares e hardwares necessários ao projeto;

- Capítulo 6: Os detalhes do processador Nios II são apresentados;

- Capítulo 7: Os conceitos básicos de multiprocessadores são descritos;

- Capítulo 8: São apresentados os aspectos arquiteturais de software e hardware da solução, assim como os resultados alcançados; e

- Capítulo 9: As conclusões do trabalho são apresentadas. 


\section{Sistemas Operacionais}

\subsection{Considerações iniciais}

As funcionalidades e a complexidade dos sistemas operacionais (SO) têm acompanhado a evolução das arquiteturas de computadores. A demanda por sistemas de controle de job a partir da geração de transistores até os modernos sistemas em tempo real das arquiteturas atuais, propiciou um grande avanço na pesquisa de sistemas operacionais, que passaram a ocupar o papel de gerenciadores de recursos e até de complexas máquinas estendidas. A tendência desse desenvolvimento é a criação de sistemas mais práticos e transparentes, que omitam a complexidade envolvida em operações de baixo nível e forneçam uma interface objetiva ao usuário.

Nessa seção são apresentados conceitos implementados na maioria dos sistemas operacionais existentes, visando trasparência e desempenho. Também é apresentada uma discussão breve relativa a sistemas operacionais para multiprocessadores, sistemas em tempo real e sistemas embarcados.

\subsection{Conceitos de sistemas operacionais}

A gerência de recursos sempre foi um dos principais aspectos envolvidos no projeto de um sistema operacional. O sistema deve ter o controle sobre todos os dispositivos disponíveis e saber como manipulá-los para obter um melhor aproveitamento de suas capacidades. O processador constitui o principal recurso e o elemento mais requerido em um sistema computacional.

Os processos, como são conhecidos os programas que executam sobre o processador, devem ser mantidos em uma fila de espera, até que o processador seja liberado para uso. A tarefa de controlar qual processo será o próximo a ocupar a CPU (Central processing Unit) é do sistema operacional, particularmente executado por um módulo conhecido 
como escalonador. O escalonador deve seguir alguns critérios para a determinação do próximo processo, esses critérios estão implementados nos algoritmos de escalonamento.

Cada processo possui seu próprio espaço de endereçamento. A memória é vista pelos processos como uma grande área de armazenamento, que nem sempre exprime o tamanho real da memória RAM(Random Access Memory). Freqüentemente é utilizado nos SOs o conceito de memória virtual. O processo enxerga uma quantidade de memória disponível, sendo que parte dela pode ser memória RAM ou pode ser disco. O endereço utilizado é virtual, e não é utilizado para o acesso direto a uma area particular da memória. A unidade MMU (Memory Management Unit) é responsável pela tradução do endereço virtual para o endereço físico.

Na memória os processos são armazenados seguindo uma disposição específica. Geralmente, podem ser armazenados em páginas de tamanho fixo, páginas de tamanho dinâmico, segmentos ou segmentos paginados. Em muitos casos, durante a execução de vários processos, a quantidade de memória necessária pode exceder a quantidade disponível em memória RAM. Quando isso acontece, o sistema operacional deve selecionar processos presentes na memória RAM para serem armazenados em disco, e processos armazenados em disco para serem armazenados na memória RAM. Esse procedimento é conhecido como swapping, que é aplicado para possibilitar a execução de diversos processos, mesmo que o espaço necessário em memória seja maior que o espaço físico disponível.

A gerência de recursos também compreende os elementos de entrada/saída (E/S). Existem dois tipos de dispositivos: de bloco e de caractere. É desejável que o sistema operacional forneça uma interface genérica para a comunicação com os softwares que descrevem o funcionamento desses hardwares. Esses softwares específicos pra cada dispositivo são os drivers, que também devem possuir uma interface adequada para a comunicação com o sistema operacional.

Os discos são um dos dispositivos de E/S mais utilizados em um computador. Esses são divididos em trilhas, e as trilhas em setores. Os dados armazenados são divididos em arquivos, os quais são unidades que seguem um formato específico de acordo com o tipo do dado. O armazenamento dos arquivos no disco segue uma disposição segundo o sistema de arquivos implementado no SO.

Existem vários outros conceitos e preocupações envolvidos no projeto de um SO. Nos últimos anos muita pesquisa tem sido realizada em torno da segurança de sistemas computacionais devido à internet. A necessidade de comunicação entre computadores de diferentes arquiteturas tem estimulado a criação de padrões para a troca de dados e 
maior flexibilidade dos sistemas. O mercado tem exigido sistemas robustos com maior desempenho.

\subsection{Sistemas operacionais para multiprocessadores}

Desde as primeiras gerações de sistemas operacionais, os projetistas buscam o aumento de desempenho na execução de tarefas. A multiprogramação resolveu o problema do desperdício de ciclos de CPU para o tratamento de E/S em processos I/O bound ${ }^{1}$. Entretanto, com a necessidade do aumento do número de processos, a troca de contexto demasiada tornou-se um gargalo no paralelismo simulado de tarefas.

Com o objetivo de criar um paralelismo real, existem os multiprocessadores, cujo objetivo é explorar a capacidade de duas ou mais CPUs, aumentando eficazmente o desempenho. Deste modo, o limite de processamento de um computador não é restrito apenas à capacidade de uma única CPU, mas também é dependente do número de CPUs existentes no sistema.

Um multiprocessador consiste em um sistema de computador com duas ou mais CPUs, que compartilham o acesso total a uma memória RAM comum (TANENBAUM, 2001). Esse modelo pode dispor de alguns modos diferentes de implementação, nos quais a arquitetura é influenciada pelos barramentos, modo que os processadores acessam à memória e utilização de cache e memória privada.

Os sistemas operacionais para multiprocessadores têm enfoque maior em questões críticas de multiprocessadores, tais como sincronização de processos, gerenciamento de recursos e escalonamento. Existem três tipos de sistemas operacionais para essa arquitetura, os quais são abordados a seguir (TANENBAUM, 2001).

\subsubsection{Um SO para cada CPU}

Uma organização simples possível é a disposição de um sistema operacional para cada CPU (Figura 2.1). Nesse modelo, a memória do sistema é dividida, sendo que cada CPU tem sua própria porção da memória, onde podem ser armazenados o SO e os dados pertinentes à CPU. O sistema operacional pode também ter um espaço privado reservado na memória, o qual seria compartilhado pelas CPUs, evitando cópias sobressalentes do SO.

\footnotetext{
${ }^{1} \mathrm{I} / \mathrm{O}$ bound refere-se a uma tarefa, cujo o tempo para término é determinado principalmente pelo tempo gasto por operações de E/S.
} 
Um problema dessa abordagem é que cada sistema operacional trabalha com os seus próprios processos em sua CPU. Esse fato negligencia o balanceamento de tarefas do sistema de acordo com a necessidade de uso da CPU. Isso pode causar ociosidade em algumas CPUs, enquanto outras têm intensa carga de trabalho.

A falta de compartilhamento de memória pode causar um outro problema de desbalanceamento de recursos. Como a alocação de memória é fixa, uma CPU pode dispor de espaço em memória, enquanto outra está paginando continuamente, não havendo possibilidade do compartilhamento da área em desuso.

Outro problema que pode ocorrer é a incoerência das caches de discos, já que cada sistema operacional possui uma cache independente, e os discos são compartilhados entre todos os sistemais operacionais.

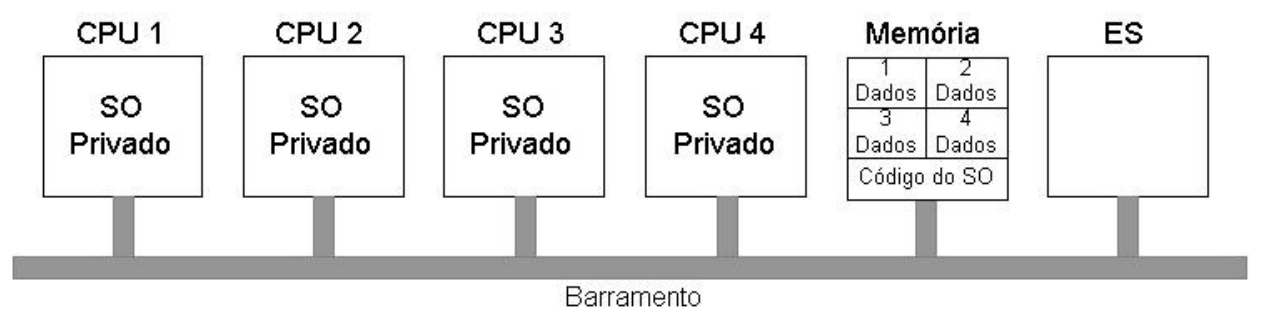

Figura 2.1: Um sistema operacional para cada CPU (TANENBAUM, 2001).

\subsubsection{Multiprocessadores 'mestre-escravo'}

No modelo mestre-escravo uma única CPU é responsável por executar o sistema operacional, conforme apresentado na Figura 2.2. O SO fica em execução na CPU1 e define os processos que cada um dos demais processadores deve executar. Quando uma CPU fica ociosa, ela sinaliza ao sistema operacional, o qual passa alguma tarefa para a execução. Assim, nenhuma CPU fica sobrecarregada enquanto outra está ociosa. As páginas de memória podem ser alocadas dinamicamente entre todos os processos e existe somente uma cache de buffer, de modo que as inconsistências não ocorrem (TANENBAUM, 2001).

O problema com essa organização é a sobrecarga do processador mestre quando existem muitas CPUs no sistema.

\subsubsection{Multiprocessadores simétricos}

Na arquitetura SMP (Symmetric Multiprocessor) cada um dos processadores pode executar o código do SO de acordo com sua necessidade, eliminando o gargalo provindo 


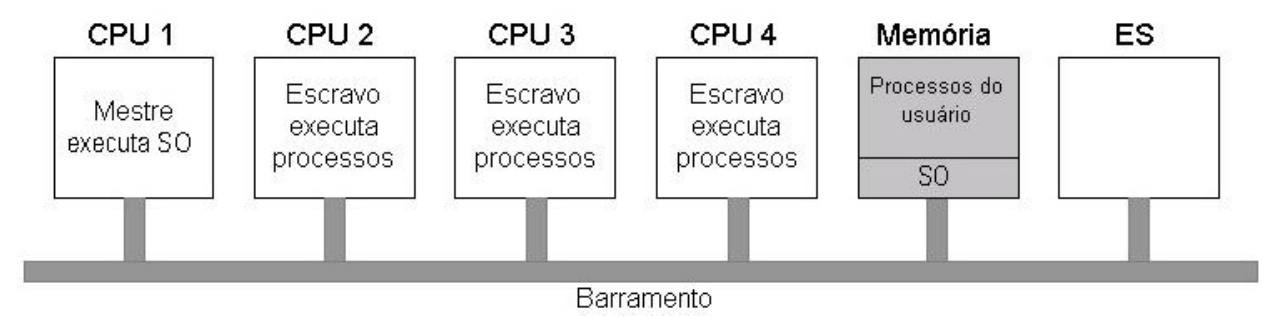

Figura 2.2: Modelo mestre-escravo (TANENBAUM, 2001).

da sobrecarga de um único processador(Figura 2.3). Entretanto, o problema desse modelo é que dois ou mais processadores podem executar simultaneamente a mesma parte do SO, podendo causar incoerências e outros eventuais problemas que podem ocasionar a parada do sistema. A solução para isso é a definição de regiões críticas, de modo a evitar o acesso simultâneo à mesma rotina do SO. Essa solução é custosa, pois todas as possibilidades de problemas devem ser consideradas, evitando possíveis deadlocks devido ao excesso de regiões críticas.

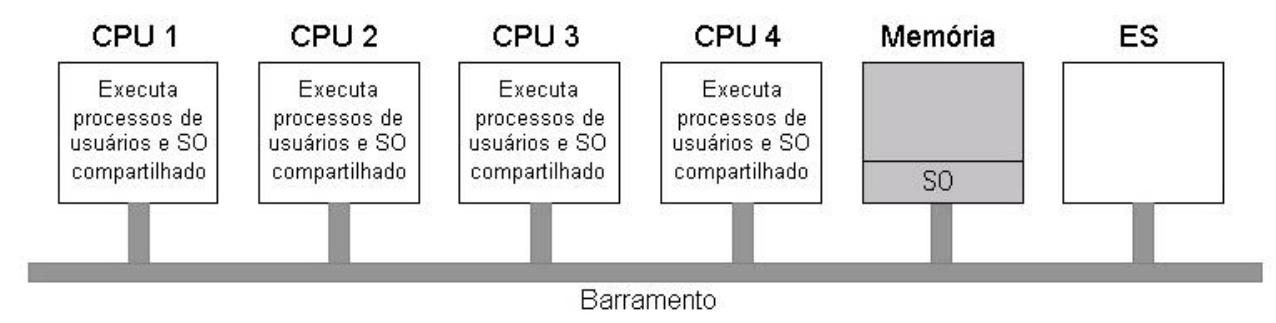

Figura 2.3: Multiprocessador Simétrico (TANENBAUM, 2001).

\subsection{Sistemas operacionais de tempo real}

A utilização da computação em sistemas que exigem tempo limitado de resposta tem motivado o projeto de sistemas mutáveis que se adaptem à realidade do ambiente e provêm meios de processar tarefas com tempos limitados pelas condições externas de modo determinístico.

O tempo de resposta de uma aplicação é o intervalo de tempo a partir de quando ela recebe um estímulo, geralmente por meio de uma interrupção de hardware, até o momento que a aplicação produz um resultado reativo àquele estímulo (DANKWARDT, 2001).

Uma aplicação pode possuir requisitos quantitativos e qualitativos. Normalmente, os requisitos qualitativos são aqueles que não necessariamente devem ser satisfeitos rapidamente, com um intervalo pré-definido de tempo, mas sim executados em tempo suficiente para não afetar a qualidade do resultado. Exemplos típicos dessas aplicações são as de 
vídeo sob demanda. Os requisitos quantitativos são relativos à restrição do intervalo do tempo de resposta. A aplicação tem um tempo máximo, a partir de um estímulo captado, para resolver algum problema. Se uma temperatura excessiva é captada na turbina de usina hidrelétrica, o funcionamento dessa turbina deve ser interrompido rapidamente, antes que qualquer outro dano aconteça. Esses são exemplos de aplicações em tempo real.

Aplicações em tempo real não são caracterizadas necessariamente pela limitação do tempo em que as tarefas devem ser executadas, mas sim pela atuação do ambiente nesses limites. As tarefas devem ser executadas em tempo hábil para satisfazer as necessidades do ambiente.

Quando existem diversas tarefas que são executadas em tempo real em um sistema, pode ser necessária uma aplicação gerenciadora dessas tarefas, que garanta a execução e o atendimento das necessidades do ambiente. Isso é fornecido por aplicações conhecidas como sistemas operacionais de tempo real (RTOS).

No passado até hoje, muitas aplicações de tempo real têm sido construídas sem um sistema operacional. Essas aplicações eram normalmente simples, com um escalonador cíclico, algumas rotinas de interrupção, e drivers de E/S escritos diretamente pelos desenvolvedores das aplicações. Entretanto, com o custo e o poder dos computadores de hoje, as aplicações de tempo real estão muito mais complexas, e requerem suporte à concorrência, aos serviços de escalonamento avançados, ao suporte à rede, ao gerenciamento avançado de memória, ao gerenciamento de tempo, e em alguns casos, até interfaces gráficas e sistema de arquivos para armazenamento secundário. Esses são serviços tipicamente fornecidos por sistemas operacionais, e isso fez seu uso mais importante em sistemas de tempo real (ARTIST, 2004).

Existem algumas características desejáveis para um sistema operacional de tempo real, as quais são apresentadas a seguir (DANKWARDT, 2001) (ARTIST, 2004) (FAQ..., ):

- Um RTOS normalmente fornece suporte para programação concorrente via processos ou threads;

- Deve implementar prioridade entre threads e ser preemptivo;

- Serviços de escalonamento em tempo real são necessários para obter um comportamento determinístico;

- O RTOS deve fornecer suporte a mecanismos de sincronização;

- A latência de interrupção deve ser previsível e coerente com as necessidades; e 
- As chamadas de sistema devem ter um comportamento previsível, independente do número de objetos do sistema.

Existem dois tipos de restrições envolvendo aplicações em tempo real, nos quais se dividem também os sistemas operacionais. O sistema de tempo real crítico envolve deadlines que devem ser cumpridos para evitar a ocorrência de resultados não aceitáveis. Por exemplo, em uma linha de montagem de automóveis, o dispositivo responsável por soldar deve agir no momento certo, a partir da captação da proximidade do objeto pelos sensores. Se a ação é antecipada ou retardada, pode haver até uma possível perda do automóvel. Outro tipo é o sistema de tempo real não crítico, onde um descumprimento ocasional de um prazo é aceitável. Exemplos desses sistemas são os de videoconferência (TANENBAUM, 2001). Nessas aplicações, a maioria dos requisitos de tempo real é derivada do ambiente que está sendo controlado ou monitorado. Isso implica que a maioria dos sistemas em tempo real são sistemas embarcados, e que um RTOS deve prover facilidades para suportar aplicações embarcadas (ARTIST, 2004).

\subsection{Sistemas embarcados}

Os custos de equipamentos eletrônicos caminham quase sempre no mesmo sentido e proporcionalmente ao avanço tecnológico, e sua redução é um dos fatores prioritários nas pesquisas da indústria eletrônica. A cada dia aparecem novas tecnologias e mais requisitos são cobrados pelos usuários finais, de modo que a indústria gasta cada vez mais na fabricação desses equipamentos.

Há alguns anos, a fabricação de chips específicos para cada tarefa tornou-se um gargalo na economia da indústria; pois a utilização de hardware especializado tem um custo alto em virtude do tempo de produção e complexidade envolvidos. Os equipamentos tinham o preço final muito alto, diminuindo suas aquisições e reduzindo o lucro.

O tempo de produção de um novo produto também exerce uma grande influência na economia industrial, conforme apresentado na Figura 2.4. O desenvolvimento tecnológico e a competitividade comercial tornam os produtos obsoletos cada vez mais cedo, reduzindo seu tempo de vida, fazendo com que o tempo de projeção seja mais limitado. Quanto maior o atraso para a introdução de um novo produto no mercado, menor o retorno financeiro alcançado.

Nos últimos anos a fabricação de produtos eletrônicos utilizando exclusivamente hard- 


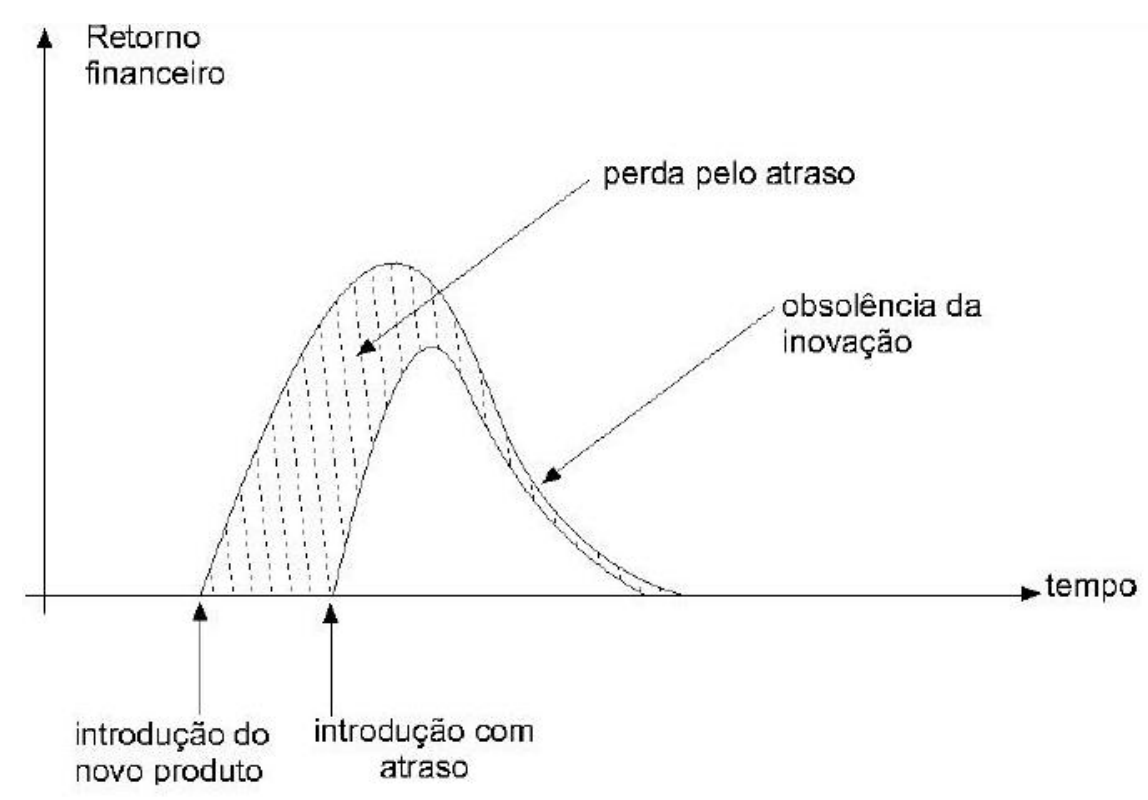

Figura 2.4: Retorno financeiro e janelas de tempo (CARRO; WAGNER, 2003).

ware especializado tem sido substituída por uma tecnologia reprogramável, que combina software e hardware programável.

Essa tecnologia é conhecida como sistemas embarcados (embedded systems), que hoje estão presentes em todo lugar, e seu mercado totaliza atualmente cerca de 100 vezes o mercado de computadores pessoais (EGGERMONT, 2002).

Um sistema embarcado é qualquer computador que seja um componente de um sistema maior e que possui seu próprio processador (WOLF, 2002). Ao contrário dos computadores pessoais, que possuem capacidade de computação genérica, os sistemas embarcados são altamente especializados, freqüentemente reativos, que fornecem processamento de informação e controle de tarefas para seus sistemas, de modo transparente ao usuário. Normalmente, esses sistemas possuem restrições de custo, tempo e consumo de energia, devendo ser confiáveis, robustos e seguros, para serem utilizados.

Como o custo exerce sempre um papel importante na comercialização do produto, uma das fases do projeto de um sistema embarcado é a otimização do seu hardware, para que o sistema utilize apenas os recursos necessários para sua função. Deste modo, o processador é adequado à solução e a lógica do sistema é otimizada.

Além da otimização, um dos pontos críticos do projeto de sistemas embarcados é a decisão de qual tarefa deve ser implementada por hardware ou por software (Figura 2.5). Essa fase é conhecida como particionamento software-hardware. As tarefas implementadas em hardware são executadas com melhor desempenho, enquanto o software oferece uma 
flexibilidade maior e, freqüentemente, um custo reduzido assim como um tempo menor para implementação.

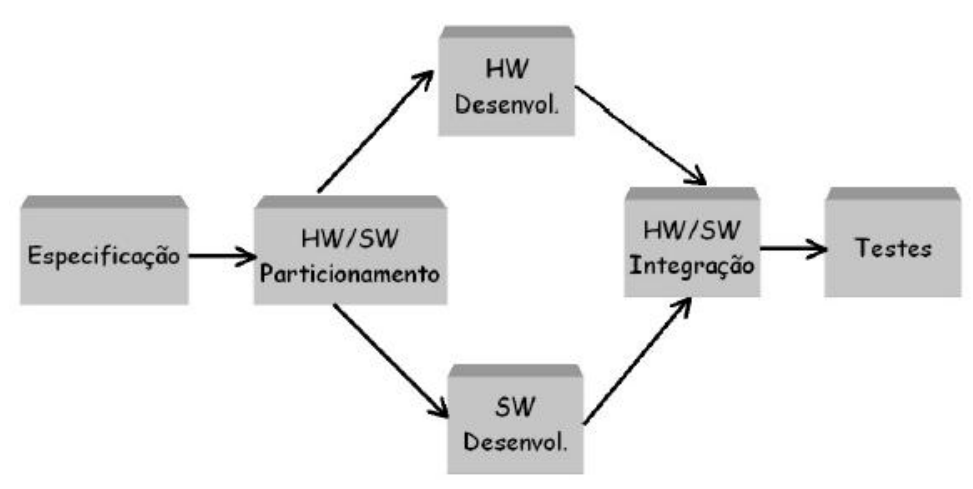

Figura 2.5: Particionamento Software-Hardware (CARRO; WAGNER, 2003).

Em muitas aplicações é adequada a integração do sistema em uma única pastilha (SoC - system-on-a-Chip). Em alguns sistemas que envolvem requisitos críticos, pode ser necessário o emprego no SoC de circuitos integrados específicos para a aplicação. Esse modelo de implementação de hardware é conhecido como ASIC (Application Specific Integrated Circuit). Em outras situações, o sistema pode ser implementado em FPGA (Field Programmable Gate Array), que constitui um modelo de hardware que permite sua reconfiguração, uma alternativa mais econômica e flexível (CARRO; WAGNER, 2003).

Em sua maioria, os sistemas embarcados são reativos, reagem continuamente ao seu ambiente, na velocidade imposta por este. Essa característica freqüentemente pode requerer capacidades de tempo real (EGGERMONT, 2002). Essa demanda por sistemas que agreguem diversas características concebe o desafio do projeto de aplicações cada vez mais integradas.

Alguns sistemas embarcados implementam sistemas operacionais que cuidam do gerenciamento de recursos, capacidades de tempo real, execução de tarefas e oferecem interfaces ao usuário que escondem toda a complexidade envolvida.

Os sistemas embarcados são empregados hoje em diversos domínios, alguns deles são: produtos de áudio e vídeo, interfaces com usuário e processamento de sinais, celulares e infraestrutura de comunicação, computadores pessoais, e áreas especializadas como medicina, controle aéreo, segurança, indústria, sistemas automotivos, entre outras. Essa variedade de aplicações de sistemas embarcados implica que a sociedade está se tornando, em grande parte, dependente dessa tecnologia. 


\subsection{Considerações finais}

É difícil vislumbrar um futuro para os sistemas computacionais apenas analisando sua evolução. A tendência desses sistemas é inusitada, visto que todos os dias muitas inovações são lançadas no mercado, e a concorrência pelo retorno financeiro é uma das principais razões para o investimento em pesquisas.

O progresso da computação está sendo marcado pela alta capacidade computacional devido o desenvolvimento digital, que segundo a lei de Moore (MOORE, 1965), tende a dobrar seu número de transistores a cada 18 meses. Com isso, problemas como espaço de alocação em memória já não é uma preocupação que merece tanto enfoque no projeto de sistemas.

Muitos problemas passados foram resolvidos pelo avanço da tecnologia eletrônica. Atualmente muitos requisitos para sistemas computacionais têm atingido aspectos de flexibilidade, integração e segurança, envolvendo transparência na interface com o usuário final. Os sistemas embarcados são um exemplo dessa nova geração que tenta reunir as melhores características de software e hardware, de modo a construir sistemas flexíveis com bom desempenho, unindo essas duas características que, em muitos casos, sempre foram adversas.

A construção de hardware também foi afetada por esse ardor de maior flexibilidade. A indústria está chegando cada vez mais próxima do ponto de intersecção entre flexibilidade e desempenho. Neste contexto, a utilização da tecnologia FPGA está trazendo resultados que demonstram a possibilidade de uma união mais intensa entre essas características, tendendo à convergência tão almejada. Essa tecnologia é apresentada no próximo capítulo. 


\section{Computação Reconfigurável}

\subsection{Considerações iniciais}

De um ponto de vista prático, a reconfigurabilidade de hardware trabalha com a flexibilidade que o software oferece e com o desempenho de hardware customizado (ASIC Application Specific Integrated Circuit). Os chips podem ser personalizados em um tempo menor, com a possibilidade de serem flexíveis a mudanças, possuindo um desempenho comparável ao hardware dedicado (BROWN; ROSE, 1996a).

A reconfigurabilidade de hardware estará cada vez mais presente e tende a marcar o desenvolvimento de sistemas embarcados (HARTENSTEIN, 2001). A computação reconfigurável representa um grande patamar de flexibilidade: a customização de um hardware que pode ser reprogramado. A flexibilidade oferecida pelos sistemas embarcados, com a integração de software e hardware, está sendo aprimorada ainda mais com aplicação de FPGA em sua fabricação.

\subsection{A tecnologia FPGA}

Existem dois métodos primários para a execução de algoritmos na computação (COMPTON; HAUCK, 2002). O primeiro deles são os circuitos integrados produzidos especificamente para uma aplicação, conhecidos como ASICs. Seu uso produz resultados com rapidez e eficiência quando executadas computações para as quais eles foram projetados. Entretanto, o circuito não pode ser alterado após a fabricação, qualquer intenção de modificação de funcionalidade implica na refabricação do circuito. Esse é um processo muito custoso, principalmente quando envolve largas escalas.

O segundo método oferece uma solução mais flexível. Consiste na implementação de algoritmos em softwares que são executados sobre um microprocessador. A função do sistema é alterada apenas com a mudança das instruções que compõem o programa. Con- 
tanto, a grande flexibilidade apresentada nesse método, acarreta perda de desempenho procedente do ciclo de instrução. Outro problema inerente consiste no conjunto de instruções que é definido na fabricação, não permitindo mudanças para a obtenção de maior desempenho dos algoritmos.

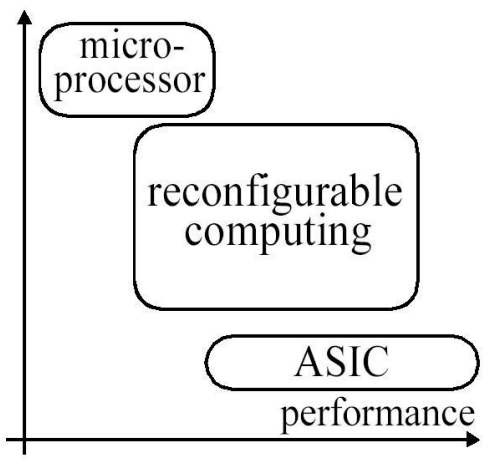

Figura 3.1: FPGA: Reduzindo a diferença entre ASIC e microprocessador (HARTENSTEIN, 2001).

A computação reconfigurável reduz a distância entre os dois métodos primários (Figura 3.1), oferecendo uma flexibilidade potencialmente maior que o hardware dedicado e um desempenho maior que algoritmos implementados em software (COMPTON; HAUCK, 2002). As configurações assumidas pela FPGA podem ser realizadas de acordo com circuitos digitais especificados por diagramas esquemáticos, por programas escritos em linguagens de descrição de hardware tais como VHDL(Very High Speed Integrated Circuit Hardware Description Language) ou Verilog, ou por linguagem de programação.

Uma FPGA consiste em uma estrutura geral que possui alta capacidade lógica. A FPGA é composta de um grande arranjo de células configuráveis (ou blocos lógicos) que podem ser conectadas para assumir diferentes configurações (ROSE; SANGIOVANNIVICENTELLI, 1993).

Cada uma dessas células contém certa capacidade computacional para implementar funções lógicas, e/ou realizar roteamento para permitir a comunicação entre células. Deste modo, circuitos digitais customizados podem ser mapeados para o hardware reconfigurável, utilizando os recursos computaionais dos blocos, e configurando o roteamento para formar o circuito necessário (RIBEIRO, 2002) (COMPTON; HAUCK, 2002).

A arquitetura de uma FPGA, apresentada na Figura 3.2, consiste em um arranjo 2-D de blocos lógicos, que podem se comunicar por meio de recursos de interconexão, para formar os circuitos desejados. A borda externa do arranjo é composta pelos blocos de E/S, que são capazes de realizar operações de entrada e saída. 


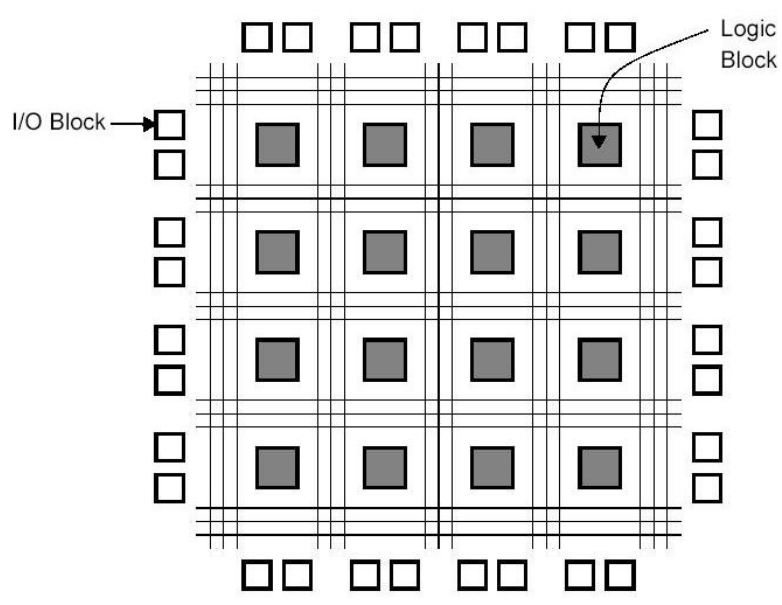

Figura 3.2: Estrutura de uma FPGA (BROWN; ROSE, 1996a).

Um bloco lógico pode ser simples como um transistor ou complexo como um microprocessador. Por meio dos recursos de roteamento, a conexão entre diversos blocos pode representar complexas funções lógicas. Para cada bloco lógico de uma FPGA podem ser empregados (ROSE; SANGIOVANNI-VICENTELLI, 1993):

- Pares de transistores;

- Portas lógicas básicas do tipo NAND ou XOR de duas entradas;;

- Multiplexadores;

- Look-up Tables (LUTs);

- Estruturas $A N D$ e $O R$ de múltiplas entradas; e

- Flip-flops associados com portas lógicas.

As FGPAs são classificadas em níveis de granularidade, de acordo com a capacidade dos blocos lógicos. A granularidade fina define arquiteturas de blocos contendo portas lógicas básicas ou transistores. As arquiteturas com granularidade média normalmente implementam flip-flops ou LUTs. As arquiteturas com granularidade grossa possuem unidades lógicas aritméticas (ULAs), ou também microprocessadores.

O roteamento nas FPGAs, normalmente é realizado por meio de comutadores programáveis eletricamente e existem diferentes tipos de tecnologias para a implementação dos comutadores (BROWN; ROSE, 1996b) (MASON, 2005) (MORRIS, 2005a). 


\subsection{Sistemas Operacionais Reconfiguráveis}

Uma FPGA pode também ser classificada de acordo com sua configurabilidade (Figura 3.3). Por definição, todas as FPGAs são consideradas programáveis e podem ser configuradas pelo menos uma vez. Na classe de reconfiguráveis estão as FPGAs que podem ser reprogramadas outras vezes após a primeira configuração. Assim, partes específicas do hardware podem ser reconfiguradas, enquanto as outras ficam inativas ou continuam em execução, não perdendo sua função lógica. As FPGAs, que possibilitam uma parte ser reconfigurada enquanto o restante permanece executando, pertencem à classe dinamicamente reconfigurável.

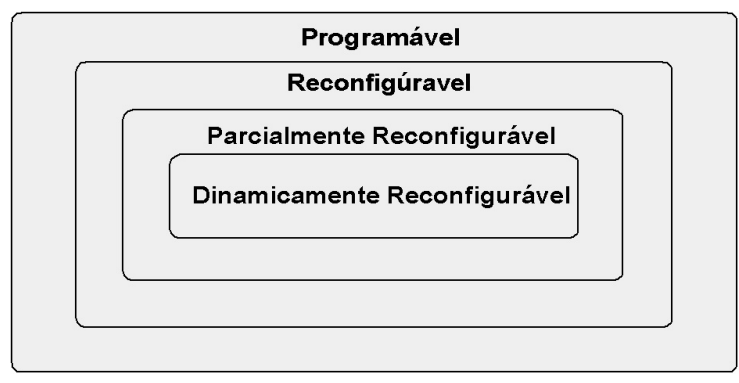

Figura 3.3: Tipos de FPGA.

Uma área de FPGA potencialmente pode ser comparada com um processador à espera de uma tarefa para executar, sendo que podem haver mais de uma tarefa executando simultaneamente. Com base no conceito de reconfigurabilidade dinâmica, a área da FPGA pode ser aproveitada para alocar várias tarefas em execução, enquanto novas tarefas podem ser iniciadas sem interromper as demais (Figura 3.4).

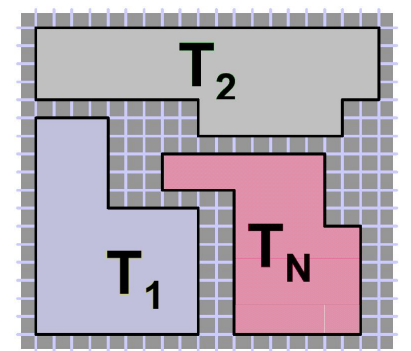

Figura 3.4: Várias tarefas em execução simultaneamente.

Um modo de aprimorar esse modelo, explorando a capacidade de paralelismo, é a adição de um módulo de gerenciamento de tarefas, responsável por carregar, trocar e alocar novas tarefas para a execução. Esse módulo é conhecido como sistema operacional reconfigurável, que gerencia os recursos da FPGA. 
Uma parte da área da FPGA é destinada ao sistema operacional reconfigurável, o qual é implementado tanto em hardware, quanto em software, necessitando assim de uma conexão com um host. Outra fração da área da FPGA é reservada para as tarefas a serem executadas, identificada na Figura 3.5 pelas áreas em branco.
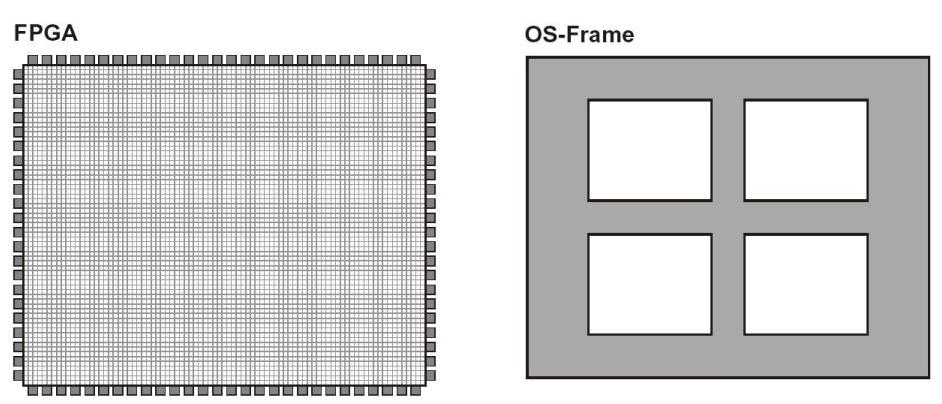

Figura 3.5: FPGA e áreas destinadas às tarefas e ao SO (RUPPEN, 2003).

Além de habilitar a multi-tarefa em hardware, o benefício de um sistema operacional reconfigurável é o aumento de produtividade e portabilidade. As abstrações de tarefas e objetos do sistema facilitam a reutilização de códigos e circuitos testados e confiáveis, podendo acelerar consideravelmente o desenvolvimento do produto, diminuindo o timeto-market ${ }^{1}$ (STEIGER et al., 2004).

Uma arquitetura do sistema operacional reconfigurável é proposta por (WALDER; PLATZNER, 2003a) e apresentada na Figura 3.6. O sistema é composto por um host (CPU) e por um dispositivo reconfigurável. A porta $\mathrm{C} / \mathrm{R}$ (configuration and readback port) oferece à CPU o estado e o controle completo sobre a configuração do dispositivo, podendo reconfigurá-lo totalmente ou parcialmente. A porta COMM (communication port) é o meio pelo qual os módulos do SO, residentes na CPU e na FPGA, podem comunicar-se. Os componentes conectados à CPU e ao dispositivo reconfigurável são componentes externos, responsáveis pelo armazenamento de dados e E/S.

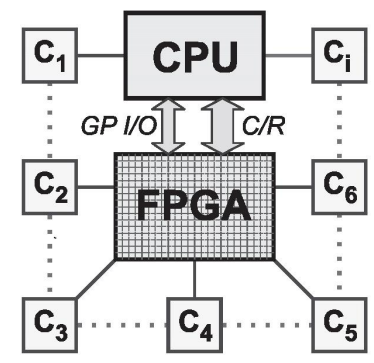

Figura 3.6: Arquitetura do sistema operacional reconfigurável (STEIGER et al., 2004).

\footnotetext{
${ }^{1}$ Time-to-market: É o tempo necessário para um novo produto ser comercializado.
} 


\subsubsection{Tarefas de Hardware}

As tarefas consistem em circuitos digitais, podendo agregar também memórias, e normalmente são mais complexas de gerenciar do que tarefas em software (WIGLEY; KEARNEY, 2002). Essas tarefas podem ser implementadas por linguagens de descrição de hardware, linguagens de programação ou diagramas esquemáticos, e devem funcionar independentemente do local onde foram inseridas na FPGA.

As tarefas ocupam uma área composta por um número de unidades reconfiguráveis (RCU - reconfigurable unit), e implementam uma interface padrão para a comunicação com o SO, para poderem funcionar em quaisquer posições em que forem introduzidas. $\mathrm{O}$ modelo da interface padrão (STI - standard task interface) é apresentado na Figura 3.7.
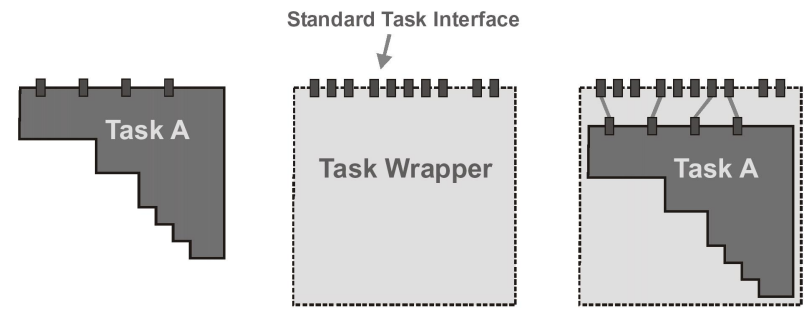

Figura 3.7: Interface padrão para tarefas (RUPPEN, 2003).

O sistema operacional deve conhecer as características de tempo e as caraterísticas estruturais da tarefa para fornecer os recursos adequados (STEIGER et al., 2004).

A principal característica de tempo é a freqüência de clock requerida para a execução de uma tarefa, que deve ser previamente informada ao SO. Entre outras características estão o número de clocks para a execução completa e o deadline de uma tarefa em tempo real.

As características estruturais compreendem o tamanho e o formato. O sistema operacional oferece uma área com um certo tamanho para alocar as tarefas, dada em números de RCUs. As tarefas podem assumir a forma de um retângulo ou um formato mais complexo, e devem ser acomodadas pelo SO. O formato que a tarefa possui tem grande importância para o sistema, pois pode induzir a fragmentação interna ${ }^{2}$ no espaço ocupado.

A complexidade do mapeamento de tarefas para dispositivos reconfiguráveis depende muito do modelo da área utilizada (STEIGER et al., 2004). Os dois principais modelos são apresentados na Figura 3.8, nos quais o formato considerado das tarefas é o retângulo.

No primeiro modelo, a tarefa pode ocupar qualquer área que não esteja ocupada no

\footnotetext{
${ }^{2}$ Fragmentação interna: espaço inutilizado dentro da área reservada para uma tarefa.
} 
sentido horizontal do disposivo, oferecendo um escalonamento mais simplificado, porém trazendo problemas de fragmentação externa ${ }^{3}$.

Dois tipos de fragmentação externa podem ocorrer no modelo de área 1D. O primeiro tipo ocorre quando a tarefa não ocupa toda a altura do espaço reservado. O segundo tipo acontece quando o espaço entre uma coluna e outra é pequeno demasiado para ser utilizado por outra tarefa.

No modelo de área 2D, as tarefas podem ocupar qualquer posição da área do dispositivo. Deste modo, pode ocorrer menor fragmentação externa, pois o espaço é melhor distribuido, entretanto possui algoritmos mais complexos.

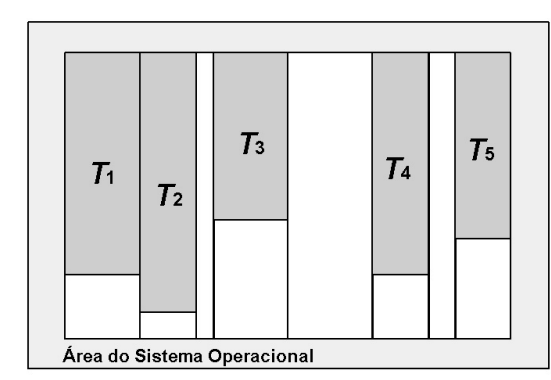

a)

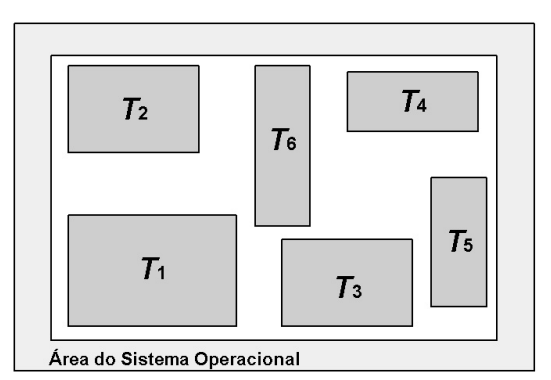

b)

Figura 3.8: Modelos de área: a) Modelo 1D; e b) Modelo 2D.

A decisão de quando uma tarefa começa a executar, é concedida ao escalonador que deve implementar alguma política para a escolha das tarefas.

A preempção de tarefas não é tão simples quando essas são implementadas em hardware. Não existe um ponto de execução como em softwares, que podem ser parados pelo SO apenas armazenando suas váriaveis de estado (tais como pilha, registradores e variáveis de memória) (WIGLEY; KEARNEY, 2001) (WIGLEY; KEARNEY, 2000). As técnicas de preempção de tarefas são discutidas em (LANDAKER, 2002).

O sistema operacional também deve prover meios para a comunicação entre processos. Uma das principais abordagens é a introdução de um barramento que possui uma STI, pelo qual os processos podem comunicar-se além de comunicar com o SO (WALDER; PLATZNER, 2003b).

\footnotetext{
${ }^{3}$ Fragmentação externa: espaços não utilizados por tarefas que não podem ser alocados a outras tarefas devido possuirem um tamanho insuficiente.
} 


\subsubsection{Módulos do sistema operacional}

Alguns módulos necessários ao sistema operacional são propostos por (WALDER; PLATZNER, 2003a) e estão apresentados na Figura 3.9.

O modelo compreende uma divisão entre os componentes implementados por software (presentes na CPU) e componentes implementados em hardware (presentes na FPGA).

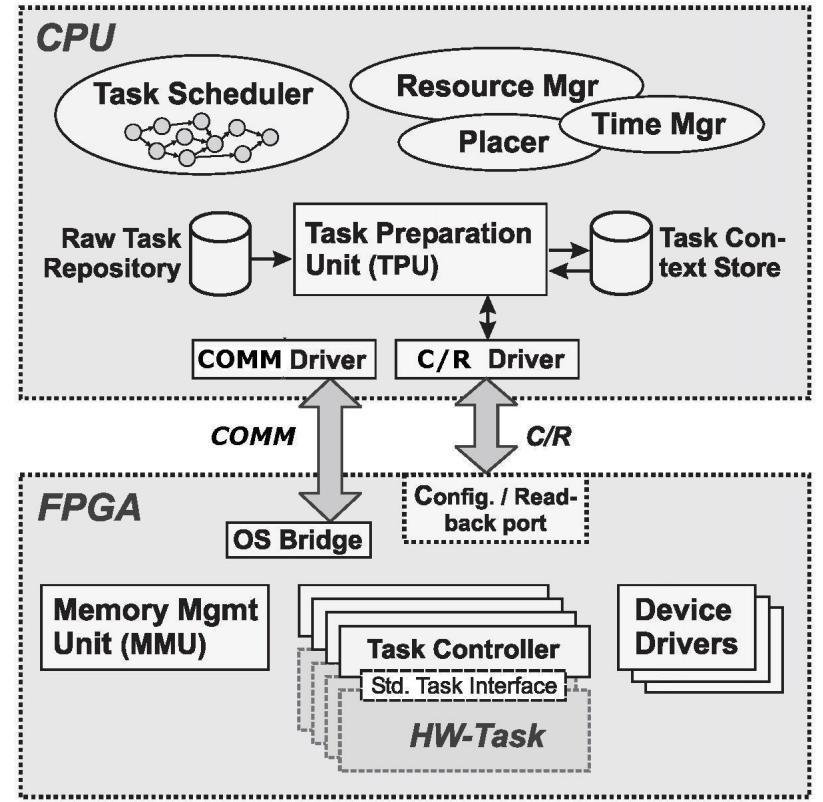

Figura 3.9: Módulos do sistema operacional reconfigurável (STEIGER et al., 2004) (WALDER; PLATZNER, 2003a).

O escalonador de tarefas (Task Scheduler) é um dos elementos presentes na CPU, o qual é responsável por decidir qual a próxima tarefa a executar, baseado em alguma política de escalonamento. Quando o escalonador decide executar uma tarefa, a área designada para tal tarefa é atribuida pelo gerenciador de recursos (Resource Manager). Esse é responsável pelo controle da alocação dinâmica de recursos, tais como áreas para tarefas, filas, triggers, e drivers.

Outro elemento importante que fornece serviços às tarefas é o gerenciador de tempo (Time Manager), que contribui com recursos de tempo, como clock e eventos periódicos.

Antes das tarefas entrarem em execução, elas ficam armazenadas no repositório de tarefas em formato primário (Raw Task Repository), e posteriormente são introduzidas na unidade de preparação de tarefa - TPU (Task Preparation Unit). Nessa unidade são gerados e analizados bitstreams ${ }^{4}$ parciais que representam as tarefas. Os seguintes serviços são fornecidos pela TPU (WALDER; PLATZNER, 2003b):

\footnotetext{
${ }^{4}$ bitstreams: Consistem em um conjunto de dados de configuração de um dispositivo FPGA.
} 
- Inserção de tarefa: São considerados a tarefa primária e uma posição na área na FPGA, e a partir disso é gerado um bitstream parcial que pode ser inserido no dispositivo;

- Extração de contexto: É extraído o contexto do bitstream parcial;

- Inserção do contexto: São considerados a tarefa em formato primário e seu contexto previamente armazenado, e a partir disso é gerado um bitstream parcial (na restauração de um processo, por exemplo, são chamados consecutivamente os serviços de inserção do contexto e de tarefa); e

- Inserção de parâmetros: Insere um conjunto de parâmetros em localizações prédefinidas.

A comunicação entre os módulos do sistema operacional localizados no dispositivo reconfigurável e na CPU é fornecida por meio da porta COMM. A porta $\mathrm{C} / \mathrm{R}$ é utilizada para a CPU manter o estado e o controle completo sobre a configuração do dispositivo, podendo reconfigurá-lo totalmente ou parcialmente.

Os módulos do sistema operacional localizados no dispositivo reconfigurável são:

- Controlador de tarefas (Task Controler): Faz a conexão entre o sistema operacional e a área da tarefa;

- Unidade de gerenciamento de memória - MMU (Memory Management Unit): Oferece serviços de memória às tarefas, tais como filas, blocos de memória privada ou blocos de memória compartilhada. A estrutura da memória pode ser provida pelas memórias internas da FPGA ou por componentes externos conectados. Outro serviço que pode ser implementado pela MMU é a memória virtual (DIESSEL; WIGLEY, 1999); e

- Drivers de dispositivos: São implementados circuitos para controle dos dispositivos externos e oferecerem serviços às tarefas.

\subsection{Processadores em FPGA}

O aumento da capacidade lógica da FPGA tem motivado o uso de vários tipos de soluções para explorar as características físicas oferecidas. A utilização de processadores 
específicos, ou mesmo de propósito geral implementados em FPGAs, é um ponto intermediário entre computação reconfigurável e a computação tradicional por meio de microprocessadores. Esse paradigma oferece a flexibilidade alcançada por software juntamente com maior flexibilidade do hardware responsável por executar as instruções.

Processadores de propósito geral, na forma de ASICs, têm sido embutidos em placas de FPGA projetadas atualmente. Esses tipos de processadores são chamados de hard processors. Os processadores implementados em FPGAs utilizando computação reconfigurável são conhecidos como soft processors.

A integração de hard processors com arquiteturas de FPGAs oferece um balanceamento do custo, do desempenho, e dos requisitos de integração do sistema. Essa integração traz uma redução do número de componentes complexos na placa e do consumo de energia, como também aumenta a confiabilidade do sistema. Os hard processors mais conhecidos integrados com placas dos fabricantes Altera (ALTERA, 2005) e Xilinx (XILINX, 2005c), são: ARM (ARM, 2005) e PowerPC (IBM, 2005).

Por outro lado, os soft processors oferecem maior flexibilidade aos projetos de hardware, podendo funcionar paralelamente para alcançar maior desempenho. Outra possibilidade é o emprego de características adicionais pelo usuário, de modo a atender melhor a necessidade de sua aplicação. As principais fabricantes de FPGA Altera (ALTERA, 2005) e Xilinx (XILINX, 2005c), disponibilizam três linhas de processadores implementados em FPGA. Esses processadores são apresentados nas próximas seções.

\subsubsection{PicoBlaze}

O PicoBlaze é um processador de 8-bits para as famílias de FPGAs Virtex e Spartan da Xilinx e para os CPLDs (Complex Programmable Logic Device) CoolRunner-II. Esse processador suporta 57 a 59 instruções com 16 ou 18-bits, possui de 8 a 32 registradores de prósito geral com 8-bits, pode ter mais de 256 portas endereçáveis diretamente e indiretamente, e interrupção. As características variam de acordo com as placas que suportam o PicoBlaze.

\subsubsection{MicroBlaze}

MicroBlaze é um soft processor RISC (Reduced Instruction Set Computer) de 32bits que pode ser utilizado para o desenvolvimento de sistemas embarcados em FPGAs fabricadas pela Xilinx, e foi desenvolvido inicialmente para a família de FPGA Xilinx 
Spartan-3 utilizando uma freqüência de $50 \mathrm{MHz}$ derivada da freqüência da placa. As famílias que suportam o MicroBlaze são: Virtex-4, Virtex-II Pro, Virtex-II, Virtex-E, Spartan-IIE e Spartan-II.

As principais características do MicroBlaze são (XILINX, 2005b):

- Cache de instruçõe e dados;

- 32 registradores de 32-bits com barramentos de endereço e de dados de 32-bits;

- Único ciclo de execução;

- Portas de entrada e saída de propósito geral; e

- Controlador UART (Universal Asynchronous Receiver/Transmitter) RS232.

\subsubsection{Nios II}

A família de processadores Nios II, introduzidos pela Altera, é uma evolução do processador Nios, e acrescenta novas características que estendem o desempenho e o baixo custo dos soft processors. As famílias de dispositivos Altera que suportam o NIOS II são: Stratix II, Stratix, Cyclone II, Cyclone e HardCopy II.

Nios II consiste em um processador de 32-bits RISC de propósito geral, desenvolvido para atender uma grande escala de dispositivos embarcados. As principais características do Nios II são:

- Conjunto de instruções, espaço de endereçamento e data path de 32-bits;

- 32 registradores de propósito geral;

- 32 fontes de interrupções externas;

- Instruções dedicadas ao cálculo de multiplicações com 64-bits e 128-bits;

- Acesso a uma variedade de periféricos on-chip, e interfaces para acesso a memórias e periféricos off-chip;

- Possibilidade de depuração;

- Desempenho a partir de 150DMIPS ${ }^{5}$;

${ }^{5}$ DMIPS - Dhrystone Millions of Instruction per Second: Dhrystone consiste em um tipo de Benchmark que visa a análise de CPUs testando a execução de aritméticas simples, operações com string, decisões lógicas e acessos à memória. 
- Oferece cerca de 2 GBytes de espaço de endereçamento; e

- O usuário tem a possibilidade de customizar 256 instruções com objetivos próprios para sua aplicação.

O fabricante oferece três linhas de processadores, com características diferentes: Nios II/f (versão rápida), Nios II/e (versão econômica) e Nios II/s (versão padrão). As principais características das três categorias de processadores estão apresentadas na Tabela 3.1.

\begin{tabular}{|c|c|c|c|}
\hline Característica & $\begin{array}{c}\text { Nios II/f } \\
\text { Rápido }\end{array}$ & $\begin{array}{c}\text { Nios II/s } \\
\text { Padrão }\end{array}$ & $\begin{array}{c}\text { Nios II/e } \\
\text { Econômico }\end{array}$ \\
\hline Tamanho aproximado & $1.800 \mathrm{LEs}$ & $1.300 \mathrm{LEs}$ & $600 \mathrm{LEs}$ \\
\hline Desempenho & $200 \mathrm{MIPS}$ & $120 \mathrm{MIPS}$ & $28 \mathrm{MIPS}$ \\
\hline Freqüência máxima & $135 \mathrm{MHz}$ & $135 \mathrm{MHz}$ & $150 \mathrm{MHz}$ \\
\hline Controle de excessões & Sim & Sim & Sim \\
\hline $\begin{array}{c}\text { Espaço externo de } \\
\text { endereçamento }\end{array}$ & 2 GBytes & 2 GBytes & 2 GBytes \\
\hline Pipeline & 6 estágios & 5 estágios & Não possui \\
\hline Previsão de salto & Dinâmica & Estática & Não possui \\
\hline $\begin{array}{c}\text { Cache de Instruções } \\
\text { Configurável } \\
\text { (512 Bytes a } 64 \text { KBytes) }\end{array}$ & $\begin{array}{c}\text { Configurável } \\
\text { (512 Bytes a } 64 \text { KBytes) }\end{array}$ & Não possui \\
\hline Cache de Dados & $\begin{array}{c}\text { Configurável } \\
\text { (512 Bytes a } 64 \text { KBytes) }\end{array}$ & Não possui & Não possui \\
\hline Instruções customizadas & \multicolumn{3}{|c}{ Até 256 } \\
\hline
\end{tabular}

Tabela 3.1: Características dos processadores Nios II.

As versões Nios II/s e Nios II/f oferecem ainda respectivamente 5 e 6 estágios de pipeline, predições de salto estático e dinâmico. Ambas possuem cache de instruções e somente a versão Nios II/f possui cache de dados, todas parametrizáveis. A versão Nios II/e não possui muitas características para o aumento de desempenho, entretanto possui um tamanho menor em elementos lógicos (LE - Logic Elements), podendo ser utilizado em quantidade maior em uma FPGA para o aumento do desempenho.

\subsection{Considerações finais}

As plataformas baseadas em FPGA estão crescendo e penetrando em um crescente número de areas de aplicação. A facilidade com que o hardware reconfigurável é reprogramado tem motivado a adoção de FPGAs em muitos sistemas embarcados. Atualmente, alguns exemplos de aplicação de FPGA encontram-se (XILINX, 2005a) (MORRIS, 2005b): 
na aviação, em aplicações de VOIP ( Voice Over IP), em telecomunicações, na computação, em instrumentação médica, em aplicações militares, em sistemas de segurança, no processamento de imagem, em aplicações de rede sem fio, em câmeras e na robótica. Nos anos 2003 e 2004, as FPGAs fizeram parte do desenvolvimento de equipamentos utilizados na missão de exploração do planeta Marte, realizada pela NASA (National Aeronautics and Space Administration) (XILINX, 2003) (XILINX, 2004).

O mercado tem demonstrado a aceitação da FPGA e os fabricantes tem retribuido com arquiteturas inovadoras, ferramentas mais poderosas e melhorias nas metodologias. Componentes cada vez menores (MORRIS, 2004), com elevados níveis de densidade e com maior poder computacional, são um atrativo para a exploração dessa recente tecnologia em uma variedade maior de áreas de aplicações. A execução de tarefas em ASICs tem sido brandamente substituída por tecnologias que oferecem maior flexibilidade.

A reconfigurabilidade dinâmica de FPGAs atraiu a atenção de pesquisadores interessados na exploração dessa característica e originou um estudo mais aprofundado em sistemas operacionais reconfiguráveis para a melhor utilização da área de FPGA, de modo a explorar ao máximo o parelismo entre tarefas de hardware.

A inserção de tarefas na FPGA por um sistema operacional reconfigurável é um trabalho custoso, realizado por complexos algoritmos (COMPTON et al., 2002), de modo a preservar sempre a utilização máxima da área destinada às tarefas, tentando evitar fragmentações externas e internas, as quais são um dos principais problemas em pesquisa nessa área.

Neste trabalho é apresentada uma abordagem diferente para melhorar a utilização da área da FPGA, a qual é transformanda em um área reservada a processadores que devem executar em paralelo tarefas implementadas em software. A gerência das tarefas deve ser realizada por um sistema operacional implementado em software, o qual também deve executar sobre os processadores, capaz de escalonar e controlar os eventos em tempo real.

As áreas, que supostamente seriam desperdiçadas pela fragmentação em um sistema operacional reconfigurável, são utilizadas para conter unidades de processamento, as quais podem aumentar o desempenho do sistema, aumentando a capacidade de paralelismo entre tarefas.

O projeto propõe a implementação de funções que habilitam o multiprocessamento no sistema operacional embarcado eCos - embedded Configurable operating system, utilizando o Nios II como processador, cujas características são apresentadas no próximo capítulo. 


\section{O sistema operacional eCos}

\subsection{Considerações iniciais}

Durante alguns anos a indústria busca por tecnologias de implementação de hardware que ofereçam desempenho a um baixo custo. A diminuição do preço das FPGAs e o aumento de seu poder computacional tornaram a computação reconfigurável um modo viável para a implementação de aplicações, que oferece muita flexilidade e um desempenho comparado com aplicações em ASICs.

Uma preocupação freqüente está relacionada com a melhor utilização dos recursos oferecidos pelos fabricantes de FPGAs, para alcançar maior desempenho nas aplicações. Com a utilização de soft processors é possível a utilização da área disponível na FPGA para acomodar várias CPUs, de modo que as tarefas possam ser executadas paralelamente.

A proposta oferecida por este trabalho, consiste na implementação de funcionalidades no sistema operacional eCos (embedded Configurable operating system) que habilitem o multiprocessamento utilizando o processador Nios II. O eCos é um sistema operacional de tempo real desenvolvido para atender aplicações embarcadas. Possui um sistema configurável permitindo a parametrização de seus recursos para satisfazer requisitos específicos de uma determinada aplicação.

O eCos tem sido muito difundido e atualmente suporta muitas arquiteturas, incluindo o processador Nios II. Apesar de comportar simultaneamente vários processadores em plataformas distintas, essa característica ainda não está empregada para o processador em questão. Esse capítulo ${ }^{1}$ é destinado a apresentar as principais características do eCos, destacando as mais importantes para a concretização deste projeto.

\footnotetext{
${ }^{1}$ Esse capítulo é baseado na documentação disponibilizada para o eCos: (HAT, 2003) (VEER; DALLAWAY, 2001) (GARNETT et al., 2003) (MASSA, 2002).
} 


\subsection{Escalonamento}

O eCos possui dois algoritmos de escalonamento implementados atualmente, dentre os quais um algoritmo específico pode ser utilizado de acordo com a configuração desejada. Os dois métodos de escalonamento são bitmap e MLQ (multi-level queue). Ambos usam um esquema de prioridade entre processos que possui 32 níveis. O algoritmo bitmap envolve uma fila simples de prioridade, a qual é limitada a comportar 32 processos, não permitindo dois ou mais processos com a mesma prioridade. O acesso ao próximo processo a executar é dado por uma simples operação de leitura de um vetor, com acesso em tempo constante, tornando-o totalmente determinístico. O MLQ suporta vários processos por prioridade, não limitando o número de processos no sistema. Para cada prioridade existe uma fila que armazena os processos e o acesso ao processo de maior prioridade exige um tempo maior que o algoritmo bitmap. Opcionalmente, o MLQ suporta timeslicing, que possibilita o escalonador trocar o processo em execução por outro após um determinado tempo.

Atualmente, o SMP é suportado utilizando somente o algoritmo MLQ por algumas arquiteturas. Entretanto, são necessárias algumas modificações no escalonador para permitir que diversos processos sejam executados simultaneamente.

\subsection{Primitivas de sincronização}

O eCos fornece diferentes tipos de primitivas de sincronização:

- Mutex: Consiste em um meio que permite a exclusão mútua entre os processos sobre um recurso;

- Variáveis de condição: Disponibilizam primitivas que permitem bloquear tarefas enquanto esperam por algum evento. São normalmente utilizadas em conjunto com mutexes;

- Semáforo: Notifica a ocorrência de um evento. Se acontecerem eventos múltiplas vezes, essa informação é armazenada;

- Mail boxes: Também notifica a ocorrência de um evento, e adicionalmente permite a troca de informações nos eventos, disponibilizando um local temporário de armazenamento; e 
- Flags de eventos: Podem ser utilizados para aguardar pela ocorrência de determinados eventos, que podem ser um ou vários. Não é armazenado o número de vezes que um evento ocorreu, como o semáforo, e também não é possível enviar informações adicionais em eventos, como Mail boxes.

\subsection{Gerenciamento de memória}

eCos não suporta o gerenciamento de memória. A noção de espaços de endereçamentos distintos não existe e todos os processos compartilham o mesmo espaço e capacidades de acessos. O gerenciamento de memória deve ser utilizado em algumas arquiteturas para melhorar o desempenho.

\subsection{Processos e controle de interrupção}

Nos sistemas embarcados os eventos de software e hardware são elementos essenciais na interação entre os módulos presentes. Quando uma tarefa deve executar uma rotina específica na ocorrência de um evento em um dispositivo, ela pode monitorar continuamente o hardware para saber o momento que a rotina deve ser executada. Esse monitoramento é conhecido por pooling, método pelo qual o processo testa continuamente uma variável para saber quando o evento ocorre. Outro modo para alcançar o mesmo resultado consiste na utilização de interrupção, o processo recebe um sinal indicando a ocorrência de um evento. Assim, o consumo de ciclos de CPU seria reduzido e quando o interrupção ocorresse, a rotina seria executada, sem necessitar de uma espera ocupada.

O uso de interrupção pode ocasionar alguns problemas de inconsistências, principalmente quando uma rotina do kernel é interrompida, ou quando a interrupção interfere em processos do tipo produtor-consumidor. Para resolver isto, a maioria dos sistemas operacionais implementam uma funcionalidade para desativar interrupções. Assim as interrupções são desabilitadas antes de regiões críticas e habilitadas novamente após, evitando que causem inconsistências no sistema. Em sistemas embarcados, principalmente os que possuem caracterização de tempo real, essa característica pode afetar seu funcionamento geral. O eCos oferece um modo para evitar inconsistências devido às interrupções, implementando uma abordagem diferente para o controle de interrupção. Cada vetor de interrupção é associado com uma ISR (Interrupt Service Rotine), a qual é executada sempre que um evento de hardware ocorre. Entretanto, uma ISR não está apta a executar 
todos os serviços oferecidos pelo kernel, somente uma pequena parte deles são disponibilizados às ISRs. Uma ISR não pode desbloquear um processo. Quando é detectado o final de uma operação de E/S a ISR pode iniciar a execução de uma DSR (Deferred Service Routine), a qual está apta a executar mais rotinas do kernel.

Outra funcionalidade implementada pelo kernel é a possibilidade de desativação do escalonador para manipulação de dados.

\subsection{Contexto de chamadas}

O eCos define diferentes contextos para a execução de tarefas. Em cada um deles, apenas um conjunto específico de funcionalidades kernel pode ser acessado. Os contextos existentes são:

- Contexto de inicialização: Quando o eCos é iniciado, as interrupções e o escalonador são desabilitados, até que o sistema seja configurado. Após a configuração, o escalonador e as interrupções são habilitados, e o controle é passado para o processo de maior prioridade, executando em contexto de processo. Algumas tarefas podem executar antes que o escalonador seja habilitado, essas tarefas executam no contexto de inicialização. Os processos que executam nesse contexto tem as interrupções desabilitadas e o escalonador desativado, e não permitido habilitá-los. Conseqüentemente algumas primitivas de sincronização não podem ser utilizadas.

- Contexto de processo: A maioria das funções do kernel estão disponíveis.

- Contexto de ISR: Quando ocorre uma interrupção, o controle é passado para a ISR, que executa em seu contexto específico. Neste contexto, a ISR está habilidata a executar funções ligadas às interrupções. A maioria dos recursos oferecidos pelo kernel não são acessíveis, incluindo diversas primitivas de sincronização. Para sincronização em sistemas SMP, é possível a utilização de spinlocks; e

- Contexto de DSR: Na execução de uma ISR pode ser detectada a finalização de uma E/S e uma DSR associada deve entrar em execução, executando no contexto DSR. É permitido o acesso a mais funcionalidades que são acessíveis no contexto ISR, incluindo primitivas de sincronização que não causam o bloqueio do processo (no caso é a DSR). 


\subsection{Sistema de arquivos}

O eCos oferece uma interface de suporte para sistemas de arquivos. Todos os sistemas de arquivos devem estar presentes na tabela principal, onde algumas características são armazenadas. Também é oferecida uma tabela dos sistemas de arquivos atualmente ativos, similarmente aos sistemas Unix, e para cada arquivo aberto deve existir uma entrada na tabela de arquivos. Diversos métodos são implementados para compor essa interface que possibilita que um novo sistema de arquivos seja facilmente adicionado.

\subsection{Entrada e saída}

O pacote de $\mathrm{E} / \mathrm{S}$ do eCos fornece um framework de propósito geral para o suporte de todas as classes de drivers de dispositivos. Os drivers devem seguir uma interface padrão para implementação, e todos são estaticamente declarados e associados aos seus dispositivos. Os nomes dos dispositivos possuem uma identificação padronizada e devem ser precedidos de "/dev".

O eCos possui um modelo de interrupção de três níveis para drivers de dispositivos. Os níveis consistem em ISR que é invocada em resposta a alguma interrupção de hardware, DSR que é iniciado a partir de um ISR, e as threads que constituem os clientes dos drivers. Para um driver receber interrupções, deve inicialmente definir rotinas ISR e DSR e posteriormente associá-los com uma interrupção.

Quando ocorre uma interrupção, a camada de abstração de hardware - HAL² (Hardware Abstraction Layer) analisa a interrupção e emite uma chamada para a ISR associada àquela interrupção. A ISR pode manipular o hardware mas lhe é permitido fazer chamadas apenas a um conjunto restrito de rotinas da API de drivers. Essa rotina pode invocar uma DSR, que tem acesso a um conjunto maior de funções, incluindo uma rotina específica para desbloquear ("acordar") processos. A partir do uso dessa rotina, o processo que estava bloqueado a espera da interrupção está apto a utilizar funções para recuperar e manipular as informações provindas de dispositivos externos.

Em arquiteturas SMP os drivers devem ser implementados com primitivas de exclusão mútua e ordenação de eventos, tal como spinlock, para evitar problemas com a execução simultânea de componentes do driver em CPUs diferentes.

\footnotetext{
${ }^{2} \mathrm{HAL}$ - Hardware Abstraction Layer: Consiste em uma interface entre o hardware e o sistema operacional. Com essa abstração o sistema operacional pode ser facilmente portado para outra arquitetura apenas modificando o HAL.
} 


\subsection{Licença}

O sistema operacional eCos está sob a lincença pública geral - GPL (General Public License), a qual garante que os usuários tenham a liberdade de executar, copiar, distribuir, estudar, modificar e aperfeiçoar o software. Todos podem distribuir cópias de softwares, mas devem garantir que os usuários terão os mesmos direitos que eles possuem. O código fonte do sistema eCos está disponibilizado gratuitamente para modificações.

\subsection{Considerações finais}

Outros sistemas operacionais, que possuem suporte ao processador Nios II, também foram analizados, visando a utilização como base do projeto, os quais são: Kros Operating System, PrKernel v4 - eSOL, Nucleus RTOS - Accelerated Technology, MicroC/OS-II Micrium, e MicroCLinux (2.6) - Microtronix.

As principais restrições na escolha para o desenvolvimento do projeto utilizando esses sistemas estão no tipo de licença que possuem e na disponibilização de documentação. Dentre os SOs pesquisados, somente o eCos, MicroC/OS-II - Micrium, e MicroCLinux (2.6) possuem licença GPL, dentre os quais o eCos é o mais popular e possui maior quantidade de documentação disponível.

No próximo capítulo é apresentada a descrição da plataforma do projeto, a qual inclui as ferramentas que podem ser utilizadas e o projeto ARMOSH (Aprendizado em Robôs Móveis via Software e Hardware), no qual este trabalho está inserido. 


\section{Ambiente de desenvolvimento}

\subsection{Considerações iniciais}

A proposta de desenvolvimento de um sistema operacional multiprocessado para o processador Nios II está vinculado ao projeto de Aprendizado em Robôs Móveis via Software e Hardware - ARMOSH. Esse capítulo apresenta os objetivos e necessidades desse projeto, destacando também as ferramentas que podem ser utilizadas para o desenvolvimento deste trabalho.

\subsection{ARMOSH}

Segundo um relatório da ONU (Organização das Nações Unidas) de 2004, a utilização de robôs domésticos crescerá sete vezes até 2007. No final de 2003 haviam 607 mil auxiliares domésticos em todo mundo, entre eles 507 mil tem a função de aspirador de pó e 37 mil são cortadores de grama. A previsão é que até 2007 existam 4,1 milhões de robôs executando tarefas de limpeza (PAULO, 2004). "A queda ou estabilização dos preços somada ao aumento dos custos de mão-de-obra e a contínua melhoria da tecnologia impulsionam o investimento das indústrias em robótica" (EUROPE, 2004)

Muitos estudos têm sido realizados para a construção de robôs confiáveis capazes de executar suas funções para o ambiente no qual foram projetados. Enfaticamente, essa interação é normalmente crítica, devendo considerar um espaço dinâmico, e tomar decisões em tempo real de acordo com a ocorrência dos eventos.

Para tanto, os robôs devem apresentar sensores e atuadores, conduzidos por algumas técnicas que permitam alcançar uma interação efetiva com o mundo real. O sistema de navegação é o componente principal dessa interação, e consiste no objetivo do projeto de Aprendizado em Robôs Móveis via Software e Hardware - ARMOSH ${ }^{1}$, em desenvolvimento

\footnotetext{
${ }^{1}$ ARMOSH: Processo FAPESP no. 2000/02959-3.
} 
no Laboratório de Computação Reconfigurável (LCR) em conjunto com o Laboratório de Inteligência Computacional (LABIC).

Este projeto propõe o estudo e a implementação de algoritmos de aprendizado de robôs móveis em software e em hardware, visando uma comparação de desempenho. Os algoritmos para navegação consideram os sensores do robô: sonar, infra-vermelho, laser e câmera de vídeo; e a definição do ambiente: fechado, aberto e desconhecido (ROMERO, 2000).

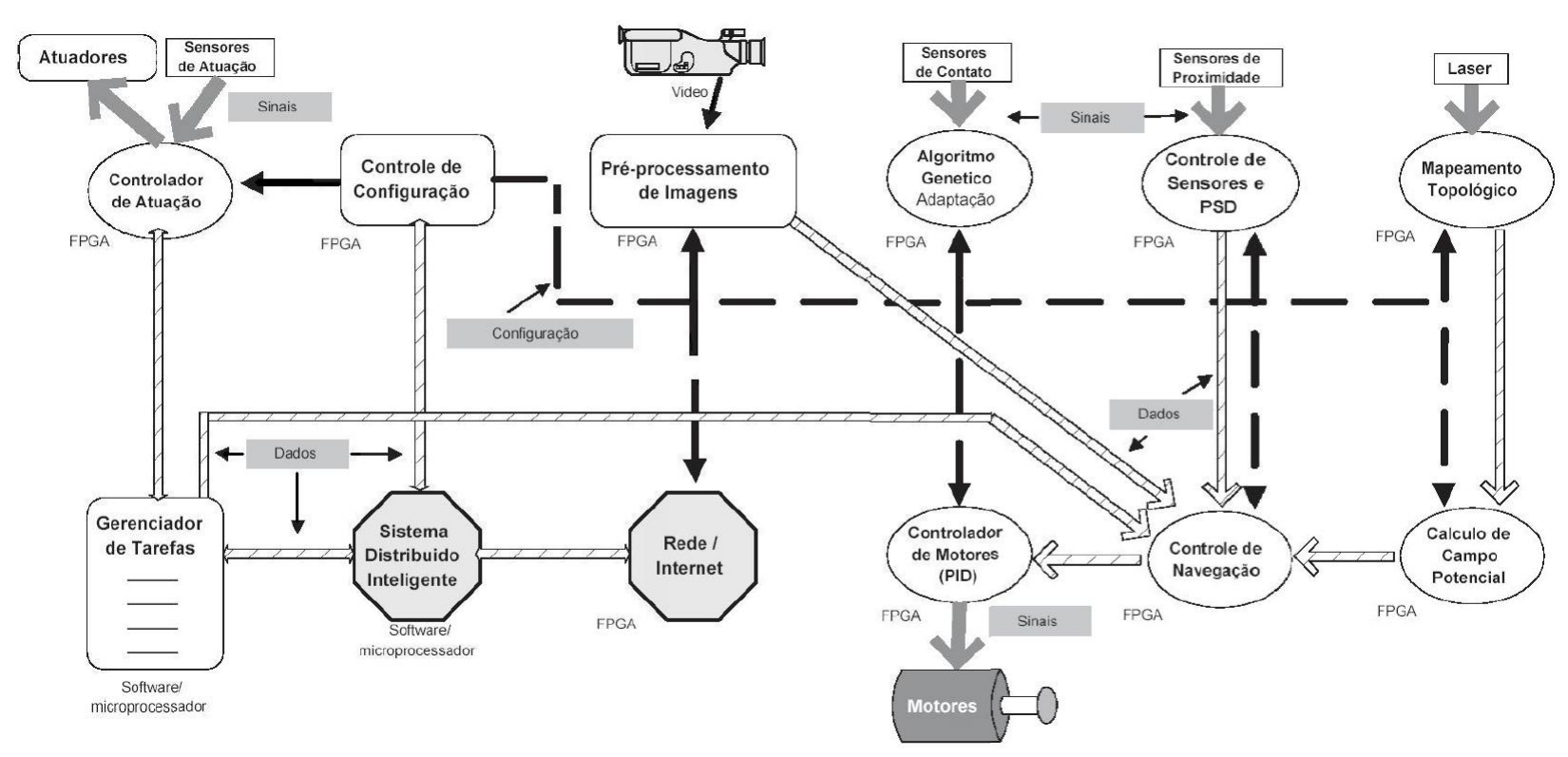

Figura 5.1: Projeto ARMOSH: Diagrama de componentes.

Na Figura 5.1 são apresentados os principais módulos que compõem o sistema. A integração desses componentes é dependente de um elemento que controle o funcionamento de cada um, coordenando de modo inteligente a execução dos algoritmos. Essa integração é tarefa do sistema operacional, o qual deve proporcionar versatilidade em tempo real ao sistema, realizando decisões de utilização de dispositivos e algoritmos que melhor se adaptam ao ambiente do robô.

Todas as tarefas vinculadas ao módulo do ARMOSH são implementadas em hardware e software sobre a arquitetura reconfigurável. Devem ser fornecidas interfaces por meio de drivers para o sistema operacional poder controlar todos os módulos.

Atualmente, diversos módulos do ARMOSH estão sendo desenvolvidos, e alguns já estão concluídos. O projeto do sistema operacional deve dar suporte para o acoplamento de todos os componentes, oferecendo características intrínsecas de robótica, como comportamento determinístico e capacidade de execução simultânea de várias tarefas. 


\subsection{Plataforma de desenvolvimento}

A implementação das funcionalidades de multiprocessamento no sistema operacional eCos deve ser realizada utilizando os seguintes componentes:

- Processador Nios II - Altera;

- Placa de FPGA DE2 - Altera;

- Quartus II - Altera; e

- Nios II IDE (Integrated Development Environment).

Esses componentes são comentados nas próximas seções.

\subsubsection{Processador Nios II - Altera}

O soft processor Nios II, desenvolvido pela Altera, consiste em uma arquitetura RISC de 32-bits, que agrega, em três linhas de processadores, características para atender um amplo número de aplicações de variados portes. O Nios II é uma solução de baixo custo e alta performance para o desenvolvimento de sistemas embarcados. Os três tipos de processadores Nios II, conforme apresentados na Seção 3.4.3, são Nios II/f, Nios II/e e Nios II/s.

Apesar do Nios II/f possuir um desempenho superior, o projeto será implementado sobre o processador Nios II/e, pelo fato de não possuir cache de instruções e nem cache de dados. A utilização de um processador com cache em uma arquitetura SMP necessita de um protocolo que reduza totalmente o risco de incoerência dos dados.

A implementação de funcionalidades que habilita o SMP sobre o Nios II no eCos se detém sobre uma arquitetura contendo inicialmente três processadores Nios II/s, em uma placa DE2 - Altera. Cada processador Nios II/e ocupa um espaço de 3,9\% da área da FPGA, a qual pode suportar aproximadamente 25 desses processadores, sem considerar o restante do hardware.

\subsubsection{DE2 - Altera}

A placa DE2 (Figura 5.2), introduzida no mercado pela Altera, possui grande capacidade lógica para implementação de sistemas lógicos programáveis. Sua principal 
finalidade é atender o mercado universitário, principalmente pela quantidade de funções disponibilizadas e pelo preço reduzido do produto (ALTERA CORPORATION, 2006c).

A FPGA utilizada pela placa consiste em Cyclone II 2C35, a qual possui capacidade 33.216 elementos lógicos, com osciladores de $50 \mathrm{MHz}$ e $27 \mathrm{MHz}$ para fontes de clock. As principais características da FPGA estão apresentadas na Tabela 5.1 (ALTERA CORPORATION, 2006b):

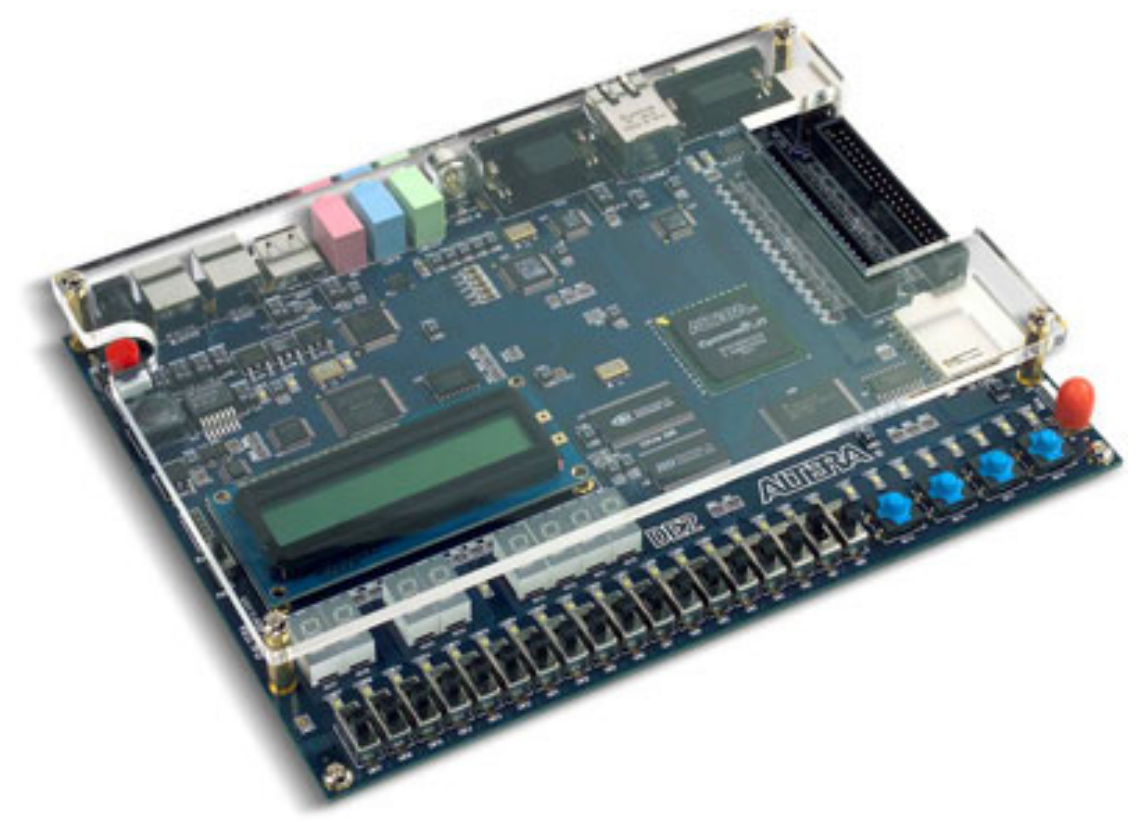

Figura 5.2: Placa de desenvolvimento DE2 - Altera. (ALTERA, 2007)

\begin{tabular}{|c|c|}
\hline Característica & 2C35 \\
\hline \hline Elem. Lógicos & 33.216 \\
\hline Mem. 4 Kbits & 105 \\
\hline bits RAM total & 483.480 \\
\hline Multiplicadores embarcados & 70 \\
\hline PLLs & 4 \\
\hline Máx. pin. E/S & 475 \\
\hline
\end{tabular}

Tabela 5.1: Principais características da FPGA 2C35.

A placa DE2 possui os seguintes dispositivos:

- FPGA Altera Cyclone® II 2C35;

- USB Blaster para programação do hardware e controle do usuário;

- Memória SRAM 512 KB;

- Memória SDRAM 8 MB; 
- Memória Flash 4MB;

- Socket para SD Card;

- 4 pushbuttons e 18 toggle switches;

- 18 LEDs vermelhos e 9 LEDs verdes;

- CODEC (24-bit) com entradas e saídas: line-in, line-out e microphone-in;

- DAC VGA com conector VGA;

- Decoder TV (NTSC/PAL) e conector TV-in;

- Controlador 10/100 Ethernet;

- Controlador USB Host/Slave com conectores tipo A e B;

- Transceiver RS-232 e conector de 9 pinos;

- Conector PS/2 para mouse/teclado;

- Transceiver IrDA; e

- Dois slots de expansão com 40 pinos.

\subsubsection{Quartus II - Altera}

A Altera oferece um software de alto nível para o desenvolvimento de hardware. O Quartus II (Figura 5.3) fornece um completo ambiente de projeto que habilita o fabricante a criar e fornecer FPGA, CPLD, e ASIC estruturado com alto nível de desempenho em menor time-to-market. O Quartus II combina projeto, síntese, alocação e roteamento, e verificação em uma única ferramenta. Os projetos podem ser implementados por meio de linguagens de descrição de hardware VHDL e Verilog como também podem ser baseados em blocos gráficos que reprentam de simples a complexos dispositivos lógicos (ALTERA, 2004b).

Juntamente com o Quartus II, a Altera disponibiliza o software SOPC Builder (Figura 5.4), o qual fornece uma plataforma destinada à composição de projetos construídos a partir de blocos ou componentes, reduzindo o tempo gasto na fase de integração do sistema. O software já apresenta alguns componentes prontos com sua propriedade intelectual (IP - Intellectual Property) protegida, esses componentes são também conhecidos como IP Cores: 


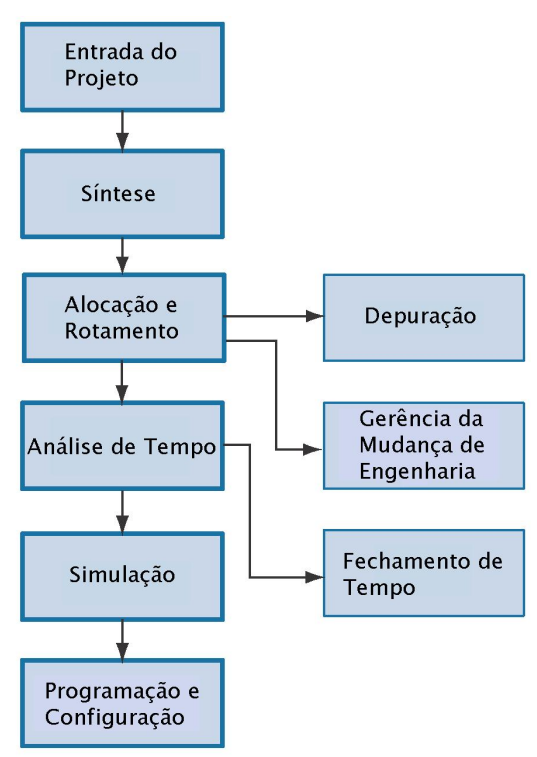

Figura 5.3: Fluxo de projeto no Quartus II (ALTERA, 2004b).

- Processadores On-Chip;

- Interfaces para processadores Off-Chip;

- Interfaces para memórias;

- Pequenos periféricos comuns;

- Periféricos de comunicação;

- Pontes e interfaces;

- Processamento digital de sinal - DSP (Digital Signal Processing; e

- Periféricos aceleradores de hardware.

\subsubsection{Nios II - IDE}

O Nios II IDE é um ambiente de desenvolvimento de software para a família de processadores Nios II. Esse ambiente é derivado do Eclipse ${ }^{2}$, e por meio dele é possível criar, editar, compilar e depurar programas, além de ter a possibilidade de enviar o programa para ser executado sobre o processador Nios II na FPGA. Na Figura 5.6 é apresentada a tela do sistema.

\footnotetext{
${ }^{2}$ Eclipse: Ambiente integrado de desenvolvimento disponível para várias plataformas e linguagens, e possui licença pública o que resulta na disponibilização livre de seu código fonte.
} 


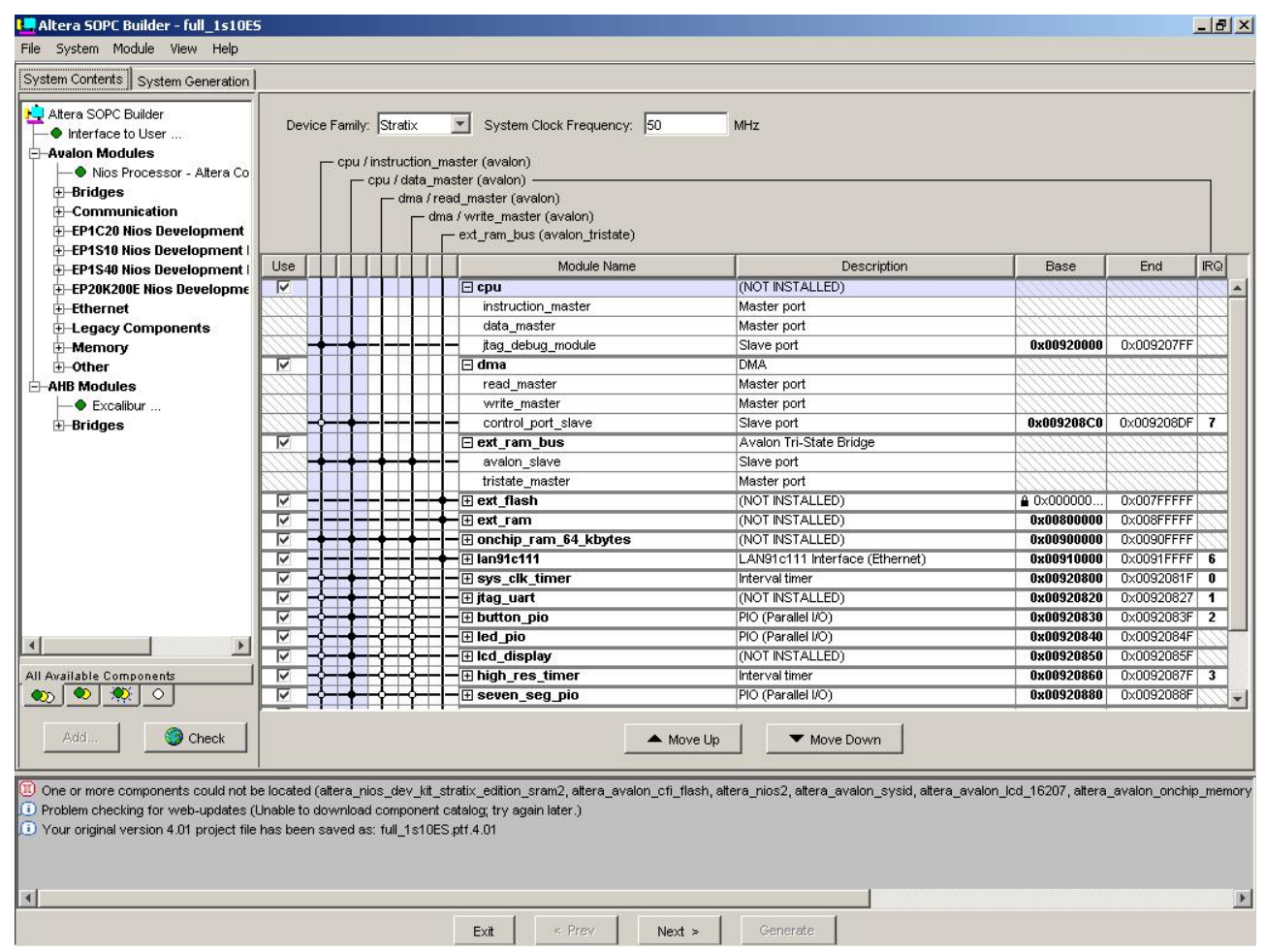

Figura 5.4: Tela do SOPC Builder.

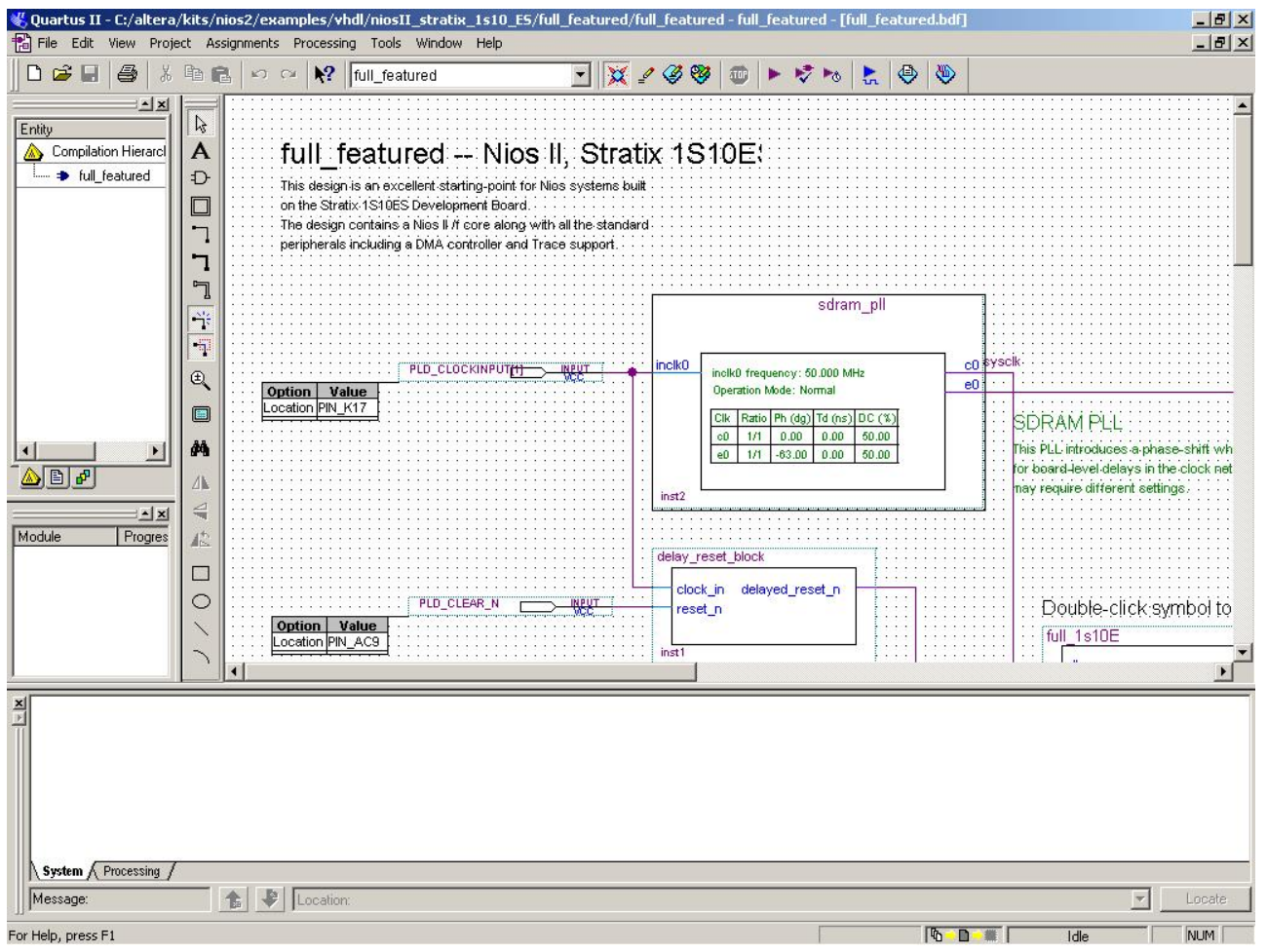

Figura 5.5: Tela do Quartus II. 


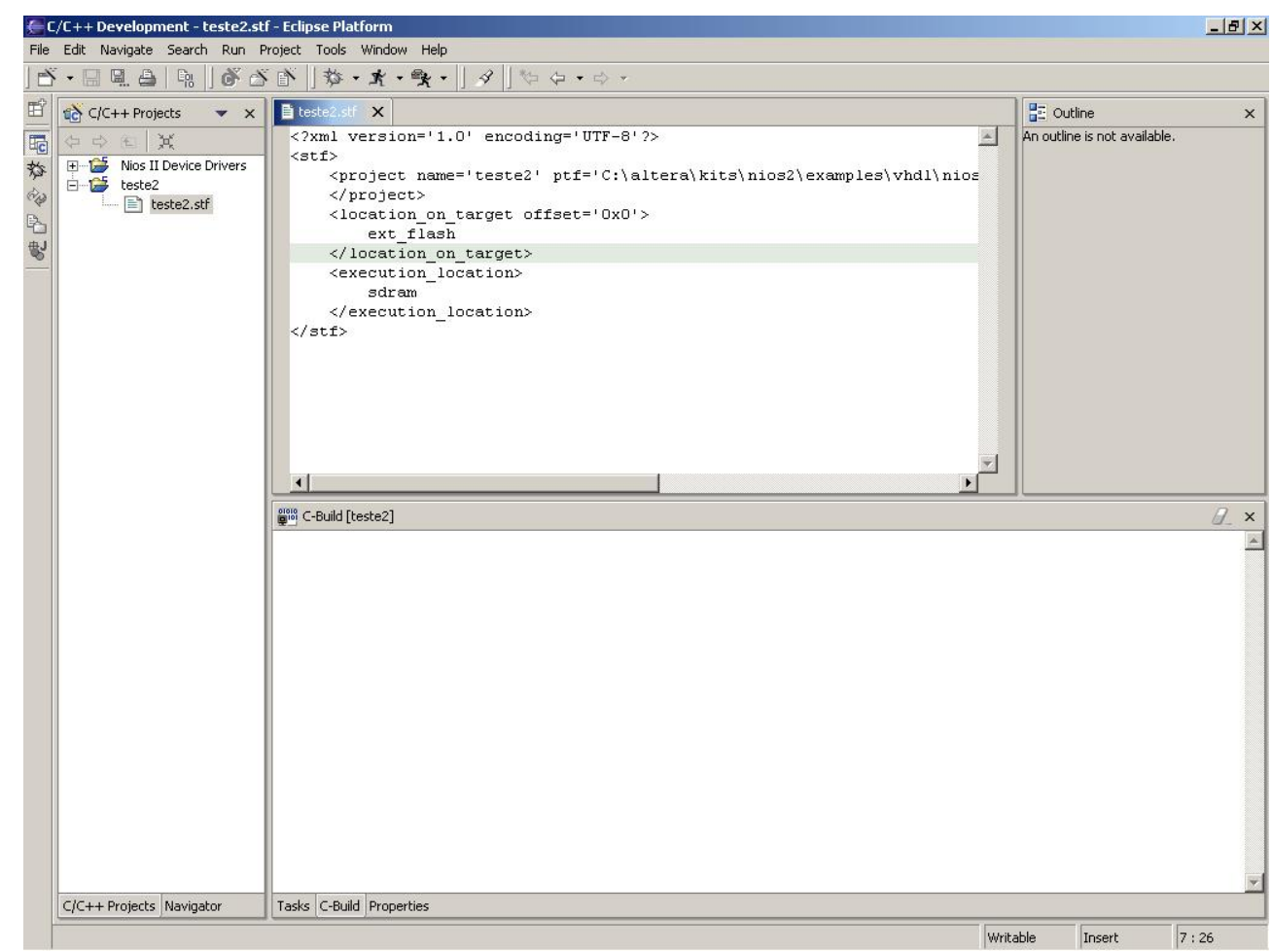

Figura 5.6: Tela do Nios II IDE.

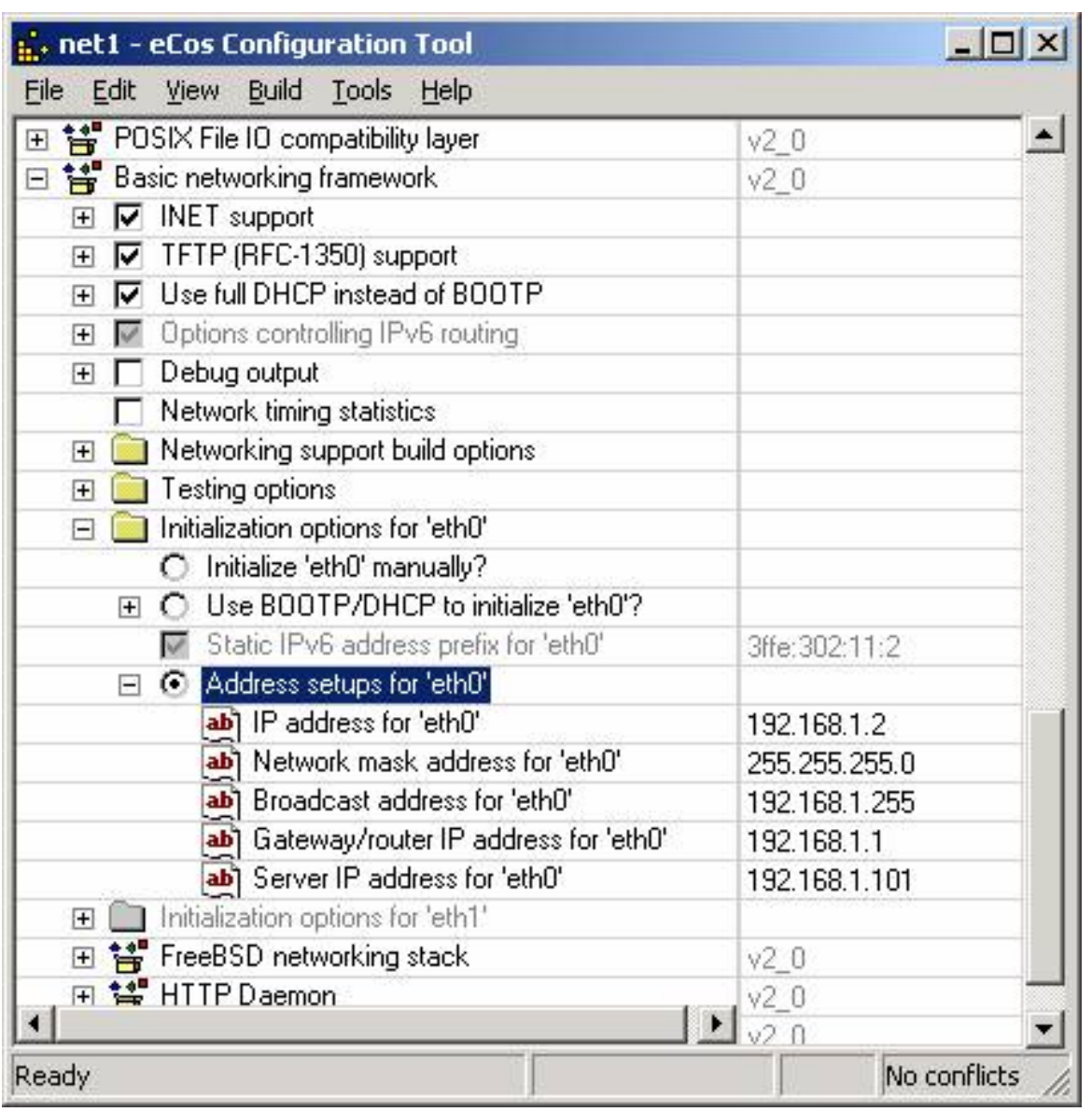

Figura 5.7: Tela da ferramenta de configuração do eCos. 


\subsection{5 eCos}

O sistema operacional eCos também fornece uma ferramenta de configuração. O eCos disponibiliza diversos componentes, e a partir dessa ferramenta o sistema operacional é adaptado conforme as necessidades do usuário e de acordo com o hardware. A tela de configuração é apresentada na Figura 5.7.

\subsection{Considerações finais}

Neste capítulo foram abordadas a plataforma de desenvolvimento e suas principais características. A placa de FPGA DE2 oferece recursos que resultam em alta performance com a utilização do processador Nios II e as ferramentas facilitam a implementação do sistema, diminuindo o tempo dedicado ao projeto. 


\section{O processador Nios II}

\subsection{Considerações iniciais}

O Nios II é um processador soft-core baseado em uma arquitetura RISC de 32 bits, que pode ser configurada de acordo com as características desejadas. Sua flexibilidade, seu custo e seu desempenho têm trazido grande popularidade, sendo atualmente um dos processadores soft-core mais utilizados ${ }^{1}$.

\subsection{Projeto de hardware com Nios II}

Um sistema Nios II contempla um conjunto de dispositivos implementados e disponibilizados pela Altera, os quais interagem para atender às necessidades do usuário. Os principais dispositivos são descritos nas próximas seções.

\subsubsection{Barramento}

Qualquer componente que interage com o sistema Nios II acessando outros periféricos, tais como processador e dipositivos de memória, utiliza a interface Avalon para a comunicação. A interação de um sistema baseado nessa interface é realizada por meio das portas master e slave presentes nos dispositivos (denominados periféricos Avalon), as quais são ligadas ao componente Avalon switch fabric, responsável pela lógica de conexão. Tal interação está apresentada na Figura 6.1

A interface Avalon define o ponto de conexão entre periféricos Avalon e Avalon switch fabric. Cada porta consiste em um grupo de sinais utilizados coletivamente que caracterizam a interface. Uma porta master é uma coleção de tipos de sinais usados para iniciar transferências. Uma porta slave é uma coleção de tipos de sinais utilizados para responder

\footnotetext{
${ }^{1}$ Altera - Nios II: http://www.altera.com/products/ip/processors/nios2/ni2-index.html
} 
a requisições de transferências. Essas duas portas são conectadas meio do Avalon switch fabric.

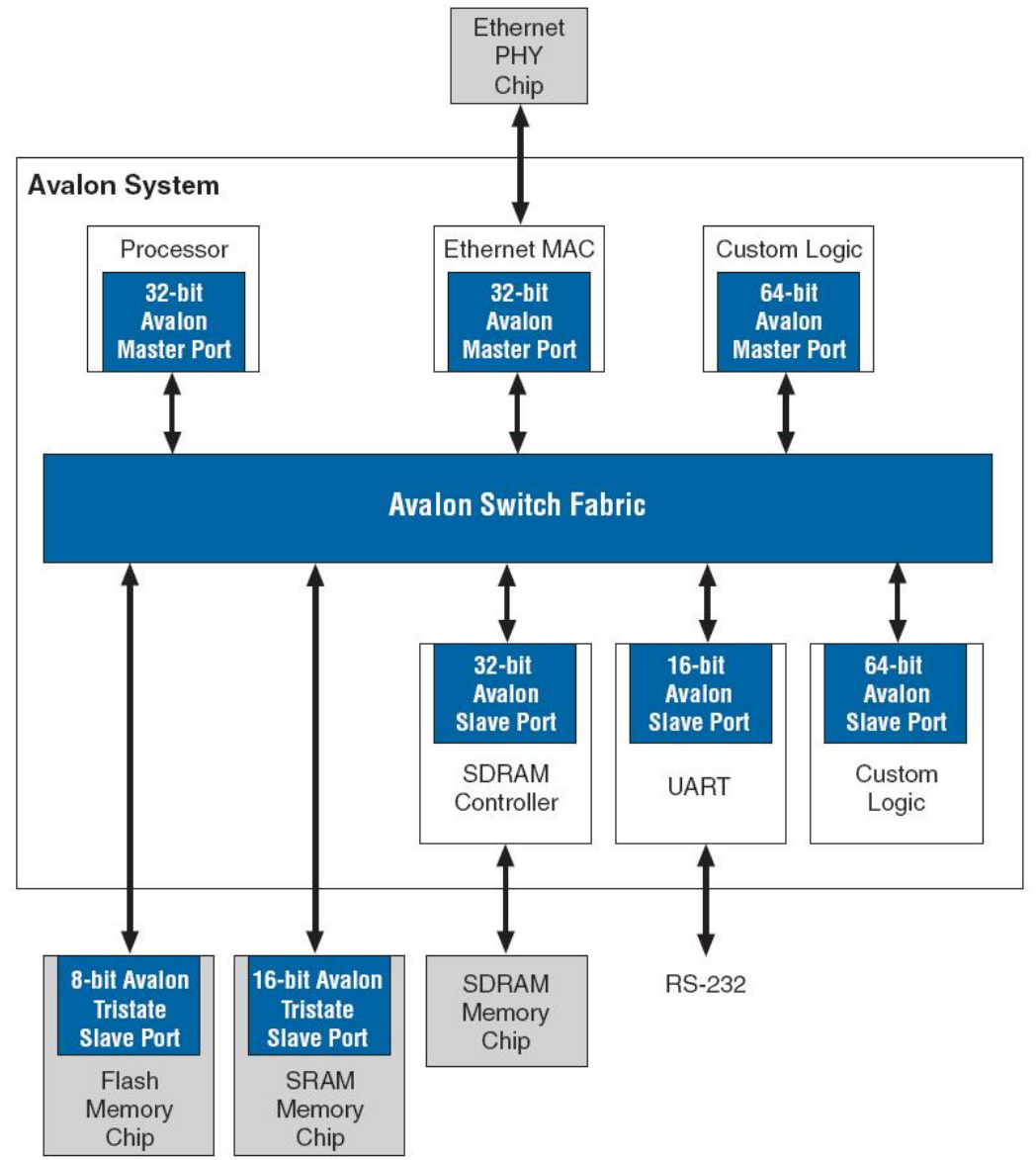

Figura 6.1: Barramento Avalon. (ALTERA CORPORATION, 2006a)

\subsubsection{Dispositivos de armazenamento}

A Altera disponibiliza meios de acesso a dispositivos de armazenamento off-chip, tais como SDRAM e flash. Esses dispositivos são utilizados através de interfaces que implementam, de um lado, os sinais para comunicação com periféricos Avalon, e de outro lado, a lógica de acesso aos periféricos externos.

O SDRAM controller contempla a interface entre sistemas customizados Avalon, e chips SDRAM. Externamente, SDRAM controller pode estar conectado a um ou mais chips SDRAM, controlando todos os requisitos do protocolo dessa memória. Entretanto, na visão da FPGA, existe somente uma porta slave, sendo que sua lógica provê acesso linear a dispositivos master que estão conectados a sua porta (independente do número de chips). 
O acesso a dispositivos flash é realizado por meio do Common Flash Interface controller, o qual permite a conexão de periféricos Avalon com memórias flash externas, que estão de acordo com a especificação Common Flash Interface(CFI) (INTEL, 2007).

\subsubsection{JTAG Universal Asynchronous Receiver/Transmitter}

O JTAG Universal Asynchronous Receiver/Transmitter (UART) consiste no módulo que implementa o método para comunicação serial entre o PC e o sistema Nios II na FPGA Altera. Esse módulo possui a interface Avalon e omite a complexidade da interface JTAG. Por meio do JTAG UART, um periférico master conectado, tal como o processador Nios II, pode comunicar-se com o host, recebendo e enviando dados. Essa comunicação é realizada por meio de um cabo JTAG da Altera, como USB-Blaster ou ByteBlaster II.

O acesso ao JTAG UART a partir do software é realizado por uma interface implementada em ANSI C, a qual se encontra no HAL do Nios II. Por meio dela, um software em execução pode ler ou enviar dados ao host utilizando rotinas implementadas em stdio.h, tal como printf().

Outra função do JTAG UART consiste em implementar meios para a depuração de software. Para isto, o sistema deve ser construído utilizando características de debug do processador Nios II, que são opcionalmente oferecidas no momento de design. O processador é conectado ao módulo de debug do JTAG UART, que controla a execução do programa por meio de registradores do Nios II apresentados posteriormente.

O conjunto de interfaces e fluxos de dados das funcionalidades desse módulo estão apresentados na Figura 6.2.

\subsubsection{Parallel Input/Output}

Além de dispositivos que utilizam protocolos complexos de comunicação, as placas de FPGA normalmente fornecem periféricos para o usuário, tais como pinos de entrada e saída, LEDs, botões, entre outros, que possuem uma lógica de utilização mais simples.

Para a manipulação desses dispositivos, a Altera fornece a Parallel Input/Output(PIO). Nessa porta podem ser conectadas saídas ou entradas de uma lógica implementada pelo usuário, como também pinos de I/O que conectam com dispositivos externos da FPGA. Alguns exemplos de utilização da PIO são:

- Controle de LEDs; 


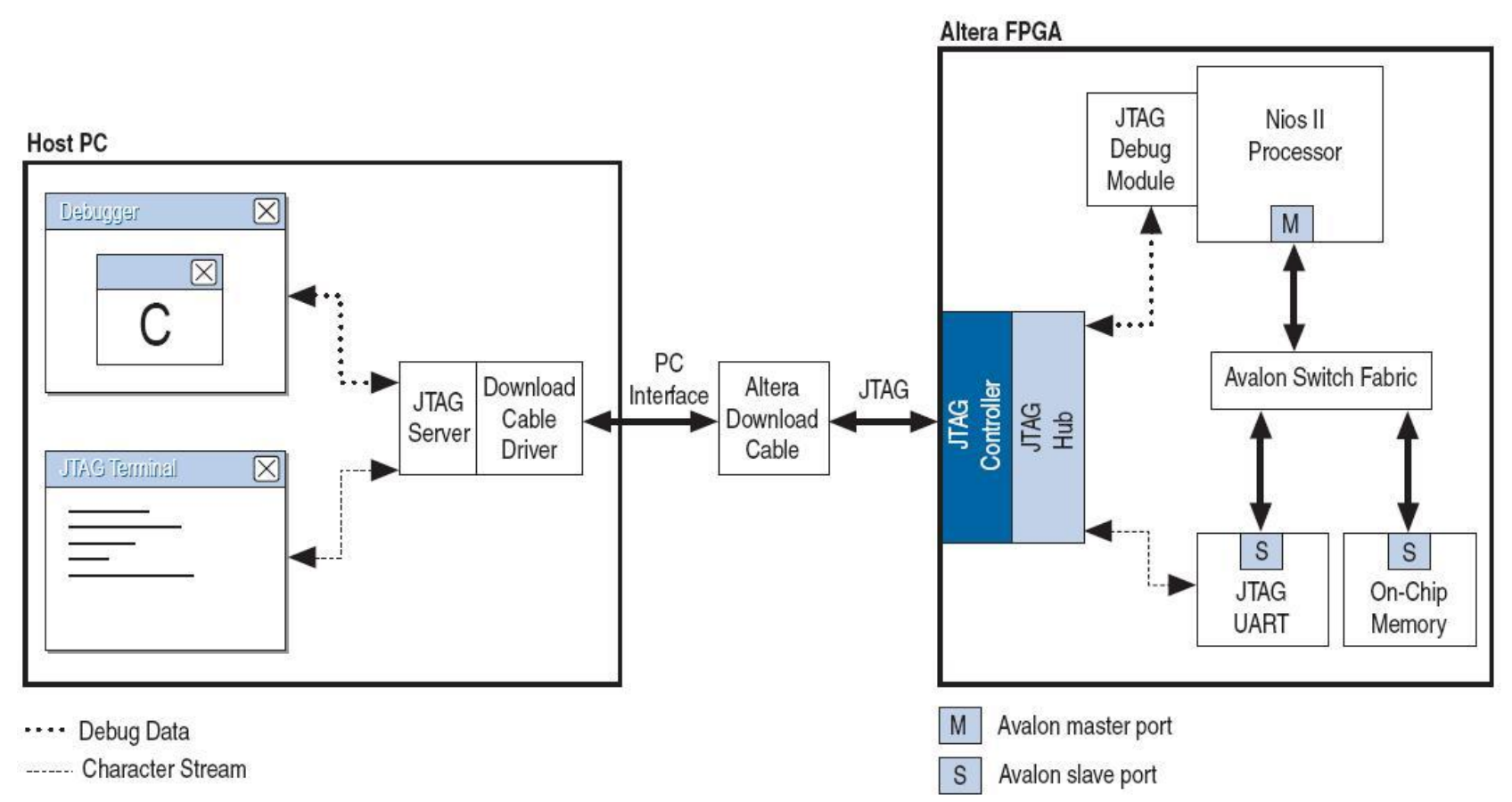

Figura 6.2: JTAG UART. (ALTERA CORPORATION, 2006f)

- Recebimento dos sinais de chaves e botões;

- Controle de dispositivos de display (tais como display de 7 seguementos e LCD); e

- Comunicação com dispositivos conectados à FPGA por meio de pinos externos.

\subsection{Endereçamento}

Cada componente de um sistema Nios II possui um intervalo de endereços que o distingue de outros componentes. Esse intervalo é utilizado para o processador endereçar dados a esse dispositivo. Na Figura 6.3 esse intervalo é determinado pelas colunas base e end.

Em sistemas com um único processador, não é permitido mais que um componente escravo ocupar o mesmo espaço de endereçamento, pois causaria conflitos. A utilização do compartilhamento de espaço de endereçamento é apenas permitida no caso de um sistema multiprocessado. Assim, cada um dos dispositivos que possui o mesmo intervalo de endereço é associado a uma diferente CPU, que enxerga somente um dispositivo naquele espaço.

O processador Nios II é capaz endereçar 2 GBytes utilizando um dimensão de 31 bits. Os periféricos devem ser associados a endereços entre 0x00000000 e 0x7FFFFFFF. No 


\begin{tabular}{|c|c|c|c|c|c|c|c|}
\hline Use & Module Name & Description & Input Clock & Base & End & $\mathbb{R} \mathbf{R Q}$ & \\
\hline \multirow[t]{4}{*}{$\sqrt{\nabla}$} & $\boxminus \mathrm{cpu}$ & \multirow{2}{*}{$\begin{array}{l}\text { Nios II Processor - Altera Corporation } \\
\text { Master port }\end{array}$} & \multirow{4}{*}{ sys_clk } & & & & ↔ \\
\hline & $\longrightarrow$ instruction_master & & & & & & \\
\hline & $\longrightarrow$ data_master & Master port & & IRQ 0 & IRQ 31 & 4 & \\
\hline & $\longrightarrow$ jtag_debug_module & Slave port & & $0 \times 02120000$ & $0 \times 021207 \mathrm{FF}$ & & \\
\hline \multirow[t]{3}{*}{$\sqrt{\nabla}$} & $\boxminus$ ext_ram_bus & Avalon Tristate Bridge & \multirow[t]{3}{*}{ sys_clk } & & & & \\
\hline & $\longrightarrow$ avalon_slave & Slave port & & & & & \\
\hline & $\Longrightarrow$ tristate_master & Master port & & & & & \\
\hline$\sqrt{V}$ & -⿴囗十 ext_flash & Flash Memory (Common Flash Interface) & & $00 \times 00000000$ & OXOOFFFFFF & & \\
\hline$\sqrt{V}$ & $-\bigoplus$ sdram & SDRAM Controller & sys_clk & A $0 \times 01000000$ & 0x01FFFFFF & & \\
\hline$\sqrt{\square}$ & $-\boxplus$ ext_ram & IDT71V416 SRAM & & A $0 \times 02000000$ & 0x020FFFFF & & \\
\hline$\sqrt{\checkmark}$ & - - & On-Chip Memory (RAM or ROM) & sys_clk & A $0 \times 02100000$ & Ox0210FFFF & & \\
\hline$\sqrt{\nabla}$ & $-\square \operatorname{lan91c111}$ & LAN91 c111 Interface (Ethernet) & & $0 \times 02110000$ & 0x0211FFFF & 6 & \\
\hline$\sqrt{v}$ & $\longrightarrow$ sys_clk_timer & Interval timer & sys_clk & $0 \times 02120800$ & $0 \times 0212081 \mathrm{~F}$ & $\mathbf{0}$ & \\
\hline$\sqrt{\square}$ & $\longrightarrow$ jitag_uart & JTAG UART & sys_clk & 0x021208B0 & $0 \times 021208 \mathrm{~B} 7$ & 1 & \\
\hline$\sqrt{\square}$ & $\longrightarrow$ button_pio & PIO (Parallel IIO) & sys_clk & $0 \times 02120860$ & $0 \times 0212086 \mathrm{~F}$ & 2 & \\
\hline \multirow[t]{2}{*}{$\sqrt{\square}$} & $\longrightarrow$ 田led_pio & PIO (Parallel IIO) & sys_clk & $0 \times 02120870$ & $0 \times 0212087 \mathrm{~F}$ & & - \\
\hline & & $\checkmark$ Move Down & & & & & \\
\hline
\end{tabular}

Figura 6.3: SOPC Builder: Endereçamento dos dispositivos.

exemplo do sistema ilustrado na Figura 6.3, qualquer instrução que possui referência a endereços dentro do intervalo [0x00000000 , 0x00FFFFFF], tem seus resultados associados ao dispositivo Flash (ALTERA CORPORATION, 2006d).

A faixa de endereços de cada dispositivo é relacionada com sua capacidade. No caso do dispositivo Flash, podem ser armazenados 16 Mbytes, de modo que sua faixa de endereçamento varia de 0x00000000 a 0x00FFFFFF. Outros dispositivos que não possuem propósito de armazenamento, normalmente possuem endereços suficientes apenas para acesso a seus registradores.

Nos processadores que possuem cache, o bit-31, de ordem mais signifativa, é utilizado para aplicação do método cache bypass. Neste contexto, toda requisição de acesso às referências de memória que contenham esse bit ativado, são privados de consulta prévia à cache. Assim, esses endereços são tratados como sendo pertencentes a dispositivos de I/O que não possuem seus dados armazenados temporariamente na cache.

Em projetos com o Nios II, cada processador no sistema deve ser associado com pelo menos um dispositivo de armazenamento, por meio do qual pode ser realizada a leitura do código e o armazenamento temporário de dados. Essa associação é informada pelos campos de Reset Address e Exception Address, apresentados na Figura 6.4.

O Reset Address indica ao processador o endereço a partir do qual está armazenado o código que deve ser executado. Esse código é executado todas as vezes em que o processador receber um comando para reiniciar seu processamento. Normalmente o Reset Address é associado a um dispositivo Flash. Nesse caso o código contido nesse endereço é um boot copier que copia todo programa para uma área de memória volátil, e em seguida o processador executa uma instrução de jump para essa área, onde o código do programa 


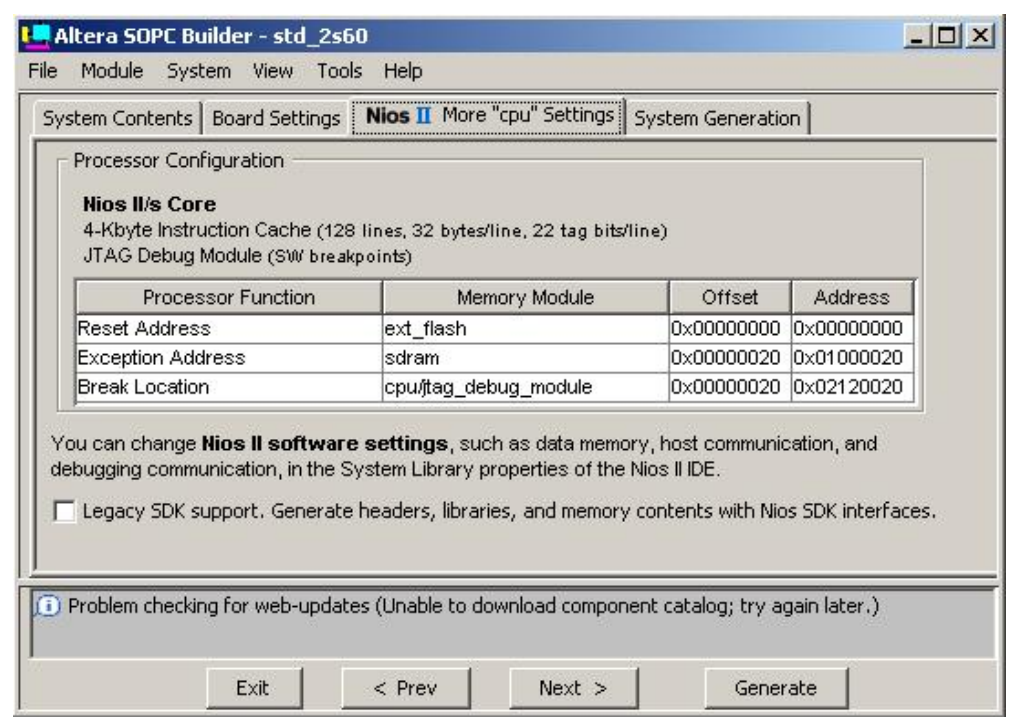

Figura 6.4: Configuração de endereços do Nios II.

é executado.

O Exception Address denota o endereço que contém o código de tratamento de exceção e interrupção. Cada vez que ocorre um evento de um dispositivo ligado a uma IRQ do processador, ou evento de interrupção por software, esse código é executado. Os detalhes de tratamento de interrupção são apresentados na Seção 6.5.

Além de indicar o endereço do tratador de interrupções, o Exception Address também é utilizado para determinar o endereço base para o software que deve ser executado em cada processador do sistema. No caso de sistemas multiprocessados, cada processador possui sua área específica da memória. O endereço final da região é determinado pelo próximo Exception Address encontrado na memória. Se não for encontrado, o endereço final é o mesmo que o endereço final da memória.

Para qualquer tipo de sistema, monoprocessado ou multiprocessado, existem cinco seções primárias de código que precisam ser associadas a endereços fixos na memória para cada processador (ALTERA CORPORATION, 2006e). As seções são:

- .text: Armazena o atual código executável;

- .rodata: Armazena os dados constantes utilizados no código;

- rwdata: Armazena todas as variáveis e ponteiros;

- heap: Área destinada à alocação dinâmica; e

- stack: Armazena parâmetros de chamadas e dados temporários. 


\subsection{Registradores}

A arquitetura do Nios II oferece 32 registradores de propósito geral e 6 registradores de controle, apresentados na Tabela 6.1 e na Tabela 6.2, respectivamente. Alguns deles possuem nomes reconhecidos pelo assembler.

- zero: Sempre retorna o valor 0, escritas nesse registrador não tem efeito;

- at: Registrador não utilizado pelo compilador, sua função é o armazenamento temporário;

- r2 e r3: Utilizados para retorno de funções;

- r4 a r6: Utilizados para passagem de parâmetros;

- r7 a r15: Caller-Saved General-Purpose Registers;

- r16 a r23: Callee-Saved General-Purpose Registers;

- et: Registrador temporário utilizado no tratamento de interrupções;

- bt: Registrador temporário utilizado pelo módulo de depuração;

- gp: Aponta para a zona de memória onde os dados estão armazenados;

- sp: Aponta para o topo da pilha do processador;

- fp: Contém o endereço da zona de memória onde a informação, relevante a um procedimento ou uma função, está armazenada;

- ea: Identifica o endereço para o qual o processamento deve retornar após o tratamento de uma interrupção;

- ba: Endereço posterior à instrução em que ocorreu o break em modo de depuração;

- ra: O registrador ra é utilizado em chamadas de procedimentos, e contém o endereço de retorno da função;

- status: Responsável por armazenar o estado atual do processador. Existem dois bits definidos, PIE e U, que indicam respectivamente se a interrupção está habilitada e o modo do processador (modo de usuário e modo supervisor);

- status: Armazena o estado do processador durante o tratamento de interrupção; 
- bstatus: Armazena o estado do processador durante a depuração;

- ienable: Cada um dos bits de ienable corresponde ao número de uma IRQ. Esse registrador indica quais IRQs tem interrupção habilitada;

- ipending: Indica qual IRQ possui interrupção pendente; e

- cpuid: Armazena o identificador único de cada CPU.

\begin{tabular}{|c|c|c|c|}
\hline \multicolumn{4}{|c|}{ Registradores de propósito geral } \\
\hline Registrador & Nome & $\begin{array}{l}\text { Usado pelo } \\
\text { compilador }\end{array}$ & Função \\
\hline r0 & zero & $\sqrt{ }$ & Retorna o valor $0 \mathrm{x} 00000000$ \\
\hline r1 & $a t$ & & Assembler Temporary \\
\hline r2 & & $\sqrt{ }$ & Valor de retorno (32 bits menos significantes) \\
\hline r3 & & $\sqrt{ }$ & Valor de retorno (32 bits mais significantes) \\
\hline $\mathrm{r} 4$ & & $\sqrt{ }$ & Registrador de argumentos (Primeira palavra de 32 bits) \\
\hline r5 & & $\sqrt{ }$ & Registrador de argumentos (Segunda palavra de 32 bits) \\
\hline r6 & & $\sqrt{ }$ & Registrador de argumentos (Terceira palavra de 32 bits) \\
\hline r7 & & $\sqrt{ }$ & Caller-Saved General-Purpose Registers \\
\hline r8 & & $\sqrt{ }$ & \\
\hline r9 & & $\sqrt{ }$ & \\
\hline $\mathrm{r} 10$ & & $\sqrt{ }$ & \\
\hline $\mathrm{r} 11$ & & $\sqrt{ }$ & \\
\hline r12 & & $\sqrt{ }$ & \\
\hline r13 & & $\sqrt{ }$ & \\
\hline $\mathrm{r} 14$ & & $\sqrt{ }$ & \\
\hline $\mathrm{r} 15$ & & $\sqrt{ }$ & \\
\hline $\mathrm{r} 16$ & & $\sqrt{ }$ & Callee-Saved General-Purpose Registers \\
\hline r17 & & $\sqrt{ }$ & \\
\hline r18 & & $\sqrt{ }$ & \\
\hline $\mathrm{r} 19$ & & $\sqrt{ }$ & \\
\hline r20 & & $\sqrt{ }$ & \\
\hline $\mathrm{r} 21$ & & $\sqrt{ }$ & \\
\hline $\mathrm{r} 22$ & & $\sqrt{ }$ & \\
\hline $\mathrm{r} 23$ & & $\sqrt{ }$ & \\
\hline $\mathrm{r} 24$ & et & & Exception Temporary \\
\hline $\mathrm{r} 25$ & $b t$ & & Break Temporary \\
\hline $\mathrm{r} 26$ & $g p$ & $\sqrt{ }$ & Global Pointer \\
\hline r27 & $s p$ & $\sqrt{ }$ & Stack Pointer \\
\hline $\mathrm{r} 28$ & $f p$ & $\sqrt{ }$ & Frame Pointer \\
\hline $\mathrm{r} 29$ & $e a$ & & Exception Return Address \\
\hline r30 & $b a$ & & Break Return Address \\
\hline r31 & $r a$ & $\sqrt{ }$ & Return Address \\
\hline
\end{tabular}

Tabela 6.1: Registradores do processador Nios II. (ALTERA CORPORATION, 2006e) 


\begin{tabular}{|c|c|c|c|c|}
\hline \multicolumn{5}{|c|}{ Registradores de controle } \\
\hline \hline Registrador & Nome & $\mathbf{3 1 . . 2}$ & $\mathbf{1}$ & $\mathbf{0}$ \\
\hline ctl0 & status & Reservado & U & PIE \\
\hline ctl1 & estatus & Reservado & EU & EPIE \\
\hline ctl2 & bstatus & Reservado & BU & BPIE \\
\hline ctl3 & ienable & Bits para habilitar interrupções \\
\hline ctl4 & ipending & \multicolumn{3}{|c|}{ Bits de interrupções pendentes } \\
\hline ctl5 & cpuid & \multicolumn{3}{|c|}{ Identificador para cada CPU } \\
\hline
\end{tabular}

Tabela 6.2: Registradores do processador Nios II.

\subsection{Processamento de exceção}

A exceção consiste em um evento no sistema que requer atenção imediata do processador. O processamento de exceção corresponde ao ato de processar e retornar uma resposta a essa exceção. Na arquitetura do Nios II, cada processador pode atender a 32 interrupções. Cada uma dessas interrupções são tratadas de acordo com sua prioridade, a qual corresponde ao número da IRQ em uso, que pode variar de 0 a 31. Quanto menor o número da IRQ, maior a prioridade da interrupção.

Quando uma interrupção ocorre, o processador executa os seguintes passos automaticamente:

1. Copia o conteúdo do registrador status para o registrador estatus;

2. Escreve zero no bit U do registrador status para entrar em modo supervisor;

3. Escreve zero no bit PIE do registrador status para desabilitar interrupções externas;

4. Armazena o endereço da próxima instrução (a partir da instrução que estava sendo executada quando ocorreu a interrupção) no registrador $e a$; e

5. Transfere a execução para o endereço onde se encontra o tratador de exceção (exception address).

O código de tratamento de exceções consiste em uma rotina que determina a causa e executa um procedimento que responde à exceção. As seguintes causas de exceção podem ocorrer na arquitetura do Nios II:

Interrupção de hardware: Um dispositivo pode requisitar uma interrupção habilitando uma das entradas de requisição de interrupção, IRQ0 a IRQ31. Uma exceção é considerada interrupção de hardware quando: O bit PIE do registrador status é 1, uma 
IRQ $n$ do sistema está ativada e seu correspondente bit $n$ no registrador ienable está habilitado.

Trap de software: Consiste em uma exceção por software, a qual um programa pode gerar, por meio da instrução trap, quando requer algum serviço do sistema operacional. O tratador de exceção do sistema operacional determina a razão para o trap e responde apropriadamente. A exceção é identificada como Trap de software, verificando se a instrução no endereço: $e a-4$ (última instrução executada) é a instrução trap.

Instrução não implementada: Alguns cores do processador Nios II não suportam todas as instruções em hardware. Nesse caso, o processador gera uma exceção depois de carregar uma instrução não implementada. Somente as seguintes instruções podem gerar essa exceção: mul, muli, mulxss, mulxsu, mulxuu, div e divu. Essa exceção é identificada comparando a instrução no endereço: ea-4 com essas instruções anteriores.

Outras: Exceções para implementações futuras do processador.

\subsection{Inicialização do processador e processo de boot}

Quando placa é ligada, ou quando o processador é forçado a reiniciar (reset), o processador executa automaticamente os seguintes passos:

1. Escreve 0x0 no registrador status. Isto desabilita as interrupções externas e coloca o processador em modo supervisor;

2. Invalida a linha da cache de instruções associada com o Reset Address. Quando o sistema é reiniciado, a cache contém dados indeterminados. Invalidando a linha referente ao Reset Address, garante que o código a ser executado provém diretamente da memória; e

3. Inicia a execução a partir do Reset Address.

Após esses passos, o processador inicia a execução a partir da rotina de boot. Essa rotina pode estar armazenada em qualquer tipo de memória do sistema. Normalmente o Reset Address é uma refêrencia para a memória Flash. Nesse caso o programa é copiado para a memória volátil, tal como sdram, e é executado pelo processador. Os primeiros 
passos a serem executados pelo programa compõe o processo de boot, os quais são descritos a seguir:

1. Inicializar as caches de instrução e de dados;

2. Configurar o stack pointer;

3. Configurar o global pointer;

4. Inicializar a região $\mathrm{BSS}^{2}$ localizada no intervalo de memória assinalado pelos símbolos __bss_start e __bss_end, no linker script ${ }^{3}$ do projeto; e

5. Chamar a função de entrada para o início de execução do programa. Normalmente essa função consiste em alt_main() para projetos que utilizam o HAL do Nios II.

\subsection{Considerações finais}

Neste capítulo foram apresentadas características importantes do processador Nios II, relevantes à implementação do projeto. No próximo capítulo são discutidas as principais arquiteturas de multiprocessadores.

\footnotetext{
${ }^{2}$ BSS: Seção de memória que contém todas as variáveis locais e globais não inicializadas.

${ }^{3}$ Linker Script: Um conjunto de declarações que descrevem como as seções de um arquivo de entrada devem ser mapeadas no arquivo de saída, e também para controlar o layout da memoria do arquivo de saída.
} 


\section{Multiprocessadores}

\subsection{Considerações iniciais}

O desempenho dos sistemas caracteriza a presença de requisitos que envolvem confiabilidade, flexibilidade, disponibilidade e throughput. Essas características são influenciadas diretamente pelos seguintes ítens (ENSLOW, 1977):

- Hardware: Dispositivos e circuitos que formam a base do sistema;

- Arquitetura: Tipos de memória, componentes do processador (tais como caches, pipeline, ALU), barramentos, entre outros;

- Organização: Topologia para interconexão das unidades funcionais; e

- Software: Escopo, velocidade, e eficiência dos sistemas operacionais, dos compiladores, e dos softwares de usuário.

A evolução dessas características, enfaticamente do hardware, tem atingido barreiras físicas que impedem seu melhor desempenho. Sobretudo atualmente, esse item avança mais rapidamente do que a Lei de Moore havia previsto (DEGALAHAL; TUAN, 2005) (MOORE, 1965) (OLUKOTUN; HAMMOND, 2005).

Além do aumento do número de transistores disponíveis, os projetistas têm aliado esse fato à extração de maior paralelismo do software, implementando, por exemplo, a organização superscalar.

Em todo esse avanço, o custo dessas arquiteturas, normalmente, acaba tornando-se um gargalo em sua utilização. Devido a esse fato, a utilização de computação paralela tem ganhado maior foco e tem crescido muito.

Neste contexto, este capítulo apresenta as principais arquiteturas paralelas, tais como Uniform Memory Access (UMA), Non-Uniform Memory Access (NUMA) e Cache Only Memory Access (COMA), com ênfase no multiprocessamento simétrico. 


\subsection{Arquiteturas paralelas}

Os elementos de processamento (EP) podem variar desde simples ALUs até CPUs e computadores completos. A quantidade de EPs depende do propósito da arquitetura paralela e da interconexão utilizada (OLIVEIRA, 2006). Essa interconexão consiste na maior divergência das arquiteturas de computadores paralelos. Existem uma série de conexões possíveis, cada qual com sua característica e utilização apropriada (TANENBAUM, 1999).

Com o propósito de classificar as arquiteturas paralelas, um dos métodos mais conhecidos consiste na Taxonomia de Flynn (FLYNN; RUDD, 1996). Esse modelo classifica as arquiteturas baseado nos fluxos de instruções e fluxos de dados. A Taxonomia de Flynn define os seguintes grupos (NULL; LOBUR, 2003) (STALLINGS, 2003):

- Single Instruction, Single Data (SISD): Possui um único fluxo de instruções executado por um processador que emite um único fluxo de dados. Um exemplo dessa categoria é o uniprocessador(Figura 7.1);

- Single Instruction, Multiple Data(SIMD): Possui um único fluxo de instruções, executado por vários elementos de processamento, cada qual ligado com sua memória, possuindo vários fluxos de dados. Essa categoria tem como exemplos os processadores vetoriais e os processadores matriciais (Figura 7.2);

- Multiple Instruction, Single Data (MISD): Existem vários fluxos de instruções, executados por um processador ligado a uma memória, provendo um único fluxo de dados. Em (FLYNN; RUDD, 1996), esta categoria é exemplificada por arrays sistólicos, entretanto, em (STALLINGS, 2003) e (BARR; REWINI, 2005) está afirmado que não existem implementações dessa categoria (Figura 7.1); e

- Multiple Instruction, Multiple Data (MIMD): Nessa categoria podem existir diversos processadores que executam simultaneamente diferentes fluxos de instruções, criando assim, multiplos fluxos de dados. Exemplos dessa categoria são SMPs e clusters.

A arquitetura MIMD pode também ser dividida em três categorias que distinguem o modo de acesso à memória:

- Arquitetura de memória compartilhada com acesso uniforme (Uniform Memory Access - UMA); 
- Arquitetura com somente memória cache (Cache-Only Memory Architecture - COMA); e

- Arquitetura de memória distribuida com acesso não uniforme (Nonuniform Memory Access - NUMA)

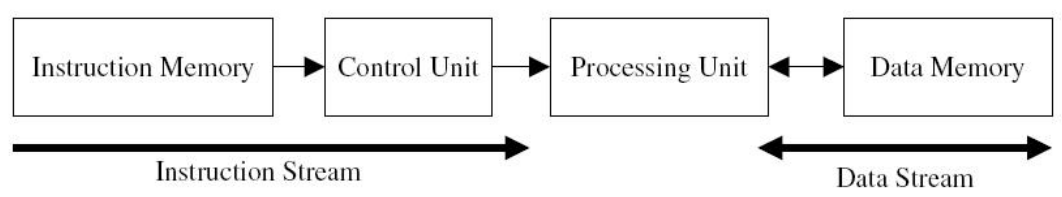

Figura 7.1: Arquitetura SISD. (BARR; REWINI, 2005)

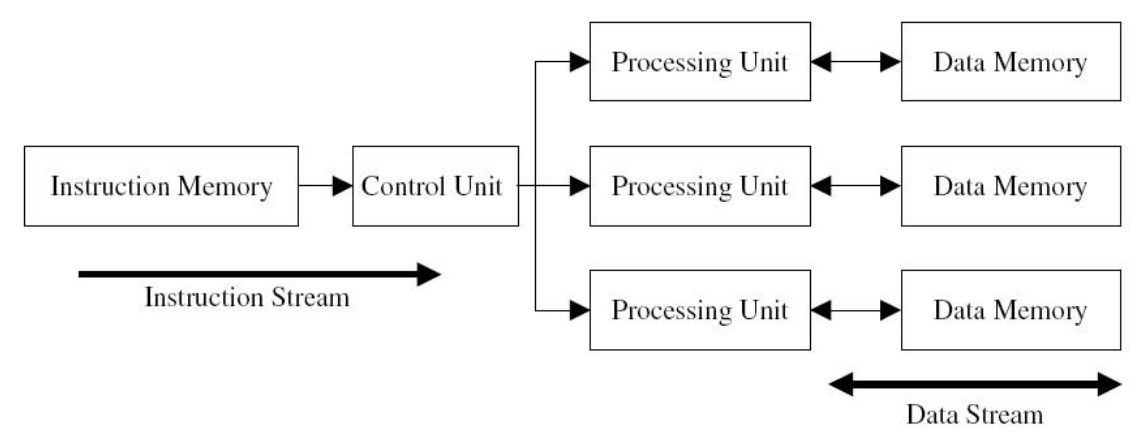

Figura 7.2: Arquitetura SIMD. (BARR; REWINI, 2005)

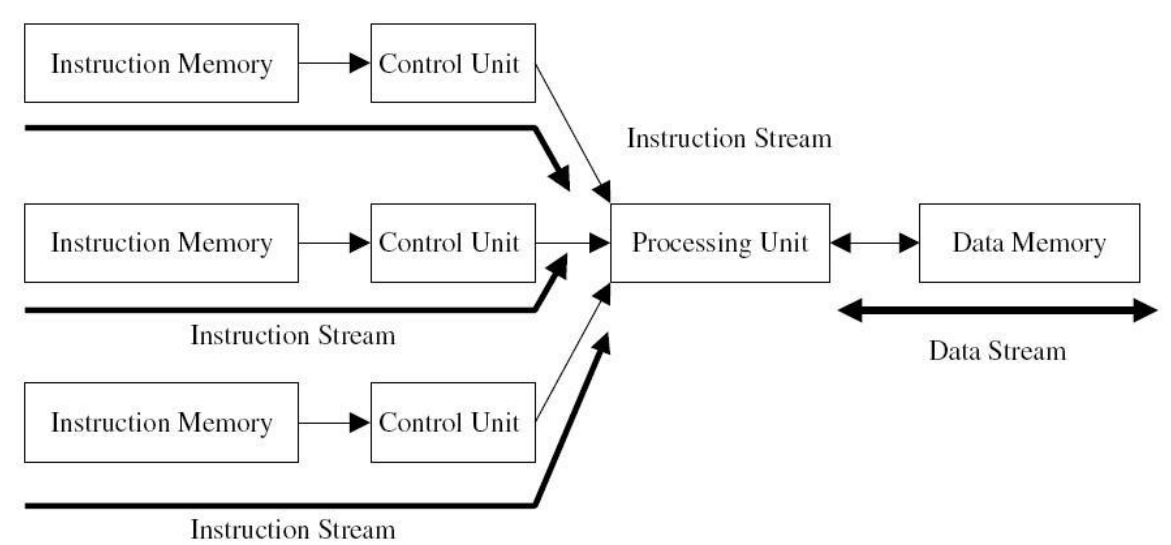

Figura 7.3: Arquitetura MISD. (BARR; REWINI, 2005)

Na Figura 7.5 está apresentada a organização para os três tipos de arquiteturas de memória compartilhada. Na arquitetura UMA, uma memória compartilhada é acessada por todos os processadores por meio de uma interconexão, tal como barramento. O tempo de acesso à memória é o mesmo para todos os processadores (BARR; REWINI, 2005). A arquitetura UMA está apresentada na Figura 7.5a. 


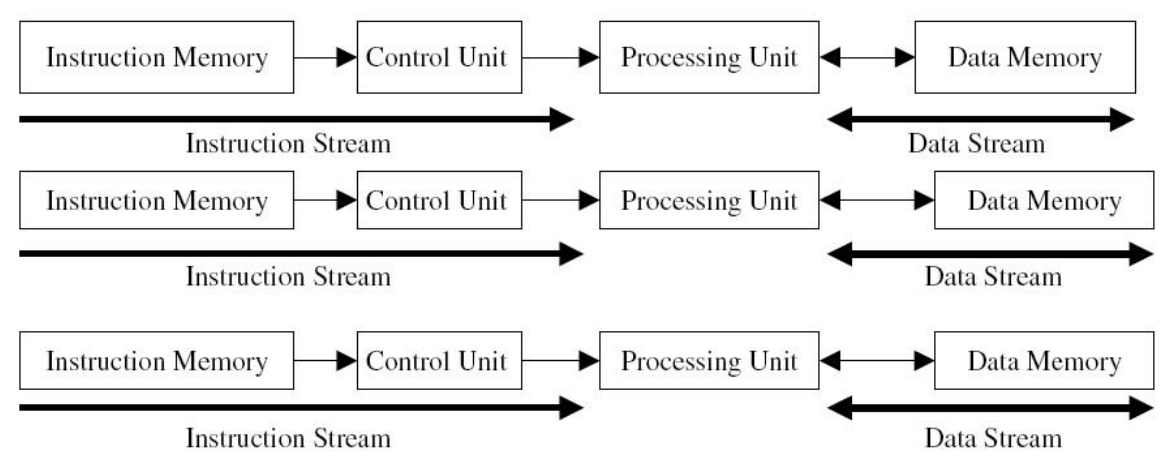

Figura 7.4: Arquitetura MIMD. (BARR; REWINI, 2005)

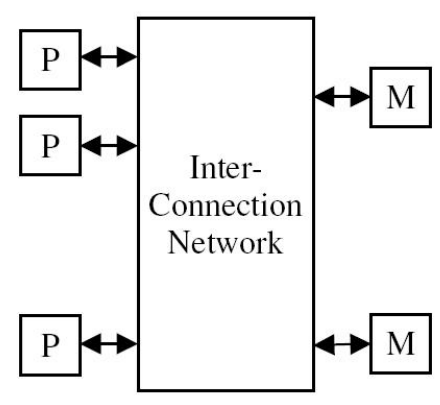

(a)

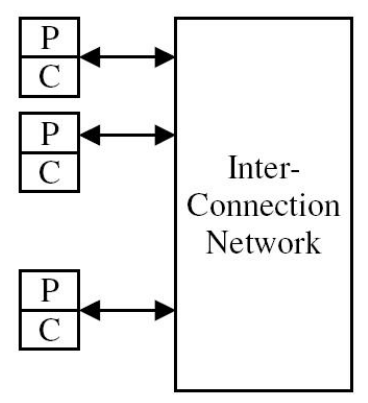

(b)

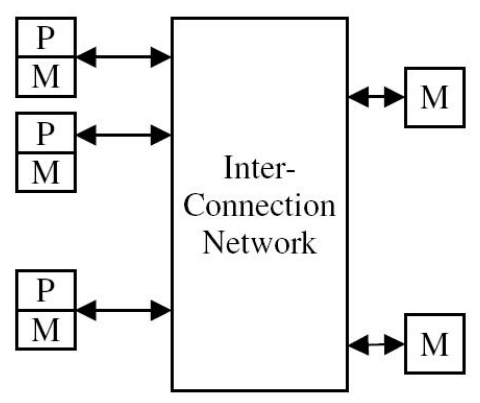

(c)

Figura 7.5: Exemplos de arquiteturas com memória distribuida: (a) UMA, (b) COMA, (c) NUMA. (BARR; REWINI, 2005) 
Em sistemas NUMA, cada processador possui uma área de memória e existe um único espaço de endereçamento. Assim, qualquer processador pode acessar qualquer localização da memória. Entretanto, o tempo de acesso para cada processador depende da região da memória que é acessada (STALLINGS, 2003). Na Figura 7.5c encontra-se ilustrada essa arquitetura.

$\mathrm{Na}$ arquitetura COMA, a memória fisicamente remota é acessada apenas por meio de cache. Isto implica que todos os dados requisitados sejam enviados à cache do processador(Figura 7.5b).

\subsection{Symmetric Multiprocessor - SMP}

O multiprocessamento simétrico consiste em um dos modelos de paralelismo entre processadores mais comuns atualmente. Esse modelo é estimulado pela contínua queda de preços de processadores e crescente aumento da demanda por desempenho.

O termo SMP refere-se à arquitetura de hardware e ao comportamento do sistema operacional que gerencia os processadores. A arquitetura envolve dois ou mais processadores compartilhando a mesma memória e dispositivos por meio de um barramento, os quais possuem capacidade de computação comparável e tem a possibilidade de executar as mesmas funções. O sistema operacional deve controlar a execução das tarefas nos processadores, evitando condições de anomalia devido o acesso simultâneo. Esse controle opera nos níveis de tarefa, de arquivos e de dados (STALLINGS, 2003).

A maioria dos sistemas operacionais atuais implementa suporte ao modelo SMP. Assim, muitos softwares também são construídos visando um potencial aproveitamento do paralelismo, possibilitado principalmente pela característica de multithread.

\subsection{Considerações finais}

A utilização de arquiteturas que exploram o paralelismo é uma tendência para os computadores modernos. Atualmente, grande parte dos computadores pessoais comercializados possuem processadores baseados em execução paralela de instruções. Essa tendência também estende-se ao mercado de embarcados, onde há uma grande propensão de migração das arquiteturas atuais para o multiprocessamento. Essa solução provê alto desempenho e pode restringir o consumo de energia (VASSILIADIS, 2006). 
Neste contexto, os sistemas embarcados baseados em FPGA oferecem, por meio dos processadores soft-core, um grande conjunto de opções flexíveis para o projetista. Os sistemas podem ser compostos de diversos tipos de processadores, sendo que o número deles é limitado apenas pelos recursos oferecidos.

Visando explorar o paralelismo entre processadores na FPGA, este projeto contempla a implementação de um sistema multiprocessado, composto pelo hardware e sistema operacional.

No próximo capítulo estão apresentados os detalhes dessa implementação. 


\section{Arquitetura e implementação do sistema}

\subsection{Considerações iniciais}

O objetivo deste trabalho é apresentar a implementação de uma arquitetura capaz de executar diversos processos paralelamente sobre vários processadores Nios II em FPGA. Para isso, o sistema operacional eCos foi escolhido, de modo a ser modificado para oferecer suporte ao multiprocessamento.

Nessa implementação os principais requisitos almejados são: arquitetura de hardware capaz de suportar dois ou mais processadores; sistema operacional que ofereça transparência das características paralelas ao usuário; flexibilidade no escalonamento de processos; inibição de potenciais regiões críticas do sistema operacional com primitivas de sincronização; organização da memória de modo a evitar incoerências com o acesso simultâneo e o desempenho na execução de tarefas.

Nas próximas seções são apresentados os detalhes da implementação.

\subsection{Considerações do projeto de hardware e do sis- tema operacional}

Nessa seção estão apresentados os principais pontos inerentes à implementação de multiprocessamento, empregando o eCos sobre a arquitetura Nios II. São apresentados também os detalhes dos tipos de sistemas operacionais para multiprocessadores, descritos no Capítulo 2, com enfoque na implementação sobre a arquitetura do processador Nios II. 


\subsubsection{Processadores com áreas de memória separadas - Um sis- tema operacional para cada CPU}

Nessa organização, uma área de memória é reservada para cada processador, o qual não tem acesso a outras regiões(Figura 8.1). Deste modo, existe um SO para cada CPU do sistema. Em (ALTERA CORPORATION, 2005), essa arquitetura é proposta para o processador Nios II. Cada programa é executado em um único processador e armazenado em uma área de memória específica.

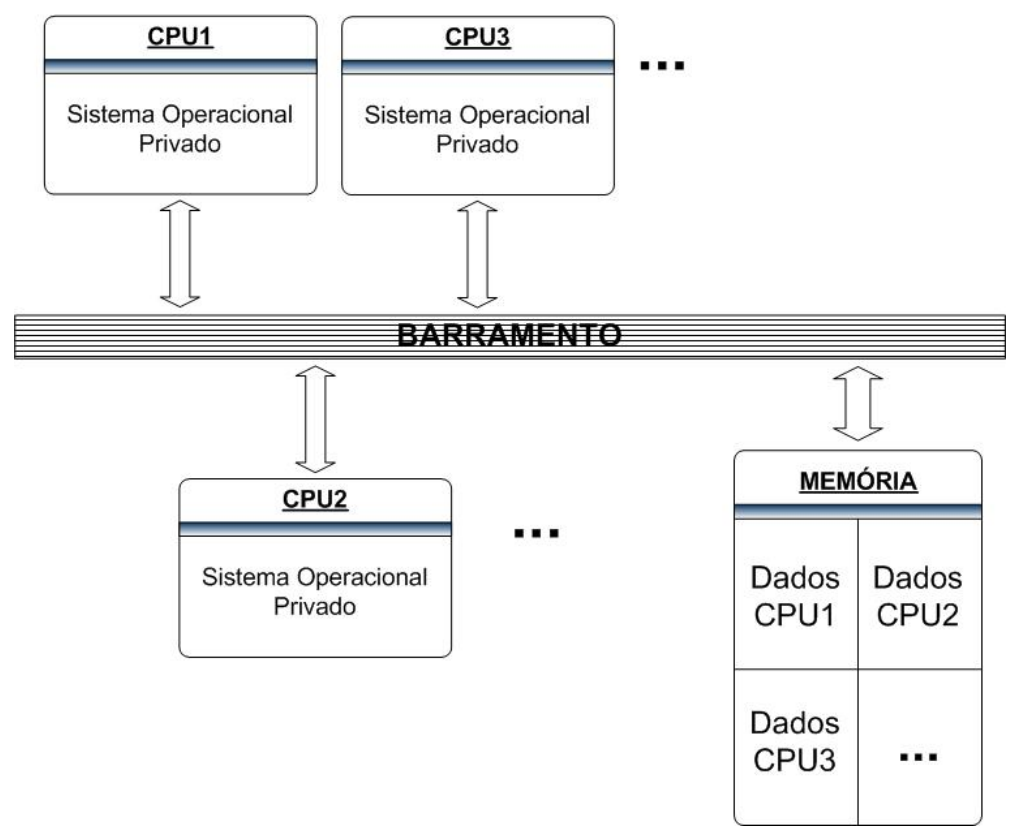

Figura 8.1: Um sistema operacional para cada CPU.

Cada CPU tem o seu próprio processo ${ }^{1}$, sendo que seu número é limitado ao número de processadores, e o usuário deve especificar o processo que deve ser executado em cada CPU. Se uma CPU terminou a execução de um processo, deve entrar em estado de inatividade, mesmo com outras CPUs sobrecarregadas.

A principal vantagem desse modelo é sua simplicidade de implementação, pois não há necessidade de codificação adicional no sistema operacional eCos. As desvantagens consistem na falta de flexibilidade e no desperdício de recursos inativos disponíveis.

\footnotetext{
${ }^{1}$ Quando um programa que utiliza o eCos é compilado, o arquivo elf gerado já possui o SO associado em seu código. O sistema operacional e o programa estão em um único arquivo executável. Nesse caso é inviável a implementação de mais de um processo, no entanto, havendo necessidade, pode ser projetada uma solução similar utilizando threads.
} 


\subsubsection{Multiprocessadores 'mestre-escravo'}

Uma possível implementação desse cenário (Figura 8.2), considerando as características da arquitetura Nios II e do sistema operacional eCos, consistiria em armazenar permanentemente um sistema operacional master e os processos na memória flash, associando seu endereço ao reset address do processador master. Neste caso, um processo consiste no sistema operacional e no programa que deve ser executado.

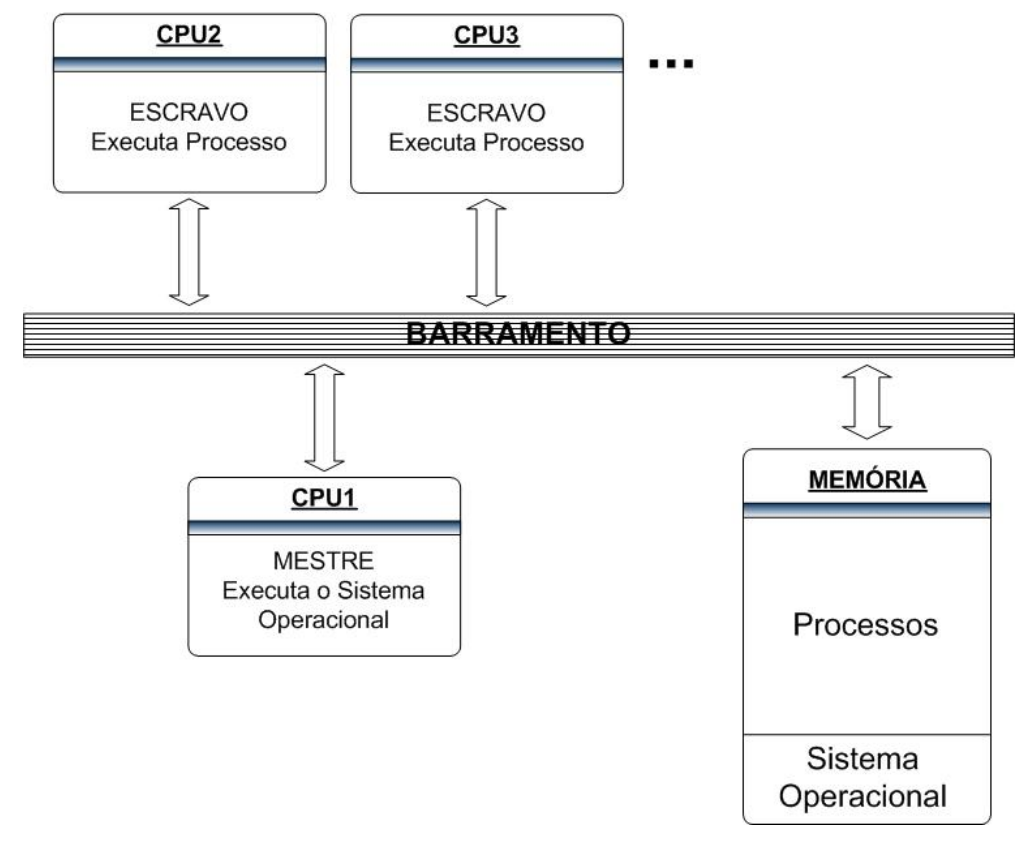

Figura 8.2: Modelo mestre-escravo.

No momento de boot, o processador master inicia a execução a partir do reset address, onde deveria conter, antes dos processos, um boot loader responsável pela cópia do conteúdo da flash para a memória. A partir desse ponto, o processador receberia um comando de jump para essa região da memória, onde executaria o sistema operacional master. Entretanto, como nesse modelo cada CPU tem associada a si uma região fixa da memória, a CPU deve executar programas residentes apenas nessa região, pois algumas seções do executável, tal como heap e pilha, são dispostas tendo como ponto de referência o final da área especificada para cada CPU (presente no linker script). Neste caso, a utilização da mesma área de memória para execução ocasionaria incoerências de dados na memória. Deste modo, para resolver esse problema, o processador master deveria ter acesso a todas as áreas e, assim, copiar os processos para as respectivas áreas das CPUs que devem executá-los. Essa cópia seria necessária todas as vezes que um novo processo fosse escalonado para um determinado processador. Essa formatação ocasiona um overhead no processamento. 
Um outro problema, inerente dessa abordagem, consiste na dependência do código em relação ao endereçamento da memória e de dispositivos ligados à CPU.

Todo software compilado para o processador Nios II possui um linker script, no qual estão especificadas referências a endereços da memória utilizadas para mapear as seções do binário gerado. Quando esses programas são copiados para uma área de memória diferente da qual foram compilados (especificadas no linker script), provavelmente seu funcionamento será incoerente, pois os endereços podem estar apontando para áreas onde outro programa está em execução.

A dependência de dispositivos pode acontecer quando um determinado componente C1 está associado ao processador P1, enquanto C2 está associado ao P2. Antes de um software ser compilado, deve ser informado o processador que deve executá-lo. Nesse momento, é gerado um header file (arquivo .h) com as declarações de endereços de todos os componentes ligados a esse processador, tal como, no caso de P1 seria incluído C1. O endereço de C1 é incluso no arquivo executável gerado na compilação. Caso o programa compilado para P1 fosse copiado para a área de memória de P2 e executado por esse último, as referências ao componente C1 seriam inválidas, pois P2 possui o componente $\mathrm{C} 2$ com endereço diferente. Como exemplo, esse componente $\mathrm{C}$ poderia consistir em um JTAG UART, o qual deve ser instanciado apenas uma vez para cada CPU.

\subsubsection{Multiprocessamento Simétrico}

Na organização SMP, apresentada na Figura 8.3, existe uma memória compartilhada onde estão armazenados o sistema operacional e os processos. A execução de rotinas do sistema operacional não é pertinente apenas a um processador específico, todos os processadores podem executá-lo. Deste modo, o sistema fica dependente de primitivas de sincronização para evitar o acesso simultâneo ao mesmo dado.

O eCos para o Nios II não possui o suporte de SMP implementado. Provavelmente esse fato decorre da falta de instruções similares ao Test-and-set ${ }^{2}$ para o controle de exclusão mútua no Nios II. Essas instruções constituem a base para os mecanismos de sincronização em ambientes multiprocessados com compartilhamento de dados. Para adequar o eCos para suportar SMP utilizando o Nios II são necessárias algumas modificações no kernel e na camada HAL (Hardware Abstraction Layer).

Em um sistema SMP, o kernel deve assumir um dos processadores como primário

\footnotetext{
${ }^{2}$ Test-and-set: Consiste em uma instrução atômica, capaz de ler e atualizar um dado na memória com um determinado valor.
} 
e os demais como secundários. A inicialização do SO é realizada apenas pelo processador primário, enquanto os secundários ficam em estado suspenso. Os processadores secundários são habilitados a partir da invocação da rotina de ativação do escalonador, a qual busca a lista de CPUs secundárias e inicia e ativa cada um dos processadores a partir do HAL. Nesse processo, o kernel instala um recurso que permite a interrupção inter-CPUs. Terminada a ativação dos processadores, o escalonador é executado no processador primário e o novo processo é selecionado para a execução. A partir desse ponto nenhuma distinção é feita pelo eCos entre processadores primários e secundários, entretanto, o hardware ainda pode distingüí-los devido às interrupções.

Uma das principais mudanças a serem realizadas no eCos para suportar SMP consiste na conversão das primitivas de sincronização do escalonador para spinlock, juntamente com a adição de um identificador CPU-ID. Outras mudanças a serem realizadas é a conversão de variáveis escalares em vetores, cujos índices são associados com os CPU-IDs.

Somente o escalonador MLQ é capaz de suportar SMP, entretanto, sua estrutura deve ser alterada para suportar diversos processos em execução simultaneamente. Devem ser informados, para cada processo em execução, os processadores que estão ocupando. Para determinar uma nova tarefa a executar, o escalonador procura entre os processos um que não esteja em execução até encontrar um processo pendente. Com o suporte de SMP, o algoritmo MLQ não é mais constante como no caso de apenas uma CPU, entretanto, não é perdida a característica de determinismo, desde que o pior caso seja limitado pelo número de CPUs no sistema.

Outra mudança a ser realizada no escalonador é o controle do timeslicing. As interrupções de tempo são enviadas apenas para um processador. Os contadores de timeslicing das demais CPUs devem ser decrementados quando é emitida a interrupção de tempo. Isto deve ser controlado pelo processador que recebe os sinais. Se o contador de timeslicing de um processador alcança zero, ele emite um sinal para o processador que recebe as interrupções, que deve invocar o escalonador para que um novo processo seja carregado no processador liberado.

Em um sistema SMP as interrupções podem ser endereçadas para uma CPU específica. Para isso devem ser implementadas rotinas que permitam atribuir características às interrupções, se devem ser roteadas dinamicamente ou para uma CPU específica.

Existem outras decisões de projetos, referentes a arquitetura e organização, relevantes à implementação de SMP utilizando o processador Nios II. Tais decisões compreendem coerência de cache, implementação de interrupção inter-CPUs, compartilhamento de 
memória, implementação de método de sincronização e interrupções de hardware.

Utilizando SMP, alguns problemas encontrados na arquitetura 'mestre-escravo' estão resolvidos. A cópia dos processos para a área de memória de cada CPU não é necessária, pois todas as CPUs devem compartilhar a mesma área, possuindo o mesmo exception address. As referências à pilha e à heap devem ser alteradas no linker script, de modo que cada processador possua a sua área. As dependências de endereços fixos não são problema, pois a compilação para um determinado processador implica que o mesmo código pode ser executado em outro, uma vez que todos possuem o mesmo intervalo de endereço. Entretanto, esse código somente vai executar em outro processador se não possuir dependência de periférico. Nesse caso, cada processador possui os seus dispositivos.

Apesar das diversas modificações a serem realizadas, esse modelo possui o melhor conjunto de características que atendem a requisitos de flexibilidade, desempenho e transparência. Diante desses parâmetros e da grande utilização dessa arquitetura em arquiteturas comerciais, este trabalho propõe sua utilização para a construção de um modelo de arquitetura multiprocessada, utilizando o sistema operacional eCos.

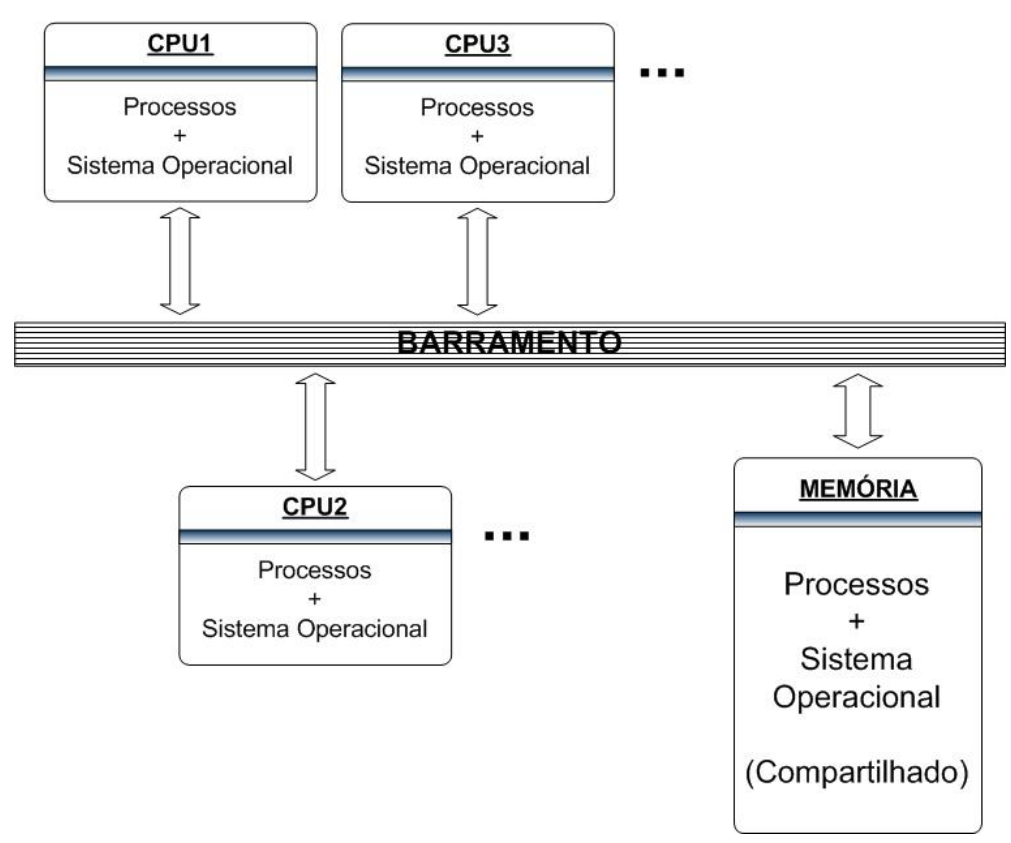

Figura 8.3: Multiprocessador Simétrico (TANENBAUM, 2001). 


\subsection{Implementação do sistema}

\subsubsection{O hardware}

A proposta inicial de hardware para avaliação da arquitetura, consiste em três processadores Nios II, uma memória SDRAM, um Timer, três componentes JTAG UARTs e um componente Mutex, como está apresentado na Figura 8.4. Alguns outros componentes foram adicionados, tais como interfaces para botões, LEDs, LCD e flash, porém, não constituem a funcionalidade fundamental do sistema.

Na Figura 8.4, cada seta de linha contínua especifica a submissão de um componente, ou seja, a direção a partir do componente master até o componente slave.

Os componentes SDRAM e Mutex são escravos de todos os processadores. Deste modo, todos os processadores podem enviar comandos de leitura e escrita a esses componentes. O JTAG UART deve ter uma instância para cada CPU, pois por meio deste, podem ser enviados comandos de início de processamento, de depuração e de download de dados na memória, a partir do host. O componente Timer tem somente uma instância na arquitetura, associado ao processador CPU1.

As setas tracejadas discriminam a direção de sinais de interrupção inter-CPUs. Deste modo, os processadores CPU2 e CPU3 possuem uma dependência do processador CPU1, o qual pode interromper os demais processadores para executar uma tarefa específica. A interrupção do processador master a partir dos demais não é possível nesse modelo.

A arquitetura completa está disposta na Figura 8.5 e sua organização está especificamente contemplada nas próximas seções.

\subsubsection{Processadores}

Nesse modelo existem três processadores com mesma capacidade de processamento. Todos podem executar as threads e rotinas do sistema operacional. As distinções concentram-se na execução do processo de boot e das rotinas de interrupção de tempo.

A CPU1 é responsável por iniciar o sistema operacional e deixar o ambiente preparado para o início da execução dos demais processadores. A seqüência de passos realizados pela CPU1 está apresentada na Seção 8.3.6.

A utilização da CPU1 para atender as rotinas de interrupções de tempo é apresentada na Seção 8.3.3. 


\section{FPGA}

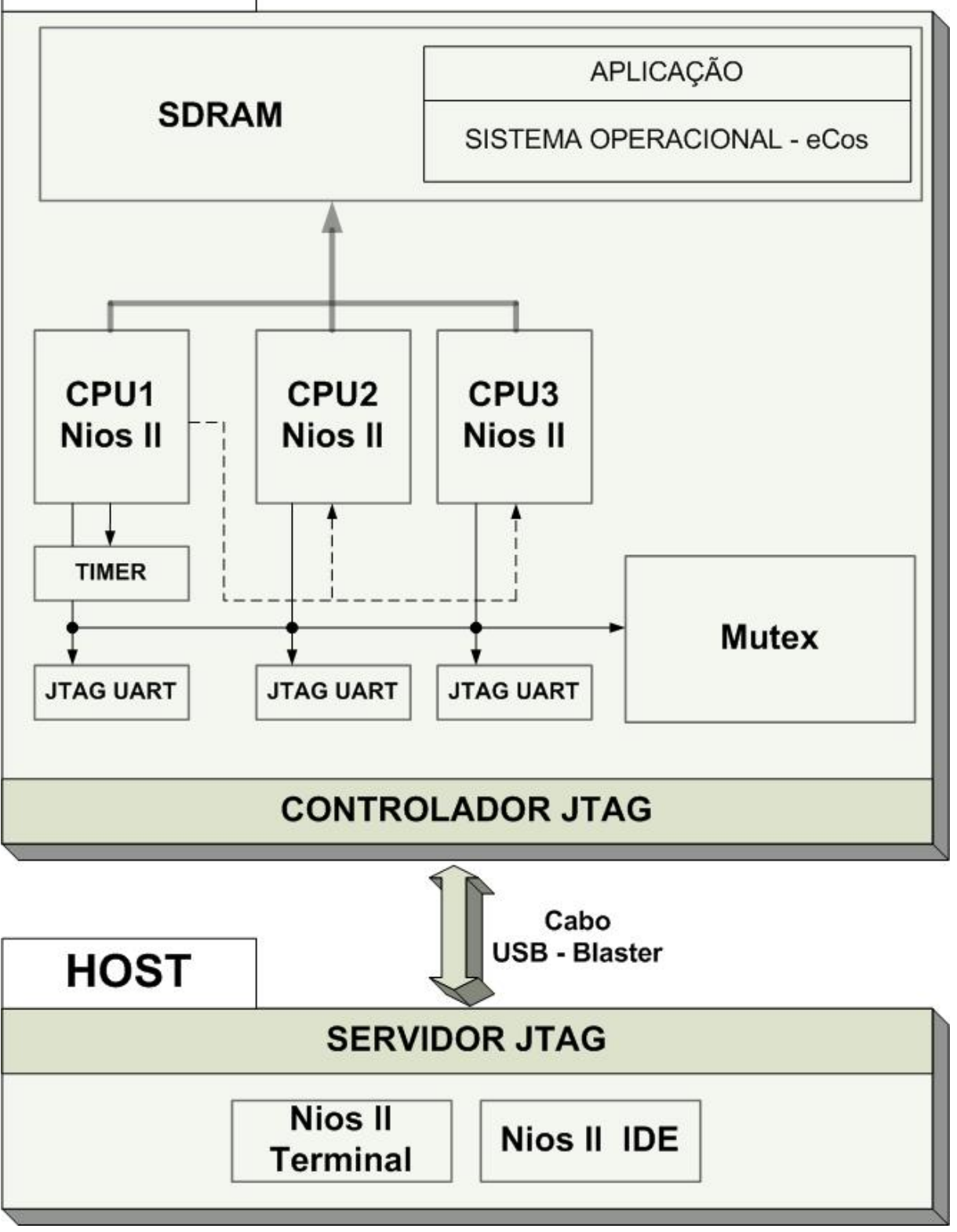

Figura 8.4: Arquitetura do sistema. 


\begin{tabular}{|c|c|c|c|c|c|c|c|c|c|}
\hline Use & \multicolumn{3}{|r|}{ Module Name } & \multirow{2}{*}{\multicolumn{2}{|c|}{$\begin{array}{l}\text { Description } \\
\text { Nios II Processor - Altera Corp... clk }\end{array}$}} & \multirow[t]{2}{*}{ Base } & \multirow[t]{2}{*}{ End } & \multirow[t]{2}{*}{ IRQ } & \begin{tabular}{l|l|l}
$\mathbb{R} Q$ & $\mathbb{R} Q$ \\
\end{tabular} \\
\hline \multirow{4}{*}{ ఐ } & & & $\boxminus$ cpu1 & & & & & & \\
\hline & & & $\longrightarrow$ instruction_master & Master port & & & & & \\
\hline & & & $\longrightarrow$ data_master & Master port & & IRQ 0 & $\mathbb{R Q Q} 31$ & 4 & \\
\hline & & & $\longrightarrow$ jtag_debug_module & Slave port & & $0 \times 00800000$ & 0x008007FF & & \\
\hline \multirow[t]{2}{*}{$\square$} & & & 曰cpu1_jtag_uart & JTAG UART & clk & & & & \\
\hline & & & $\longrightarrow$ avalon_tag_slave & Slave port & & $0 \times 00800828$ & $0 \times 0080082 F$ & 1 & \\
\hline \multirow[t]{2}{*}{$\square$} & & & $\boxminus$ cpu1_timer & Interval timer & clk & & & & \\
\hline & & & $\longrightarrow \mathrm{s1}$ & Slave port & & $0 \times 00800840$ & $0 \times 0080085 F$ & 0 & \\
\hline \multirow[t]{2}{*}{$\square$} & & & 曰cpu1_ipic_master_output & PIO (Parallel IIO) & clk & & & & \\
\hline & & & $\rightarrow$ s1 & Slave port & & A $0 \times 008008 \mathrm{~B} 0$ & $0 \times 008008 \mathrm{BF}$ & & \\
\hline \multirow[t]{4}{*}{$\nabla$} & & & $\boxminus$ cpu2 & Nios II Processor - Altera Corp... & clk & & & & \\
\hline & & & $\longrightarrow$ instruction_master & Master port & & & & & \\
\hline & & & $\longrightarrow$ data_master & Master port & & IRQ 0 & IRQ 31 & $\leftarrow$ & \\
\hline & & & $\longrightarrow$ jtag_debug_module & Slave port & & $0 \times 00800000$ & 0x008007FF & & \\
\hline \multirow[t]{2}{*}{ ఐ } & & & 曰cpu2_jtag_uart & JTAG UART & clk & & & & \\
\hline & & & $\longrightarrow$ avalon_ttag_slave & Slave port & & $0 \times 00800828$ & $0 \times 0080082 F$ & & 0 \\
\hline \multirow[t]{2}{*}{$\nabla$} & & & 曰cpu2_ipic_input & PIO (Parallel INO) & clk & & & & \\
\hline & & & $\longrightarrow$ s1 & Slave port & & a $0 \times 008008 \mathrm{Co}$ & $0 \times 008008 \mathrm{CF}$ & & 31 \\
\hline \multirow[t]{3}{*}{ 甲 } & & & $\boxminus$ cpu3 & Nios II Processor - Altera Corp... & clk & & & & \\
\hline & & & $\longrightarrow$ instruction_master & $\begin{array}{l}\text { Master port } \\
\text { Master port }\end{array}$ & & IRQ 0 & IRQ 31 & & \\
\hline & & & $\longrightarrow$ jtag_debug_module & Slave port & & $0 \times 00800000$ & $0 \times 008007 \mathrm{FF}$ & & \\
\hline \multirow[t]{2}{*}{$\square$} & & & 曰cpu3_jtag_uart & JTAG UART & clk & & & & \\
\hline & & & $\longrightarrow$ avalon_tag_slave & Slave port & & a $0 \times 00800898$ & $0 \times 0080089 F$ & & 0 \\
\hline \multirow[t]{2}{*}{ ఐ } & & & 曰cpu3_ipic_input & PIO (Parallel IIO) & clk & & & & \\
\hline & & & $\longrightarrow$ s1 & Slave port & & a 0x008008D0 & $0 \times 008008 \mathrm{DF}$ & & 31 \\
\hline \multirow[t]{2}{*}{$\square$} & & & $\boxminus$ sdram & SDRAM Controller & clk & & & & \\
\hline & & & $\longrightarrow$ s1 & Slave port & & $0 \times 00000000$ & OX007FFFFF & & \\
\hline \multirow[t]{2}{*}{ 田 } & & & $\boxminus$ sysid & System ID Peripheral & clk & & & & \\
\hline & $-1-$ & -- & $\longrightarrow$ control_slave & Slave port & & $0 \times 008008 \mathrm{C} 0$ & $0 \times 008008 \mathrm{C7}$ & & \\
\hline 田 & & & $\boxminus$ uart_o & UART (RS-232 serial port) & clk & & & & \\
\hline & -- & - & $\longrightarrow s 1$ & Slave port & & $0 \times 00800860$ & $0 \times 0080087 F$ & 3 & \\
\hline 田 & & & 曰Icd_16207_0 & Character LCD $(16 \times 2$, Optre $\times 162 \ldots$ & clk & & & & \\
\hline & $-1-$ & -- & $\longrightarrow$ control_slave & Slave port & & $0 \times 00800830$ & $0 \times 0080083 F$ & & \\
\hline 田 & & & $\boxminus$ led_green & PIO (Parallel INO) & clk & & & & \\
\hline & $-1-$ & -- & $\longrightarrow s 1$ & Slave port & & $0 \times 00800880$ & $0 \times 0080088 \mathrm{~F}$ & & \\
\hline ఐ & & & 曰led_red & PIO (Parallel IIO) & clk & & & & \\
\hline & -- & - & $\longrightarrow s 1$ & Slave port & & $0 \times 00800890$ & $0 \times 0080089 F$ & & \\
\hline 田 & & & $\boxminus$ button_pio & PIO (Parallel IIO) & clk & & & & \\
\hline & - & - & $\longrightarrow$ s1 & Slave port & & $0 \times 00800800$ & $0 \times 0080080 F$ & $2 \longdiv { 2 }$ & $2 \longdiv { 2 }$ \\
\hline$\nabla$ & & & $\boxminus$ switch_pio & PIO (Parallel INO) & clk & & & & \\
\hline & -- & - & $\longrightarrow$ s1 & Slave port & & OX008008A0 & $0 \times 008008 \mathrm{AF}$ & & \\
\hline 田 & & & 曰SEG7_Display & SEG7_LUT_8 & clk & & & & \\
\hline & -- & - & $\longrightarrow$ avalons & Slave port & & $0 \times 008008 \mathrm{C} 8$ & $0 \times 008008 \mathrm{CB}$ & & \\
\hline 田 & & & $\boxminus$ tas_avalon_interface_0 & tas_avalon_interface & clk & & & & \\
\hline & -17 & - & $\longrightarrow$ avalon_slave_0 & Slave port & & $0 \times 00800810$ & $0 \times 0080081 \mathrm{~F}$ & & \\
\hline 田 & & & 曰cfi_flash_0 & Flash Memory (Common Flash Inte... & & & & & \\
\hline & & & $\longrightarrow$ s1 & Slave port & & $0 \times 00900000$ & Ox009FFFFF & & \\
\hline 田 & & & $\boxminus$ tri_state_bridge_0 & Avalon Tristate Bridge & clk & & & & \\
\hline & & & $\longrightarrow$ avalon_slave & $\begin{array}{l}\text { Slave port } \\
\text { Master port }\end{array}$ & & & & & \\
\hline 田 & & & $\boxminus$ mutex & Mutex & clk & & & & \\
\hline & & & $\longrightarrow$ s1 & Slave port & & $0 \times 00800820$ & $0 \times 00800827$ & & \\
\hline
\end{tabular}

Figura 8.5: Projeto do hardware no SOPC-Builder. 


\subsubsection{Interrupções}

Os componentes que podem provocar eventos, por intervenção externa ou por processamento próprio $^{3}$, têm a possibilidade de gerar requisições de interrupções. Esses sinais de controle não estão diretamente ligados à transferência de dados, mas indicam a necessidade de algum processamento por parte do componente master ligado ao slave que gerou o evento.

Uma requisição de interrupção, ou Interrupt Request - IRQ, ligada a uma porta slave, pode ser emitida a qualquer tempo, e o periférico pode manter esse sinal continuamente até que a porta master envie um sinal de reset para essa IRQ. A partir da porta master podem ser associados sinais IRQ e seus respectivos números. Com isso, a porta master pode detectar e responder a interrupções das portas slaves do sistema.

$\mathrm{Na}$ arquitetura de validação proposta, existem vários componentes capazes de gerar interrupções. Como exemplo, podem ser citados interfaces para botões externos da placa, componentes JTAG UART, ligações inter-CPUs e Timer. Cada uma dessas IRQs está associada a um número que determina a prioridade entre essas requisições. Essa prioridade é utilizada para determinar o grau de criticidade para atendimento da interrupção relacionada. Em casos de recebimento de várias interrupções, o componente master deve utilizar a prioridade para saber qual é a primeira interrupção a ser atendida. As principais IRQs da arquitetura estão apresentadas na Tabela 8.1.

\begin{tabular}{|c|c|c|c|}
\hline Componente & \multicolumn{3}{|c|}{ Processadores/Prioridade } \\
\hline \hline & $\begin{array}{c}\text { CPU1 } \\
\text { (master })\end{array}$ & CPU2 & CPU3 \\
\hline Timer & 0 & - & - \\
\hline JTAG UART & 1 & 0 & 0 \\
\hline inter-CPUs & - & 31 & 31 \\
\hline
\end{tabular}

Tabela 8.1: Principais IRQs da arquitetura de validação.

\subsubsection{Timer}

O componente Timer emite uma interrupção a cada período de tempo pré-configurado em momento de projeto. O processador recebe a interrupção e pode executar uma tarefa específica, gerenciando suas tarefas depententes do tempo. No caso de um sistema operacional em execução, essa interrupção pode ser utilizada para manter o tempo que uma thread executando, escalonando outra quando o tempo da primeira expirar.

\footnotetext{
${ }^{3}$ Componentes que não possuem um comportamento totalmente dependente de comandos de outros componentes, tal como a dependência entre SDRAM e CPU
} 
Nessa arquitetura é utilizada somente uma instância desse componente, cujo período de clock é 1 ms. A CPU1 é o único processador que recebe eventos do Timer, e deve gerenciar a execução das tarefas do sistema relacionadas ao tempo. Com a centralização desse controle na CPU1, os demais processadores ficam livres para executar outras tarefas do sistema, sem preocupar-se com o tratamento da interrupção.

\subsubsection{JTAG UART}

O componente JTAG UART é responsável pela interface entre o processador Nios II e o host. A utilização desse componente é obrigatório, e deve ser instanciado apenas um por processador.

\subsubsection{Interrupção inter-CPUs}

Em todo sistema multiprocessado, existe a necessidade de comunicação entre os processadores. No caso específico deste projeto, a comunicação estabelecida consiste na faculdade de interrupção dos processadores escravos, pelo mestre. A interrupção inter-CPUs é implementada por meio de ligações entre os processadores utilizando o componente PIO.

A CPU1 deve possuir um componente PIO de saída, contendo dois bits, cada bit para um processador do sistema. Cada um dos demais processadores deve possuir um componente PIO de entrada, configurado para gerar interrupções na subida de borda do sinal de entrada. A interrupção gerada utiliza o número 31. Após isso, cada canal de saída do processador master é ligado a um canal de entrada de outro processador, conforme apresentada na Figura 8.6.

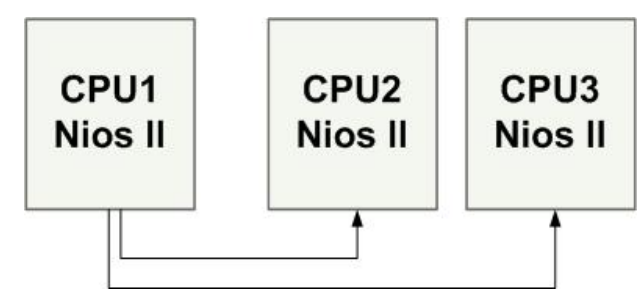

Figura 8.6: Interrupção inter-CPUs.

Especificamente, essa interrupção é utilizada para sinalizar a necessidade de troca da thread corrente em execução. Isto pode ocorrer quando o tempo de execução dessa thread expira, ou quando existe outra com maior prioridade que deve ser executada naquele momento. 


\subsubsection{Memória}

A memória de aplicações Nios II, em sistemas monoprocessados ou multiprocessados, é dividida nas seguintes seções: .text, .rodata, .rwdata, heap e stack, as quais são associadas a endereços fixos na memória, para cada processador. A divisão proposta para este projeto, consiste em um único conjunto contendo essas seções, conforme a Figura 8.7.

A seção .text, responsável pelo armazenamento do código executável, é única, de modo que todos os processadores podem compartilhar. Cada processador não deve executar programas diferentes em seções separadas, mas sim, executar os códigos de threads disparadas em um programa principal. Todo o multiprocessamento está diretamente relacionado à execução das threads de uma única aplicação. Assim, as seções rodata e .rwdata, que armazenam respectivamente os dados constantes e variáveis do programa, também são fixas e únicas.

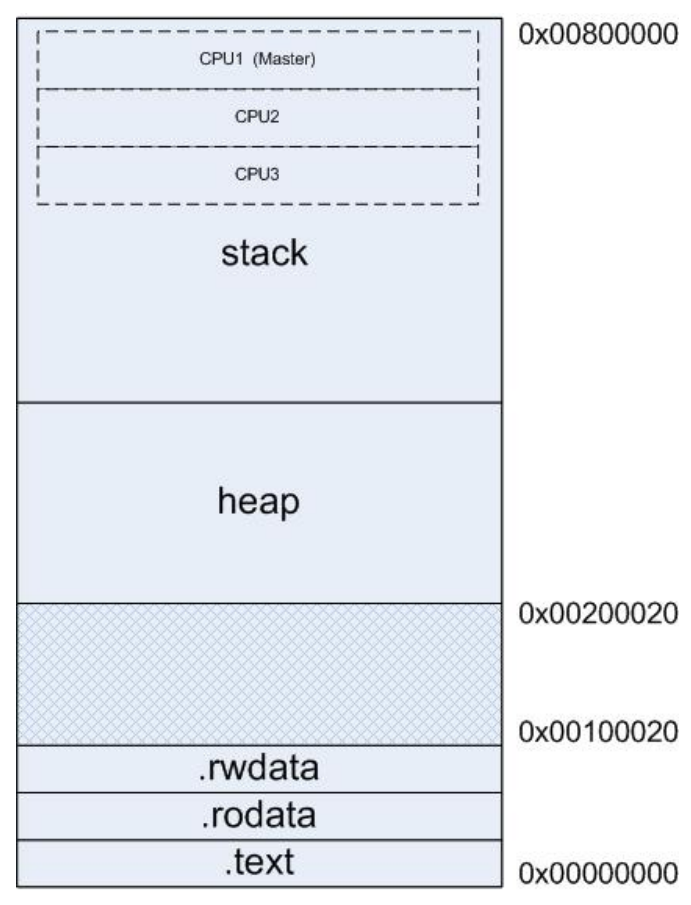

Figura 8.7: Disposição da memória.

Para a área de heap, existe um ponteiro (__heap1) no linker script que aponta para o fim da região .rwdata. Esse ponteiro determina o início da área de memória reservada à heap. Não existe um limite determinado para a área heap, sua extensão é determinada pelo início da área da pilha, indicada pelo ponteiro cyg_interrupt_stack_base no linker script.

No modelo implementado, cada processador possui sua própria seção stack. O registrador $s p$ tem seu endereço decrementado a cada valor inserido na pilha. No momento 
de boot, a CPU recebe uma fatia de espaço, com tamanho fixo, utilizado para essa seção, de modo que o endereço inicial de $s p$ está associado ao limite superior reservado à seção stack.

O eCos possui a variável global cyg_interrupt_stack declarada no linker script. Após as declarações de todas as seções do executável, existe uma associação dessa variável ao endereço limite superior da memória para esse executável.

No momento de inicialização da pilha de cada processador, essa variável é utilizada para calcular a posição de memória inicial que será atribuida ao registrador $s p$. Neste projeto, a fatia de memória reservada para a pilha de cada processador, consiste em um tamanho constante de 512 KB. Esse tamanho pode ser configurado para um valor menor, dependendo do número de processadores presentes no sistema.

O primeiro processador que executa o código do sistema operacional reserva a primeira fatia a partir do final da memória. Os valores são armazenados na pilha com endereço decrescente.

Nas aplicações que não utilizam o eCos, construídas a partir da ferramenta Nios II IDE, o registrador $s p$ é inicializado com o endereço do final da memória, na existência de somente um processador no sistema. Quando existem vários processadores, o $s p$ de um processador recebe o início do exception address do próximo processador. Quando não existem processadores subsequentes, a inicialização é realizada com o endereço final da memória.

Essa associação automática, realizada pela ferramenta da Altera, não considera sistemas com vários processadores utilizando o mesmo exception address. Nesses casos, a execução das aplicações tem comportamento imprevisto. O registrador $s p$ de cada processador é inicializado com o exception address do processador subsequente. Porém, todos os processadores estão associados ao mesmo exception address, que geralmente aponta para o início da memória. Nesses casos um erro é gerado na execução de qualquer aplicação desenvolvida o Nios II IDE.

O intervalo de memória de 0x00100020 a 0x00200020 está reservado para a execução de uma aplicação de jump nos processadores slave, a qual desvia a execução para o início da memória onde estão posicionadas as instruções de inicialização do sistema operacional. Neste projeto, essa área também está reservada para a heap. Assim, existe um limite de alocações antes da inicialização dos outros processadores. Se forem realizadas muitas alocações de memória antes da execução da aplicação de jump, podem ocorrer 
inconsistência de dados nesse intervalo.

Esse problema pode ser contornado de dois modos. A aplicação de jump pode executar no final da memória, sendo que o valor do endereço limite superior da pilha é diminuído para o endereço de ínicio da execução da aplicação de jump. Outro modo consiste na vinculação do endereço inicial da área de heap ao endereço 0x00200020 no linker script. Deste modo, nenhuma inconsistência deve ocorrer.

\subsubsection{Sincronização}

A exclusão mútua em regiões que possibilitam acesso concorrente a um recurso, deve ser mantida para preservar a consistência dos resultados do processamento em ambientes paralelos.

Algumas primitivas são utilizadas para a exclusão mútua em regiões críticas, tais como spin lock, semáforos e mutexes. A base para implementação dessas primitivas, normalmente consiste na instrução Test-and-set, disponibilizada por alguns processadores.

Essa instrução realiza, atomicamente, uma leitura e uma escrita em uma posição de memória. A instrução lê o valor de uma variável e em seguida armazena 1 . O valor lido é retornado, caso seja 1, a variável já havia sido atribuída anteriormente por um outro processo, e assim nesse caso pode ser feita uma espera ocupada enquanto não retornar 0. Se o valor retornado for 0 , a atribuição do 1 à variável foi realizada com sucesso.

Essa instrução é necessária para os métodos de exclusão mútua presentes no eCos, e seu suporte não é oferecido no processador Nios II.

Para a resolução desse problema, esse projeto contempla a implementação de uma macro que realiza essa operação. A atomicidade é garantida por meio de um mutex, componente presente no hardware do sistema, que é utilizado somente para esse propósito. No momento da execução da macro, todas as interrupções do processador corrente são desabilitadas para evitar qualquer desvio do fluxo de execução. Posteriormente, o mutex é consultado, aguardando a liberação caso esteja ocupado. O valor atual da variável é armazenado e atualizado para 1. O valor antigo é retornado, o mutex é liberado e as interrupções são novamente habilitadas.

A macro Test-and-set é utilizada para a implementação do spin lock, componente básico para a sincronização do escalonador. 


\subsubsection{Sistema operacional}

\subsubsection{Boot}

A inicialização do processador para o carregamento do sistema operacional é realizado no momento que o processo é carregado na memória. Um sinal é enviado ao processador para começar a executar.

A sequência de inicialização do eCos está programada em assembly no arquivo vector.s. Após a compilação do sistema operacional juntamente com a aplicação, a parte binária relacionada a esse arquivo é disposta na memória logo após a seção do controle de interrupções. Assim, esse código é o primeiro executado pelo processador quando processo é carregado ${ }^{4}$.

A sequência de inicialização do sistema operacional está apresentado na Figura 8.8. Os seguintes passos são executados:

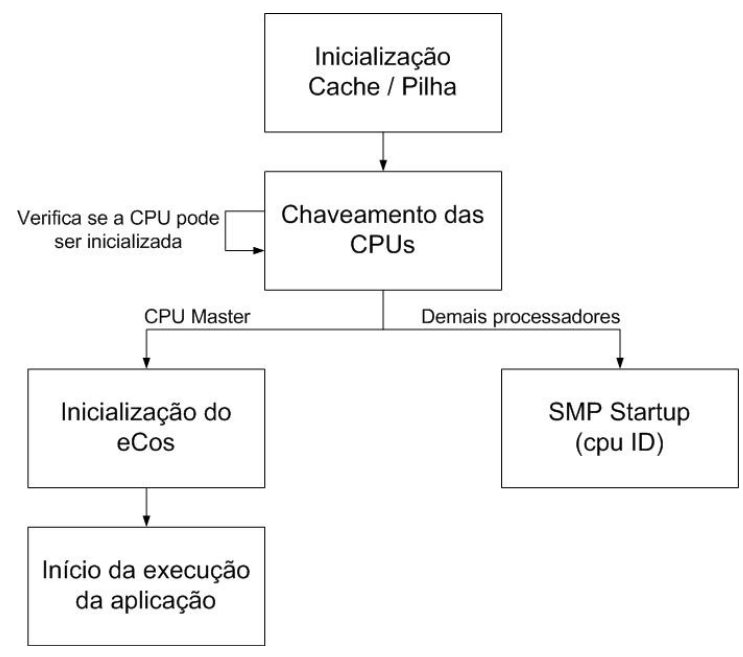

Figura 8.8: Boot do sistema operacional.

1. Inicialização da cache e pilha: A cache de dados é inicializada para remover todas as referências anteriores, evitando incoerência de dados. Entretanto, esse procedimento não é necessário para o processador Nios II/s (padrão), que não possui cache de dados. A inicialização da cache não é utilizada neste projeto. Após esse passo, cada CPU recebe um espaço na memória destinado à pilha. O particionamento é

\footnotetext{
${ }^{4}$ A carga do processo na memória da FPGA para a execução, é realizada por meio do comando nios2download -g-instance $=[$ instância da interface de comunicação com a FPGA (JTAG UART)] [nome do executável]. Cada processador possui somente uma instância do JTAG UART, e por meio do parâmetro instance é definido qual processador é utilizado para carregar o processo na memória. O endereço base para o armazenamento da memória é o exception address. A opção -g (go) indica ao processador que a execução deve iniciar após o armazenamento do executável.
} 
realizado com um tamanho fixo de $512 \mathrm{~KB}$ para cada processador. O bloco com endereço de ordem mais significativa é reservado ao primeiro processador que executa esse processo, a CPU master. A pilha é iniciada a partir do endereço limite superior reservado para o processador.

2. Chaveamento das CPUs: Todos os processadores, com exceção da CPU master, ficam em espera ociosa até o momento de continuarem executando. A CPU master executa o restante da inicialização normalmente, ativando o escalonador e liberando as outras CPUs para execução. O controle de qual processador pode executar é realizado por meio de uma variável, na qual cada bit corresponde ao CPU-ID de um determinado processador. Um bit habilitado indica que a CPU, cujo CPU-ID correspondente à sua posição, deve sair da espera ociosa e continuar a execução. A CPU master libera a execução do restante das CPUs somente após a ativação do escalonador.

3. Inicialização do eCos: Os objetos do sistema operacional são criados (escalonador, interrupção, clock, entre outros), as rotinas para atendimento de interrução de tempo são associadas às IRQs correspondentes, e uma chamada é realizada à função cyg_start.

4. Início da execução da aplicação: Quando a função cyg_start é chamada, a rotina principal ( cyg_user_start $^{5}$ ) da aplicação é invocada fazendo inicializações, criando threads e primitivas de sincronização e, se necessário, instalando rotinas de interrupção. Após sua execução, o escalonador é iniciado, habilitando as interrupções e liberando os demais processadores para a execução.

5. SMP Startup: Realiza a inicialização de algumas variáveis relacionadas ao processador que está em execução, instala as rotinas de atendimento à interrupção inter-CPUs correspondente à IRQ 31 e inicia a execução das threads criadas pelo processador master.

\subsubsection{Escalonamento}

O algoritmo de escalonamento utilizado consiste no MLQ, pois o bitmap não suporta o modelo SMP.

\footnotetext{
${ }^{5}$ A função cyg_user_start() normalmente é utilizada em aplicações para o eCos como substituta ao main().
} 
O sistema operacional recebe uma interrupção de tempo (tick) a cada 1 ms (Seção 8.3.3.1). Essa interrupção é utilizada para o controle dos elementos de tempo real do eCos (Counters, Clocks, Alarms e Timers), como também do escalonamento das threads (timeslice).

O eCos possui uma constante chamada CYGNUM_KERNEL_SCHED_TIMESLICE_TICKS, a qual armazena o número de ticks de duração para a execução de uma thread antes que seja ativado o escalonamento de outra. Com a finalidade de testes, neste projeto essa constante corresponde ao valor 1000, de modo que as threads em execução são trocadas a cada 1 segundo. Essa troca é realizada por meio de interrupção interCPUs. A CPU master envia um pulso por meio de seu PIO de saída com o número correspondente da CPU cuja thread deve ser trocada(Seção 8.3.3.3).

O kernel foi programado para ativar o timeslice somente quando todas as CPUs entrarem em execução. Essa decisão de projeto está implementada para evitar problemas de troca de threads no momento em que outra CPU inicia sua execução do sistema operacional.

\subsubsection{Interrupções de hardware}

Em qualquer evento de interrupção o processador deve executar a função _exception_vector presente no vector.s. Seu código binário está posicionado na memória no exception address do processador master.

Essa função examina os bits dos registradores estatus e ipending, verificando se a interrupção foi de software ou hardware. No eCos existe um vetor de ponteiros para funções chamado hal_vsr_table, cujos índices 0 e 1 apontam respectivamente para rotinas de interrupção de software (_software_exception_handler) e hardware (_interrupt_handler), declaradas em vector.s.

O eCos possui outro vetor, hal_interrup_handlers, que armazena a estrutura de tratamento de interrupções para cada IRQ. A função_interrupt_handler salva o contexto de execução e acessa o vetor hal_interrup_handlers utilizando como índice o número da interrupção (IRQ). A função ISR correspondente é executada.

Posteriormente, a função_interrupt_end é iniciada. Essa rotina constitui parte do controle de interrupção do kernel. Parte de seu código é protegido pelo chaveamento do escalonador: cyg_scheduler::lock(). A chamada ao cyg_scheduler::unlock() inicia a chamada a todas as DSRs pendentes, inclusive a DSR correspondente à interrupção em 
questão.

Após essa sequência, é realizada uma verificação da necessidade de escalonamento de uma nova thread para a execução. O escalonamento pode ocorrer por dois motivos: tempo de execução da thread alcançado e chegada de uma thread de maior prioridade. Se uma nova thread é selecionada, o contexto da corrente é armazenado em sua própria pilha, e o contexto da nova thread é carregado. Caso contrário, o contexto da thread atual salvo antes da execução da interrupção é carregado, de modo que a execução retorna ao ponto onde foi interrompida.

Quando os processadores recebem uma interrupção cuja IRQ é 31, executam as funções ISR e DSR responsáveis pela troca de thread devido ao tempo de execução excedido. Essa interrupção é enviada aos processadores pela CPU master que controla o escalonador. A função DSR, relacionada a essa interrupção, executa a rotina cyg_scheduler_timeslice_cpu que seleciona uma nova thread para execução. Ao final da execução de cyg_scheduler::unlock(), os contextos são trocados e a nova thread entra em execução.

\subsubsection{Coerência de dados em cache}

A utilização de processadores com cache de dados carece de mecanismos que promovam a coerência dos dados lidos e armazenados na memória. Dos três tipos de processadores, o Nios II/s foi utilizado neste projeto, mas somente o Nios II/f possui cache de dados.

Neste caso, como não existe nenhum componente da Altera que forneça mecanismos para coerência, existem dois métodos que poderiam ser utilizados para evitar que os dados fossem armazenados ou buscados na cache do processador:

1. Bit 31 dos endereços de memória: O bit mais significativo dos endereços de memória é utilizado para ativar o cache bypass. Todas as referências a endereços com esse bit ativado não são buscados e nem armazenados na cache.

2. Instruções ldwio/stwio: Existe um parâmetro de compilação -mbypass-cache que troca todas as intruções $l d w / s t w$ por ldwio/stwio. Essas instruções são interpretadas pelo processador como instruções de acesso a dispostivos de I/O, enquanto que $l d w / s t w$ são utilizadas especificamente para acesso à memória. Na execução das instruções ldwio/stwio, o processador despreza a existência da cache e envia os dados, ou requisita-os, diretamente pelo barramento. 


\subsection{Uma outra implementação: Erika RTOS}

A utilização de multiprocessamento com o processador Nios II pode gerar um bom desempenho para determinadas aplicações em sistemas embarcados. Entretanto, somente um sistema operacional possui suporte ao multiprocessamento no Nios II, atualmente. Este sistema denomina-se Erika.

Erika consiste em um sistema operacional de tempo real, desenvolvido por Evidence S.r.l., para suportar multiprocessamento com porte para o processador Nios II. Algumas características de Erika são apresentadas a seguir (EVIDENCE S.R.L., 2007a) (EVIDENCE S.R.L., 2007b):

- Multi-tarefa preempetivo e não preempetivo;

- Escolanamento por prioridades;

- Técnicas de compartilhamento de pilha;

- Compartilhamento de recursos;

- Alarmes e controle de erros;

- Integração com o HAL da Altera;

- Particionamento de software: Os desenvolvedores podem decidir em qual processador uma determinada tarefa deve executar. As tarefas podem ser executadas em diferentes processadores sem a necessidade de mudança do código fonte;

- Suporte a interrupção inter-CPUs; e

- Suporte para desabilitar a cache para determinadas estruturas.

Seu funcionamento basea-se no particionamento estático das tarefas para uma determinada CPU, em tempo de compilação. O usuário pode definir qual CPU executará os processos. A memória SDRAM não tem espaço compartilhado entre as CPUs, de modo que cada processador possui seu próprio conjunto de tarefas.

\subsection{Resultados}

A validação desse projeto de suporte a SMP no eCos foi justificada por meio da implementação de alguns algoritmos paralelos para a prova de conceito. Dentre os quais estão 
o algoritmo PSRS - Parallel Sorting by Regular Sampling e o algoritmo de multiplicação de matrizes. Nesta seção a execução dos dois algoritmos está descrita.

\subsubsection{O algoritmo PSRS}

O PSRS consiste em um algoritmo de ordenação que considera uma arquitetura multiprocessada com $p$ processadores. Seu funcionamento é dividido em quatro fases, conforme ilustrado na Figura 8.9. As quatro fases executam os seguintes passos (SHI; SCHAEFFER, 1992) (LI et al., 1993):

1. Ordenar os dados locais: Dado um vetor com $n$ elementos, cada processador recebe um conjunto de aproximadamente $n / p$. A ordenação desses conjuntos é realizada paralelamente, utilizando o algoritmo Quicksort. Após a ordenação, cada processador escolhe $p$ elementos de amostra. No exemplo da Figura 8.9 a amostra é composta pelos elementos: $(0,16,27,7,13,23,3,10,22)$.

2. Encontrar pivôs e particionar: Um único processador ordena a lista de amostras com $p^{2}$ elementos, em seguida $p-1$ pivôs são selecionados. Cada processador recebe esses pivôs e divide seu conjunto de elementos em $p$ partições. No exemplo da Figura 8.9 os pivôs selecionados são 10 e 22 .

3. Troca de partições: Cada processador possui $p$ partições, e cada partição $i$ deve ser enviada ao processador $i$.

4. Merge das partições: Cada processador, em paralelo, uni todas suas partições por meio de um algoritmo de merge. No final dessa fase, cada partição $i$ do processador $i$ está ordenada, assim como as $p$ partições estão ordenadas entre si. 


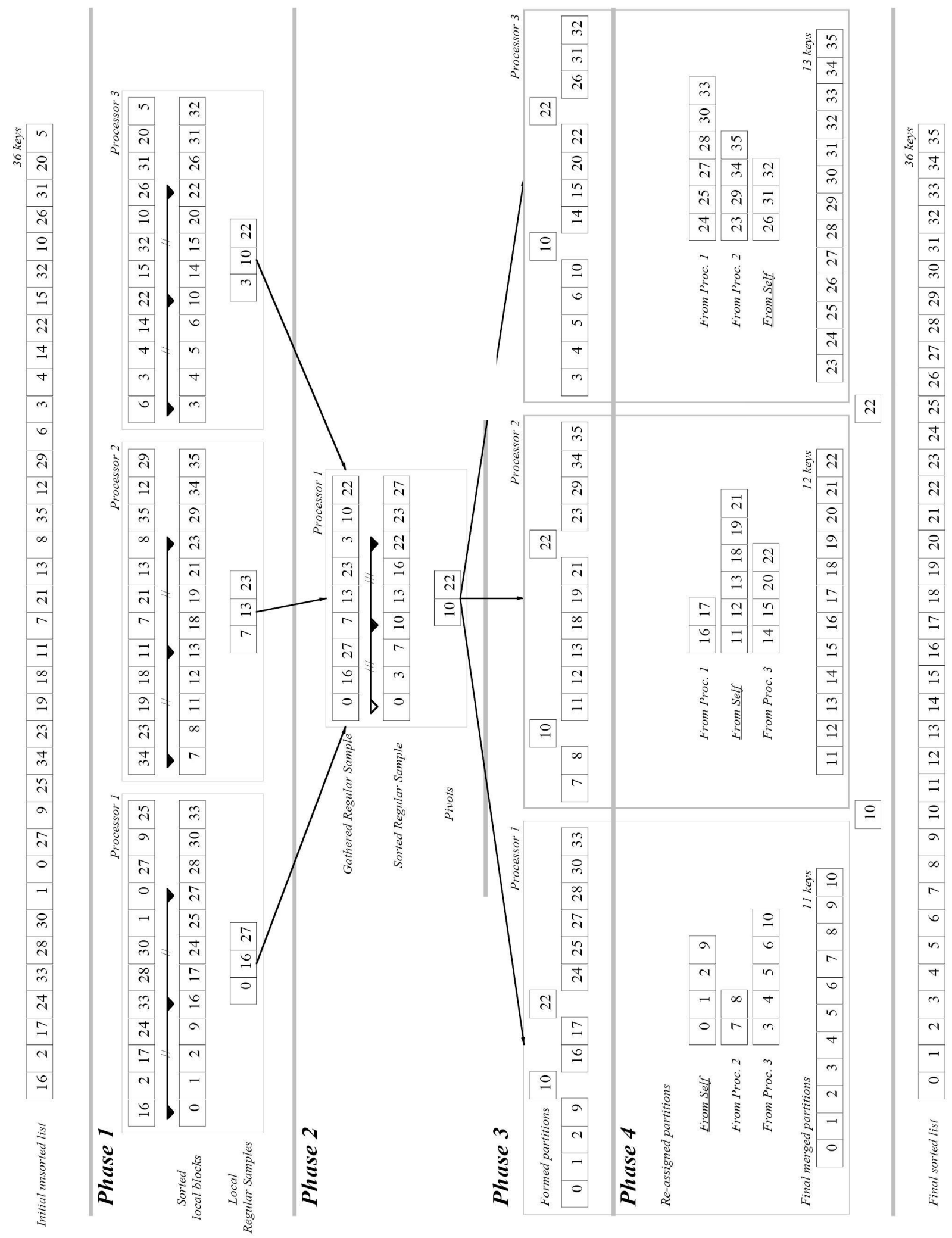

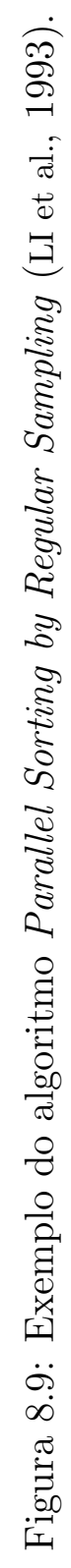


Os tempos resultantes de execução desse algoritmo nos três processadores são comparados com os tempos do algoritmo Quicksort em um processador.

Para a implementação, foram utilizados dois vetores de inteiros armazenados na heap, os quais possuem o mesmo número de elementos. Esses vetores são inicializados com valores aleatórios, sendo que ambos possuem o mesmo conjunto de elementos.

A memória disponível para o armazenamento dos vetores inicia a partir do endereço 0x00200020, devido à área reservada para a aplicação de jump. O endereço final consiste no limite entre a pilha e a heap. Para os testes, a pilha de cada processador está configurada para $1 \mathrm{~KB}$, a área reservada para a pilha é de 3072 Bytes. A memória possui 8 MB (seu endereço final é 0x00800000), de modo que o início da área da pilha está no endereço 0x007FF400. O espaço livre para o armazenamento de dados é (0x007FF400 - 0x00200020) $=0 x 5 F F 3 E 0$ (6288352) Bytes. Considerando dois vetores de inteiros, sendo 4 Bytes cada elemento, poderiam ser armazendos 786044 elementos para cada vetor.

São iniciadas três threads, cada uma é executada em um processador. A execução do algoritmo somente é iniciada quando os três processadores estão iniciados, devido a ativação do timeslice (Seção 8.3.6.2). Como o evento de timeslice envolve operações de I/O, os resultados da execução de algoritmos sem sua ativação podem ser muito melhores. Esse planejamento assegura que os resultados obtidos pelo algoritmo Quicksort são compatíveis com os resultados do PSRS, com a mesma condição do ambiente.

A estimativa do tempo de execução dos algoritmos foi realizada por meio da função cyg_current_time(), a qual retorna o número de ticks corrente da CPU master. O período entre cada tick é $1 \mathrm{~ms}$. Sendo assim, visando uma estimativa aproximada, considera-se o retorno da função cyg_current_time() sendo o tempo do sistema mensurado em milissegundos.

As métricas utilizadas para análise da qualidade do paralelismo são Speedup e eficiência. O Speedup é utilizado para verificar o ganho de desempenho obtido com o uso de uma aplicação paralela em relação à aplicação seqüencial mais rápida que executa a mesma tarefa. A eficiência estima o aproveitamento de tempo do algoritmo paralelo nos processadores (QUINN, 1994).

Em arquiteturas homogêneas, com processadores de mesma potência computacional e mesma quantidade de memória, o Speedup é dado pela equação 8.1. O Speedup obtido com $p$ processadores, $S(p)$, consiste na razão entre o tempo $T_{1}$ gasto para executar o programa seqüencial (em um processador) e o tempo $T_{p}$ gasto para executar o programa 
paralelo em $p$ processadores (OLIVEIRA, 2006).

$$
S(p)=\frac{T_{1}}{T_{p}}
$$

A Eficiência $E(p)$ é dada pela equação 8.2, que é a razão entre o speedup $S(p)$ e o número de processadores $p$ utilizado.

$$
E(p)=\frac{S(p)}{p}
$$

O caso ideal seria $S(p)=p$ e $E(p)=1$, um ganho igual ao número de processadores utilizado e uma utilização de $100 \%$ dos processadores.

Os algoritmos Quicksort e PSRS foram executados sobre dois vetores distintos. Nas estimativas, os tamanhos dos vetores variam de 50 a 700000 elementos. Os experimentos foram executados duas vezes para cada número de elementos. O tempo resultante é a média dos tempos alcançados nas duas execuções. Os resultados estão apresentados na Tabela 8.2 .

\begin{tabular}{|c|c|c|c|c|}
\hline Elementos & Quicksort $(m s)$ & PSRS $(m s)$ & Speedup $(\boldsymbol{S}(\mathbf{3}))$ & Eficiência $(\boldsymbol{E}(\mathbf{3}))$ \\
\hline \hline 50 & 2 & 2 & 1 & 0.333 \\
\hline 100 & 3 & 2 & 1.5 & 0.5 \\
\hline 500 & 12 & 8 & 1.5 & 0.5 \\
\hline 1000 & 28 & 17 & 1.647 & 0.549 \\
\hline 5000 & 131 & 90 & 1.567 & 0.522 \\
\hline 10000 & 330 & 208 & 1.587 & 0.529 \\
\hline 50000 & 1895 & 1107 & 1.712 & 0.571 \\
\hline 100000 & 3882 & 2327 & 1.668 & 0.556 \\
\hline 200000 & 8360 & 4757 & 1.757 & 0.586 \\
\hline 300000 & 13278 & 7401 & 1.794 & 0.598 \\
\hline 400000 & 18014 & 9969 & 1.807 & 0.602 \\
\hline 500000 & 24444 & 13216 & 1.850 & 0.617 \\
\hline 600000 & 29437 & 15540 & 1.894 & 0.631 \\
\hline 700000 & 35276 & 18745 & 1.882 & 0.627 \\
\hline
\end{tabular}

Tabela 8.2: Tempos de execução dos algoritmos de ordenação.

De acordo com os resultados alcançados, o algoritmo PSRS tem seu aproveitamento relacionado com o número de elementos ordenados. O aumento da quantidade de elementos ocasionou um aumento nos valores de índices para Speedup e Eficiência. Os melhores índices foram alcançados para conjuntos de valores com os maiores números de elementos.

Os algoritmos poderiam ter tempos menores de execução se a interrupção de tempo fosse desabilitada. Entretanto, essa interrupção é necessária para mensurar o próprio 
tempo de execução por meio da função cyg_current_time().

O armazenamento dos dois vetores em mémorias on-chip, localizadas na própria FPGA, também acarretaria menores tempo de execução. Se os elementos lógicos dessa memória fossem utilizados para compor outros processadores no sistema, isso também poderia melhorar os tempos de execução.

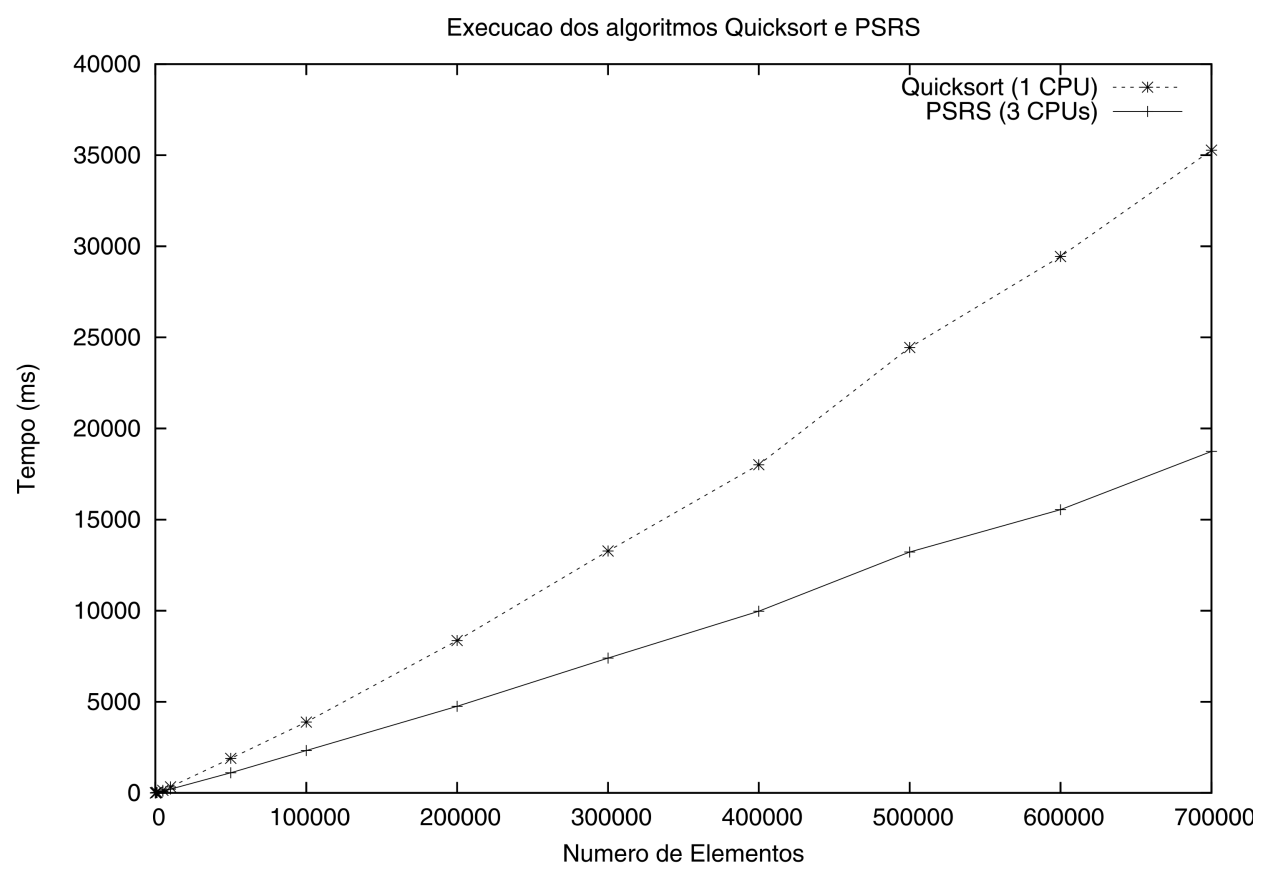

Figura 8.10: Tempos de execução dos algoritmos.

\subsubsection{O algoritmo de multiplicação de matrizes}

Outro algoritmo utilizado para a validação da implementação é a multiplicação de matrizes. Para os testes, duas matrizes quadradas de elementos inteiros foram multiplicadas, cujo $\mathrm{N}$ variou de 5 a 600 .

Foi alocado espaço na memória para três matrizes, duas delas foram iniciadas com valores aleatórios e a terceira é a matriz resultante da multiplicação. O armazenamento é realizado a partir do endereço 0x00200020 e o número N máximo é 600, para evitar ultrapassar área máxima de 0x5FF3E0 Bytes disponível para armazenamento.

Na execução foram considerados os mesmos fatores descritos para o algoritmo PSRS. A execução seqüencial somente é iniciada quando os três processadores são iniciados, pois neste momento o timeslice é ativado. Deste modo, o algoritmo seqüencial possui as mesmas condições de execução do algoritmo paralelo de multiplicação. 
Após a execução do algoritmo seqüencial é inicada a multiplicação paralela. A estimativa de todos os tempos de execução foi realizada por meio da função cyg_current_time(), sendo que os algoritmos foram executados duas vezes para cada $\mathrm{N}$, e os valores considerados consistem em médias dessas execuções. Os resultados estão apresentados na Tabela 8.3.

\begin{tabular}{|c|c|c|c|c|}
\hline Elementos (N) & $\begin{array}{c}\text { Multiplicação } \\
\text { Seqüêncial }(m s)\end{array}$ & $\begin{array}{c}\text { Multiplicação } \\
\text { Paralela }(m s)\end{array}$ & $\begin{array}{c}\text { Speedup } \\
(\boldsymbol{S}(\mathbf{3}))\end{array}$ & $\begin{array}{c}\text { Eficiência } \\
(\boldsymbol{E}(\mathbf{3}))\end{array}$ \\
\hline \hline 5 & 1 & 1 & 1 & 0.333 \\
\hline 10 & 3.5 & 2 & 1.750 & 0.583 \\
\hline 20 & 17.5 & 9 & 1.944 & 0.648 \\
\hline 40 & 129 & 84 & 1.536 & 0.512 \\
\hline 100 & 1999 & 1240 & 1.612 & 0.537 \\
\hline 200 & 16143.5 & 10253 & 1.575 & 0.525 \\
\hline 300 & 54467.5 & 35637 & 1.528 & 0.509 \\
\hline 400 & 130152.5 & 66110.5 & 1.969 & 0.656 \\
\hline 500 & 252388.5 & 150588.5 & 1.676 & 0.559 \\
\hline 600 & 410586.5 & 189186 & 2.170 & 0.723 \\
\hline
\end{tabular}

Tabela 8.3: Tempos de execução dos algoritmos de multiplicação de matrizes.

De acordo com os resultados obtidos, a variação do speedup e da eficiência não é crescente de modo contínuo para o aumento de N. Entretanto, pode ser notado que esses valores são maiores para valores maiores de N. Quando N é 600, o valor de speedup é 2.170 e a eficiência é 0.723 , denotando um maior ganho e um maior aproveitamento dos processadores em relação aos resultados alcançados com o algoritmo de ordenação paralela.

\subsection{Considerações finais}

Foram apresentados neste capítulo os objetivos do trabalho, a implementação do sistema, bem como as considerações de projeto que levaram a tal implementação. Para a validação e a prova de conceito foram executados alguns algoritmos, dentro os quais o PSRS e a multiplicação de matrizes foram descritos neste capítulo, demonstrando os ganhos da implementação paralela. 


\section{Conclusões}

\subsection{Considerações finais}

Os processadores tiveram uma grande evolução nos últimos anos, satisfazendo demandas provindas de aplicações que exigem crescente capacidade computacional. Entretanto, essa evolução tedencialmente deve esbarrar em limites físicos e arquiteturais, os quais podem limitar o aumento de desempenho nos processadores.

As arquiteturas paralelas são alternativas para grande crescimento de poder computacional, o qual não é dependente diretamente desses limites físicos para seu avanço. Dentre as arquitetura paralelas, está o multiprocessamento simétrico, no qual dois ou mais processadores estão ligados por meio de um barramento, compartilhando a mesma memória e executando aplicações paralelamente.

Com base nessa idéia, o objetivo deste trabalho foi a implementação de suporte a SMP no sistema operacional eCos para o processador Nios II. Este trabalho foi motivado, entre outros fatores, pela possibilidade de utilizar a capacidade da FPGA para comportar diversos processadores executando tarefas paralelamente, especificamente algoritmos inerentes à robótica, os quais necessitam de mais de um processador Nios II para alcançarem um desempenho aceitável, comprovado por trabalhos desenvolvidos no LCR (GATES, 2007). Em virtude disso, utiliza-se a arquitetura paralela SMP, a qual apresentou melhores condições para implementação entre os modelos analisados.

$\mathrm{Na}$ arquitetura, três processadores são utilizados, dos quais um tem a responsabilidade de gerenciar os eventos de tempo do sistema operacional. O HAL e o kernel do eCos foram alterados para prover suporte ao multiprocessamento simétrico.

Para validação do projeto, foram implementados algumas aplicações paralelas, dentre as quais está o algoritmo de ordenação paralela PSRS e o algoritmo de multiplicação de matrizes, descritos na Seção 8.5. De acordo com os resultados obtidos, o modelo SMP, com os três processadores gerenciados pelo sistema operacional eCos, obteve um rendimento 
compatível com o número de elementos utilizados nos algoritmos. No PSRS, quanto maior o número de elementos utilizados, maiores os índices de speedup e eficiência alcançados. Os melhores resultados foram 0.631 para eficiência e 1.894 para speedup, na ordenação de 700000 elementos. Na multiplicação de matrizes os melhores resultados alcançados foram 0.723 para eficiência e 2.170 para speedup com $\mathrm{N}$ igual a 600 , os quais demonstram a capacidade de processamento da arquitetura implementada.

Desta forma, este projeto contribui para a utilização da flexibilidade do software unida ao desempenho alcançado no paralelismo entre diversos processadores implementados em hardware na FPGA. Tal implementação pode ser utilizada para finalidades diversas, entre as quais podem ser citadas sistemas de robótica embarcados, cujos algoritmos carecem de grande capacidade de processamento e de concorrência no processamento de sensores.

Finalmente, a integração do sistema operacional eCos com os três processadores Nios II, formando um sistema embarcado multiprocessado baseado em computação reconfigurável, demonstrou uma grande complexidade. Apesar das dificuldades, o trabalho foi concluido com êxito, conforme mostram os resultados obtidos.

\subsection{Sugestões para trabalhos futuros}

O projeto de implementação de suporte a SMP no eCos faz parte de um estudo que pode ser ampliado, de modo a oferecer mais flexibilidade e desempenho. Para tal, são apresentadas a seguir algumas sugestões de trabalhos futuros:

- Implementação de um módulo em CDL que procure componentes ligados aos demais processadores que não sejam o master. Cada componente é especificado automaticamente no system. $h$, com endereços e registradores de acesso. Neste projeto, os componentes que são ligados apenas aos demais processadores, são incluidos manualmente nesse arquivo. Isto ocorre devido a ferramenta atual do eCos permitir a checagem apenas dos componentes de um processador passado por parâmetro, o processador master;

- Automatização do código do eCos para aceitar um número variável de processadores;

- Geração automática de scripts para execução do programa paralelo. Atualmente, são executados três softwares, a aplicação principal e duas aplicações de jump para as CPUs slaves; 
- Projetar o hardware para comportar maior número de processadores, com o objetivo de aplicação em robótica embarcada; e

- Portar algoritmos de robótica para este ambiente. 


\section{Referências}

ALTERA. The Industry s Fastest FPGAs. 2004. Disponível em: http://www.altera.com/products/devices/stratix2/features/performance/st2-performance.html. Acesso em março de 2005.

ALTERA. Introduction to Quartus II. December 2004. Disponível em: http://www.altera.com/literature/manual/intro_to_quartus2.pdf. Acesso em fevereiro de 2005.

ALTERA. FPGA, CPLD, and Structured ASIC Devices; Altera, the Leader in Programmable Logic. 2005. Disponível em http://www.altera.com. Acesso em fevereiro de 2005.

ALTERA. Stratix III FPGAs. 2006.

Http://www.altera.com/products/devices/stratix3/st3-index.jsp. Acesso em fevereiro de 2007.

ALTERA. Altera's Development and Education Board. 2007.

Http://www.altera.com/education/univ/materials/boards/unv-de2-board.html.

Acesso em janeiro de 2007.

ALTERA CORPORATION. Creating Multiprocessor Nios II: Systems Tutorial. San Jose, CA, 2005.

ALTERA CORPORATION. Avalon Memory-Mapped Interface Specification. San Jose, CA, 2006. Disponível em http://www.altera.com/literature/manual/mnl_avalon_spec.pdf. Acesso em fevereiro de 2007.

ALterA CORPORATION. Cyclone II Device Handbook, Volume 1. San Jose, CA, 2006. Disponível em http://www.altera.com/literature/litcyc2.jsp. Acesso em janeiro de 2007.

ALTERA CORPORATION. DE2 Development and Education Board: User Manual. San Jose, CA, 2006.

ALTERA CORPORATION. Nios II Processor Reference Handbook. San Jose, CA, 2006. Disponível em http://www.altera.com/literature/hb/nios2/n2cpu_nii5v1.pdf. Acesso em fevereiro de 2007.

ALTERA CORPORATION. Nios II Software Developers Handbook. San Jose, CA, 2006. Disponível em http://www.altera.com/literature/hb/nios2/n2sw_nii5v2.pdf. Acesso em fevereiro de 2007. 
ALTERA CORPORATION. Quartus II Version 6.1 Handbook Volume 5: Embedded Peripherals. San Jose, CA, 2006. Disponível em http://www.altera.com/literature/hb/nios2/n2cpu_nii5v3.pdf. Acesso em fevereiro de 2007.

ARM. ARM. 2005. Disponível em: http://www.arm.com. Acesso em fevereiro de 2005.

ARTIST. Selected topics in embedded system design: Roadmaps for research. 2004.

BARR, M. A. E.; REWINI, H. E. Fundamentals of Computer Organization and Architecture and Advanced Computer Architecture and Parallel Processing. USA: John Wiley \& Sons, Inc., 2005. ISBN 047170380X.

BROWN, S.; ROSE, J. Architecture of fpgas and cplds: A tutorial. IEEE Design and Test of Computers, v. 13, n. 2, p. 42-57, 1996.

BROWN, S.; ROSE, J. Fpga and cpld architectures: A tutorial. IEEE Des. Test, IEEE Computer Society Press, Los Alamitos, CA, USA, v. 13, n. 2, p. 42-57, 1996. ISSN 0740-7475.

CARRO, L.; WAGNER, F. R. Sistemas computacionais embarcados. XXII Jornadas de Atualização em Informática - JAI'03, 2003. Capítulo 2. Disponível em: http://www.javasoft.com.br/academic/sbc2003/arq0245.pdf. Acesso em março de 2005.

COMPTON, K.; HAUCK, S. Reconfigurable computing: A survey of systems and software. ACM Computing Surveys, n. 2, p. 171-210, 2002.

COMPTON, K.; LI, Z.; COOLEY, J.; KNOL, S.; HAUCK, S. Configuration relocation and defragmentation for run-time reconfigurable computing. IEEE Transactions on Very Large Scale Integration (VLSI) Systems, v. 10, n. 3, p. 209-220, June 2002.

DANKWARDT, K. Real-time linux. Embedded Linux Journal Online, 2001. Disponível em: http://www.linuxdevices.com/articles/AT5997007602.html. Acesso em março de 2005.

DEGALAHAL, V.; TUAN, T. Methodology for high level estimation of fpga power consumption. In: ASP-DAC '05: Proceedings of the 2005 conference on Asia South Pacific design automation. New York, NY, USA: ACM Press, 2005. p. 657-660. ISBN 0-7803-8737-6.

DIESSEL, O.; WIGLEY, G. Opportunities for Operating Systems Research in Reconfigurable Computing. 1999. Disponível em: http://citeseer.ist.psu.edu/diessel99opportunities.html. Acesso em fevereiro de 2007.

EGGERMONT, L. D. Embedded Systems Roadmap 2002: Vision on technology for the future of PROGRESS. March 2002.

ENSLOW, J. P. Multiprocessor organization a survey. ACM Comput. Surv., ACM Press, New York, NY, USA, v. 9, n. 1, p. 103-129, 1977. ISSN 0360-0300.

EUROPE, U. N. E. C. for. World Robotics 2004. October 2004. Disponível em: http://www.unece.org/press/pr2004/04robots_index.htm. Acesso em fevereiro de 2005. 
EVIDENCE S.R.L. ERIKA Enterprise Manual. Pontedera (PI), Italy, 2007. Disponível em http://www.evidence.eu.com/download/manuals/pdf/ee_refman_1_4_2.pdf. Acesso em fevereiro de 2007.

EVIDENCE S.R.L. ERIKA Enterprise Manual for the Altera Nios II target. Pontedera (PI), Italy, 2007. Disponível em http://www.evidence.eu.com/download/manuals/pdf/arch_nios2_1_2_0.pdf. Acesso em fevereiro de 2007.

FAQ: Real Time Computing. Disponível em: http://www.faqs.org/faqs/realtimecomputing/faq. Acesso em janeiro de 2005.

FLYNN, M. J.; RUDD, K. W. Parallel architectures. ACM Comput. Surv., ACM Press, New York, NY, USA, v. 28, n. 1, p. 67-70, 1996. ISSN 0360-0300.

GARNETT, N.; LARMOUR, J.; LUNN, A.; THOMAS, G.; VEER, B. eCos Reference Manual. 2003. Disponível em: http://ecos.sourceware.org/docs-2.0/pdf/ecos-2.0-refa4.pdf. Acesso em fevereiro de 2005.

GATES, B. A robot in every home. Scientific American, 2007. Http://www.sciam.com/article.cfm?chanID=sa006\&colID=1\&articleID=9312A198E7F2-99DF-31DA639D6C4BA567. Acesso em fevereiro de 2007.

HARTENSTEIN, R. A decade of reconfigurable computing: a visionary retrospective. Design, Automation and Test in Europe (DATE 01), Munich, Alemanha, Proceedings IEEE Computer Society Press, 2001.

HAT, R. eCos User Guide. 2003. Disponível em: http://ecos.sourceware.org/docs2.0/pdf/ecos-2.0-user-guide-a4.pdf. Acesso em fevereiro de 2005.

IBM. PowerPC features. 2005. Disponível em: http://www.chips.ibm.com/products/powerpc. Acesso em fevereiro de 2005.

INTEL. Intel Flash Memory Software Builder. 2007. Http://www.intel.com/design/flash/swb/cfi.htm. Acesso em janeiro de 2007.

LANDAKER, W. J. Using hardware context-switching to enable a multitasking reconfigurable computer system. Dissertação (Mestrado) - Department of Electrical and Computer Engineering - Brigham Young University, August 2002. Disponível em: http://splish.ee.byu.edu/docs/thesis-wjl.pdf. Acesso em fevereiro de 2005.

LI, X.; LU, P.; SCHAEFFER, J.; SHILlingTON, J.; WONG, P. S.; SHI, H. On the versatility of parallel sorting by regular sampling. Parallel Computing, v. 19, n. 10, p. 1079-1103, 1993. Disponível em: citeseer.ist.psu.edu/li93versatility.html.

MASON, M. Considering the total cost of fpgas. FPGA and Programmable Logic Journal, Janeiro 2005. Disponível em: http://www.fpgajournal.com/linkto.php?turl=articles_2005/20050125_actel.htm. Acesso em janeiro de 2005.

MASSA, A. J. Embedded Software Development with eCos. 1th edition. ed. [S.1.]: Prentice Hall, 2002. 
MOORE, G. E. Cramming more components onto integrated circuits. Electronics Magazine,, v. 38, p. 114-117, April 1965.

MORRIS, K. Mr. moore's wild ride - 90nm fpgas go mainstream. FPGA and Programmable Logic Journal, 2004. Disponível em:

http://www.fpgajournal.com/articles/mrmoore.htm. Acesso em fevereiro de 2005.

MORRIS, K. Flash news flash: Actel unveils proasic3. FPGA and Programmable Logic Journal, Janeiro 2005. Disponível em: http://www.fpgajournal.com/articles_2005/20050125_flash.htm. Acesso em janeiro de 2005 .

MORRIS, K. Prime-time processing: Are embedded systems on fpga ready? FPGA and Programmable Logic Journal, February 2005. Disponível em: http://www.fpgajournal.com/articles_2005/20050208_primetime.htm. Acesso em fevereiro de 2005.

NULL, L.; LOBUR, J. Essentials of Computer Organization and Architecture. USA: Jones and Bartlett Publishers, Inc., 2003. ISBN 076370444X.

OLIVEIRA, J. A. de. Um estudo comparativo de cargas de trabalho e politicas de escalonamento para aplicações paralelas em clusters e grids computacionais. Dissertação (Mestrado) - ICMC - USP, São Carlos - SP, 2006.

OLUKOTUN, K.; HAMMOND, L. The future of microprocessors. Queue, ACM Press, New York, NY, USA, v. 3, n. 7, p. 26-29, 2005. ISSN 1542-7730.

PAULO, F. de S. Robôs "do lar" serão mais de 4 milhões em 200\%. Outubro 2004. Disponível em: http://www1.folha.uol.com.br/folha/informatica/ult124u17298.shtml. Acesso em fevereiro de 2005.

QUINN, M. J. Parallel Computing: Theory and practice. 2. ed. New York: McGraw Hill, 1994. $446 \mathrm{p}$.

RIBEIRO, A. A. de L. Reconfigurabilidade dinâmica e remota de FPGAs. Dissertação (Mestrado) - Universidade de São Paulo - USP - São Carlos, 2002.

ROMERO, R. A. F. ARMOSH: Aprendizado em Robôs Móveis via Software e Hardware. São Carlos, SP, 2000.

ROSE, A. e. G. J.; SANGIOVANNI-VICENTELLI, A. Architecture of field-programmable gate arrays. Proceedings of the IEEE, v. 81, n. 7, 1993.

RUPPEN, M. Reconfigurable OS Prototype. [S.l.], 2003. Disponível em: http://www.tik.ee.ethz.ch/ walder/HomePage/SADA/ReconfigurableOSPrototype/ROSP_CF.pdf. Acesso em março de 2005.

SHI, H.; SCHAEFFER, J. Parallel Sorting by Regular Sampling. Journal of Parallel and Distributed Computing, v. 14, n. 4, p. 361-372, 1992. Disponível em: citeseer.ist.psu.edu/shi92parallel.html.

STALLINGS, W. Computer Organization and Architecture. 6th edition. ed. [S.1.]: Prentice Hall, 2003. 
STEIGER, C.; WALDER, H.; PLATZNER, M. Operating systems for reconfigurable embedded platforms: Online scheduling of real-time tasks. IEEE Transactions on Computer, v. 53, n. No. 11, 2004.

TANENBAUM, A. S. Structured Computer Organization. 4th edition. ed. [S.l.]: Prentice Hall, 1999.

TANENBAUM, A. S. Modern Operating Systems. 2. ed. Upper Saddle River, NJ: Prentice-Hall, Inc., 2001. ISBN 0-13-031358-0.

VASSILIADIS, S. The HiPEAC Roadmap on Embedded Systems. [S.l.], 2006.

VEER, B.; DALLAWAY, J. The eCos Component Writer's Guide. 2001. Disponível em: http://ecos.sourceware.org/docs-2.0/pdf/ecos-2.0-cdl-guide-a4.pdf. Acesso em fevereiro de 2005 .

WALDER, H.; PLATZNER, M. Reconfigurable hardware operating systems: From concepts to realizations. Proc. Int'l Conf. Eng. of Reconfigurable Systems and Algorithms (ERSA), p. 284-287, 2003.

WALDER, H.; PLATZNER, M. Reconfigurable Hardware OS Prototype. 2003. Disponível em: http://citeseer.ist.psu.edu/article/walder03reconfigurable.html. Acesso em janeiro de 2005.

WIGLEY, G.; KEARNEY, D. The first real operating system for reconfigurable computers. In: Australasian Computer Systems Architecture Conference, Goldcoast, Queensland Australia. [S.l.]: IEEE Computer Society Press, 2000. p. 129-136.

WIGLEY, G.; KEARNEY, D. The development of an operating system for reconfigurable computing. Proc. IEEE Symp. FPGAs for Custom Computing Machines (FCCM), 2001.

WIGLEY, G. B.; KEARNEY, D. A. Research issues in operating systems for reconfigurable computing. Proceedings of the 2nd International Conference on Engineering of Reconfigurable Systems and Architectures (ERSA), CSREA Press, 2002.

WOLF, W. Embedded computing - what is embedded computing? IEEE Computer, v. 35, n. 9 , p. $136-137,2002$.

XILINX. Xilinx FPGAs Aboard Mars 2003 Exploration Mission. 2003. Disponível em http://www.xilinx.com/prs_rls/design_win/03104mars.htm. Acesso em fevereiro de 2005.

XILINX. Xilinx chips land on Mars: Xilinx radiation-tolerant devices play critical role in JPL's Successful Mars Mission. 2004. Disponível em http://www.xilinx.com/prs_rls/design_win/0412_marsrover.htm. Acesso em fevereiro de 2005.

XILINX. Custumer Success Stories. 2005. Disponível em: http://www.xilinx.com/company/success/cscust.htm. Acesso em fevereiro de 2005.

XILINX. MicroBlaze Microcontroller Reference Design User Guide v1.3.1. January 2005. Disponível em: http://direct.xilinx.com/bvdocs/userguides/ug133.pdf. Acesso em fevereiro de 2005. 
XILINX. Xilinx: Programmable Logic Devices, FPGA and CPLD. 2005. Disponível em http://www.xilinx.com. Acesso em fevereiro de 2005. 